\title{
Cell Metabolism
}

\section{Impairment of glycolysis-derived L-serine production in astrocytes contributes to cognitive deficits in Alzheimer's disease \\ --Manuscript Draft--}

\begin{tabular}{|c|c|}
\hline Manuscript Number: & CELL-METABOLISM-D-19-00854R4 \\
\hline Full Title: & $\begin{array}{l}\text { Impairment of glycolysis-derived L-serine production in astrocytes contributes to } \\
\text { cognitive deficits in Alzheimer's disease }\end{array}$ \\
\hline Keywords: & $\begin{array}{l}\text { Astrocytes; Alzheimer's Disease; L-serine; D-serine; NMDA; synaptic plasticity; } \\
\text { spatial behavior }\end{array}$ \\
\hline First Author: & Juliette Le Douce \\
\hline \multirow[t]{20}{*}{ Order of Authors: } & Juliette Le Douce \\
\hline & Marco Matos \\
\hline & Pierrick Jego \\
\hline & Pierre-Antoine Vigneron \\
\hline & Emilie Faivre \\
\hline & Xavier Toussay \\
\hline & Michel Vandenberghe \\
\hline & Yael Balbastre \\
\hline & Ayumi Koyanagi \\
\hline & Shigeki Furuya \\
\hline & Mylene Gaudin-Guerif \\
\hline & Sebastien Goutal \\
\hline & Aurélie Ghettas \\
\hline & Alain Pruvost \\
\hline & Alexis-Pierre Bemelmans \\
\hline & Marie-Claude Gaillard \\
\hline & Karine Cambon \\
\hline & Lev Stimmer \\
\hline & Veronique Sazdovitch \\
\hline & Charles Duyckaerts \\
\hline
\end{tabular}




\begin{tabular}{|c|c|}
\hline \multicolumn{2}{|r|}{ Anne-Sophie Herard } \\
\hline & Thierry Delzescaux \\
\hline & Philippe Hantraye \\
\hline & Emmanuel Brouillet \\
\hline & Bruno Cauli \\
\hline & Stephane Oliet \\
\hline & Aude Panatier \\
\hline & Gilles Bonvento, Ph.D. \\
\hline & Pierrick Jégo \\
\hline & Yaël Balbastre \\
\hline & Nguyet Thuy Tran \\
\hline & Stéphane Marinesco \\
\hline & Mylène Gaudin-Guérif \\
\hline & Sébastien Goutal \\
\hline & Véronique Sazdovitch \\
\hline & Anne-Sophie Hérard \\
\hline & Stéphane H.R. Oliet \\
\hline Abstract: & $\begin{array}{l}\text { Alteration of brain aerobic glycolysis is often observed early in the course of } \\
\text { Alzheimer's disease }(A D) \text {. Whether and how such metabolic dysregulation contributes } \\
\text { to both synaptic plasticity and behavioral deficits in } A D \text { is not known. Here, we show } \\
\text { that the astrocytic L-serine biosynthesis pathway, which branches from glycolysis, is } \\
\text { impaired in young AD mice and in AD patients. L-serine is the precursor of D-serine, a } \\
\text { co-agonist of synaptic NMDA receptors (NMDARs) required for synaptic plasticity. } \\
\text { Accordingly, AD mice display a lower occupancy of the NMDAR co-agonist site as well } \\
\text { as synaptic and behavioral deficits. Similar deficits are observed following inactivation } \\
\text { of the L-serine synthetic pathway in hippocampal astrocytes, supporting the key role of } \\
\text { astrocytic L-serine. Supplementation with L-serine in the diet prevents both synaptic } \\
\text { and behavioral deficits in 3xTg-AD mice. Our findings reveal that astrocytic glycolysis } \\
\text { controls cognitive functions and suggest oral L-serine as a ready-to-use therapy for } \\
\text { AD. }\end{array}$ \\
\hline Suggested Reviewers: & $\begin{array}{l}\text { Pierre Magistretti } \\
\text { pierre.magistretti@kaust.edu.sa } \\
\text { Strong expertise in neuron-glia metabolic interactions }\end{array}$ \\
\hline & $\begin{array}{l}\text { Giles Hardingham } \\
\text { Giles.H@ed.ac.uk } \\
\text { Strong expertise in energy metabolism in Alzheimer }\end{array}$ \\
\hline & $\begin{array}{l}\text { Giovanni Marsicano } \\
\text { giovanni.marsicano@inserm.fr } \\
\text { Expertise in glia metabolism and behavior }\end{array}$ \\
\hline & $\begin{array}{l}\text { Philip Haydon } \\
\text { philip.haydon@tufts.edu } \\
\text { Expert in glia physiology }\end{array}$ \\
\hline & $\begin{array}{l}\text { Andrea Volterra } \\
\text { andrea.volterra@unil.ch } \\
\text { Expert in glia physio and pathology }\end{array}$ \\
\hline & $\begin{array}{l}\text { Christian Henneberger } \\
\text { christian.henneberger@uni-bonn.de } \\
\text { Expert in Astrocyte-LTP metabolism }\end{array}$ \\
\hline & Brian MacVicar \\
\hline
\end{tabular}




\begin{tabular}{|l|l|}
\hline & $\begin{array}{l}\text { brian.macvicar@ubc.ca } \\
\text { Expert in neuron-glia metabolic interactions }\end{array}$ \\
\hline Opposed Reviewers: & $\begin{array}{l}\text { Cristina Alberini } \\
\text { ca60@nyu.edu } \\
\text { Expert in neuron-glia metabolism and behavior }\end{array}$ \\
\hline $\begin{array}{l}\text { Herman Wolosker } \\
\text { hwolosker@tx.technion.ac.il } \\
\text { conflict of interest }\end{array}$ \\
\hline $\begin{array}{l}\text { Gerry Dienel } \\
\text { gadienel@uams.edu } \\
\text { conflict of interest }\end{array}$ \\
\hline $\begin{array}{l}\text { Joseph Coyle } \\
\text { joseph_coyle@hms.harvard.edu } \\
\text { conflict of interest }\end{array}$ \\
\hline
\end{tabular}




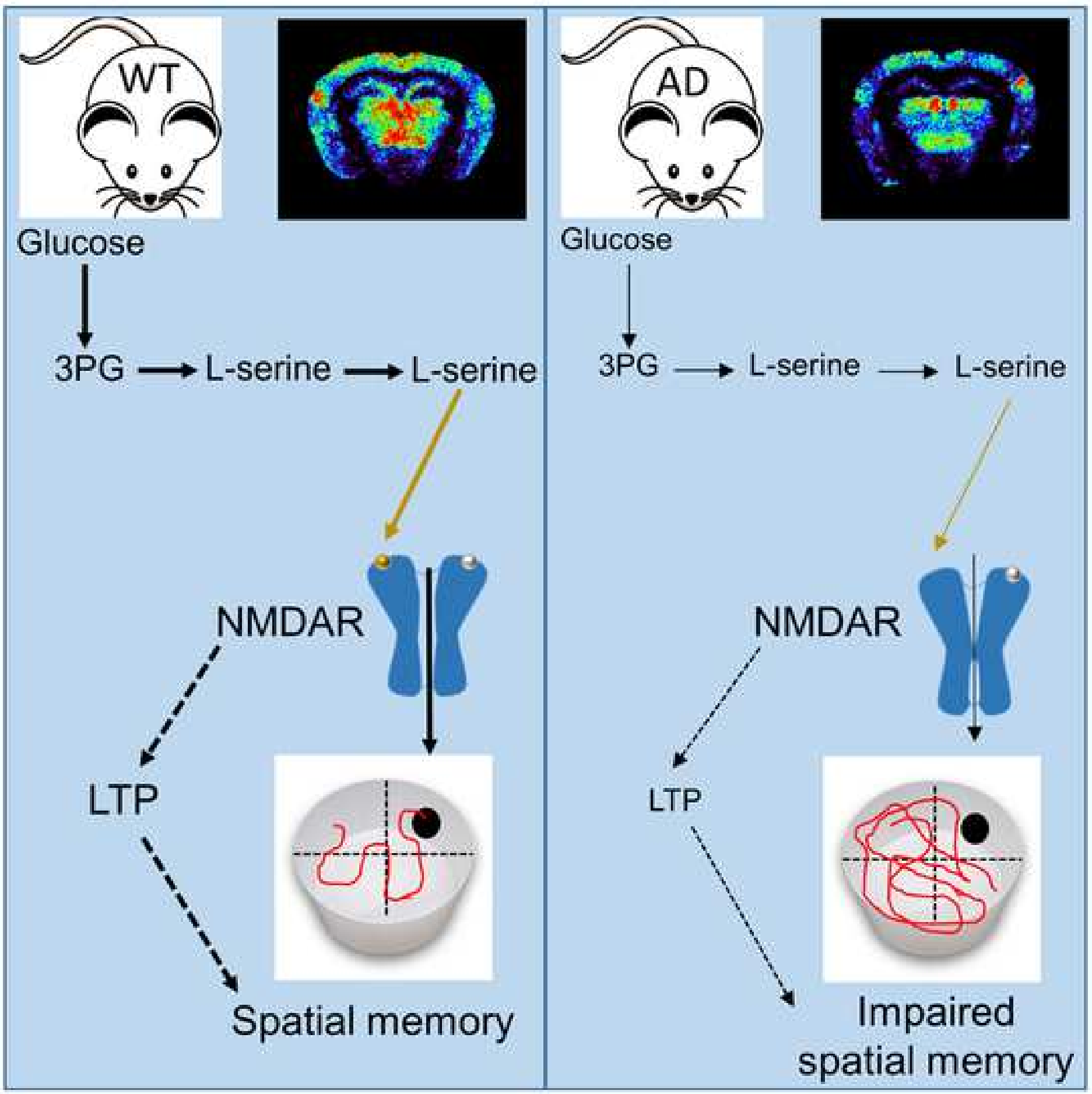




\section{Impairment of glycolysis-derived L-serine production in astrocytes contributes to cognitive deficits in Alzheimer's disease}

Juliette Le Douce ${ }^{1^{*}}$, Marianne Maugard ${ }^{1^{*}}$, Julien Veran ${ }^{2,3^{*}}$, Marco Matos ${ }^{2,3^{*}}$, Pierrick Jégo ${ }^{1+}$, PierreAntoine Vigneron ${ }^{1+}$, Emilie Faivre ${ }^{1+}$, Xavier Toussay4, Michel Vandenberghe ${ }^{1}$, Yaël Balbastre ${ }^{1}$, Juliette Piquet $^{4}$, Elvire Guiot ${ }^{4}$, Nguyet Thuy Tran ${ }^{5}$, Myriam Taverna ${ }^{5,6}$, Stéphane Marinesco ${ }^{7}$, Ayumi Koyanagi ${ }^{8}$, Shigeki Furuya ${ }^{8}$, Mylène Gaudin-Guérif ${ }^{1}$, Sébastien Goutal ${ }^{1}$, Aurélie Ghettas ${ }^{9}$, Alain Pruvost $^{9}$, AlexisPierre Bemelmans ${ }^{1}$, Marie-Claude Gaillard ${ }^{1}$, Karine Cambon ${ }^{1}$, Lev Stimmer ${ }^{9}$, Véronique Sazdovitch ${ }^{11}$, Charles Duyckaerts ${ }^{11}$, Graham Knott ${ }^{12}$, Anne-Sophie Hérard ${ }^{1}$, Thierry Delzescaux ${ }^{1}$, Philippe Hantraye ${ }^{1}$, Emmanuel Brouillet ${ }^{1}$, Bruno Cauli ${ }^{4}$, Stéphane H.R. Oliet ${ }^{2,3}$, Aude Panatier ${ }^{2,3, \#, ~ a n d ~ G i l l e s ~ B o n v e n t o ~}{ }^{1, \#, \&}$

1 Commissariat à l'Energie Atomique et aux Energies Alternatives (CEA), Direction de la Recherche Fondamentale, Institut François Jacob, Molecular Imaging Center (MIRCen), CNRS UMR 9199, Université Paris-Sud, Université Paris-Saclay, Fontenay-aux-Roses, France

2 Neurocentre Magendie, INSERM U1215, Bordeaux, France

${ }^{3}$ Université de Bordeaux, Bordeaux, France

${ }^{4}$ Sorbonne Universités, UPMC Université Paris 06, Institut de Biologie Paris-Seine (IBPS), UM 119, Neuroscience Paris Seine, Paris, France, CNRS, UMR 8246, Neuroscience Paris Seine, Paris, France, INSERM, UMR-S 1130, Neuroscience Paris Seine, Paris, France

${ }_{5}^{5}$ Université Paris-Saclay, CNRS, Institut Galien Paris Sud, Châtenay-Malabry, France

${ }^{6}$ Institut Universitaire de France (IUF)

7 AniRA-NeuroChem Technological Platform, Lyon Neuroscience Research Center, CNRS, UMR 5292, INSERM U1028, University Lyon 1, Lyon, France

8 Laboratory of Functional Genomics and Metabolism, Department of Bioscience and Biotechnology, Graduate School of Bioresource and Bioenvironmental Sciences, Kyushu University, Fukuoka, Japan

${ }^{9}$ Université Paris-Saclay, CEA, INRAE, Département Médicaments et technologies pour la santé,Gif-surYvette, France.

10 INSERM US27, Platform for Experimental Pathology, Molecular Imaging Research Center (MIRCen), Fontenay-aux-Roses, France

11 Laboratoire de Neuropathologie Raymond Escourolle, Hôpital de la Pitié-Salpêtrière, AP-HP, Paris, France

12 BioEM Facility, School of Life Sciences, Swiss Federal Institute of Technology Lausanne (EPFL), Lausanne, Switzerland

\footnotetext{
* These authors contributed equally

+ These authors contributed equally

\# Senior authors

\& Lead contact
} 


\section{CORRESPONDING AUTHORS:}

Gilles Bonvento, PhD

MIRCen and CNRS UMR 9199,

Fontenay-aux-Roses, France

Tel.: +33146548330

Fax: +33146549116

Email: gilles.bonvento@cea.fr

Aude Panatier, PhD

Neurocentre Magendie, INSERM U1215

146 rue Léo Saignat

Bordeaux, France

Tel: +33 557573730

Email: aude.panatier@inserm.fr 


\section{Abstract}

Alteration of brain aerobic glycolysis is often observed early in the course of Alzheimer's disease (AD). Whether and how such metabolic dysregulation contributes to both synaptic plasticity and behavioral deficits in $A D$ is not known. Here, we show that the astrocytic L-serine biosynthesis pathway, which branches from glycolysis, is impaired in young $A D$ mice and in $A D$ patients. L-serine is the precursor of $D$ serine, a co-agonist of synaptic NMDA receptors (NMDARs) required for synaptic plasticity. Accordingly, AD mice display a lower occupancy of the NMDAR co-agonist site as well as synaptic and behavioral deficits. Similar deficits are observed following inactivation of the L-serine synthetic pathway in hippocampal astrocytes, supporting the key role of astrocytic L-serine. Supplementation with L-serine in the diet prevents both synaptic and behavioral deficits in $A D$ mice. Our findings reveal that astrocytic glycolysis controls cognitive functions and suggest oral L-serine as a ready-to-use therapy for AD. 


\section{INTRODUCTION}

Alzheimer's disease $(A D)$ is a neurological disorder characterized by progressive memory decline and cognitive impairment. Functional and physical disruption of synapses is central to the disease process (Forner et al., 2017; Spires-Jones and Hyman, 2014). Dementia due to AD is also characterized by early and progressive metabolic disturbances as observed using $\left[{ }^{18} \mathrm{~F}\right]-$ fluorodeoxyglucose positron emission tomography (FDG-PET). FDG-PET changes even precede brain atrophy and neuronal dysfunction (Gordon et al., 2018; Mosconi et al., 2006; Protas et al., 2013). As such, FDG-PET is included among the core biomarkers for clinical and prodromal AD (Garibotto et al., 2017). Although both amyloid- $\beta(A \beta)$ and tau are central to $A D$ pathogenesis, it remains enigmatic whether, and how, glucose dysregulation contributes to synaptic defects in AD. Recent observations suggest that changes in aerobic glycolysis prevail in the early phase of AD (An et al., 2018; Vlassenko and Raichle, 2015). One major function of aerobic glycolysis is to maintain high levels of glycolytic intermediates to support anabolic reactions in cells (Lunt and Vander Heiden, 2011). L-serine, a non-essential amino acid, is generated through diversion of the glycolytic intermediate 3-phosphoglycerate (3PG) into the phosphorylated pathway. This L-serine biosynthesis pathway is a short metabolic sequence consisting of three enzymatic reactions starting with the oxidation of 3PG to 3-phosphohydroxypyruvate by 3-Phosphoglycerate Dehydrogenase (PHGDH). L-serine is a carbon donor for the biosynthesis of many macromolecules and is racemized into D-serine in the brain (Ehmsen et al., 2013). We and others have previously shown that the induction of long-term synaptic potentiation in the adult hippocampus requires the presence of D-serine, the endogenous co-agonist of synaptic NMDARs (Henneberger et al., 2010; Panatier et al., 2006; Papouin et al., 2012; Yang et al., 2003). Therefore, a shortage of glucose may not only directly reduce the availability of ATP required to sustain synaptic transmission, but also decrease the production of both L- and D-serine. In this study, we investigated the contribution of the phosphorylated pathway to early synaptic and behavioral deficits in AD. Our findings highlight oral L-serine as a potential therapy for $A D$ as well as other neurodegenerative diseases. 


\section{RESULTS}

The serine biosynthesis pathway directly branches from glycolysis (Figure 1A). Alteration of aerobic glycolysis is an early feature of AD. In the brain, a substantial fraction of glucose is thought to be processed via aerobic glycolysis in astrocytes (Bak and Walls, 2018; Barros and Weber, 2018; Magistretti and Allaman, 2015 , 2018). We used young 3xTg-AD mice to measure brain glucose metabolism in vivo, aerobic glycolysis flux in astrocytes and serine levels in vivo.

\section{Alteration of glucose metabolism in 3xTg-AD mice}

We measured energy metabolism in two groups of animals at two stages of progression of the pathology. We used six to seven months-old 3xTg-AD female mice to study the early phase of $A D$, as only intraneuronal $A \beta$ is present in the brain, and 11 to 12 months-old animals, that display senile plaques (Figures S1A-S1C for the anatomopathological evaluation of our colony of 3xTg-AD mice). In vivo 2deoxyglucose autoradiography (Figure 1B) was followed by 3D voxel-wise statistical analysis to map the differences in cerebral glucose metabolism between control and 3xTg-AD mice (Barros et al., 2018). This approach allows statistically significant unbiased identification of metabolic differences between groups at the voxel level, without operator-dependent delineation of regions of interest (Dubois et al., 2010). We found that six to seven months-old 3xTg-AD mice displayed localized decreases in glucose uptake in the amygdala, entorhinal cortex, and hippocampus including CA1, dentate gyrus and CA2 (Figures 1C and $1 \mathrm{E})$. We also observed increases in glucose uptake in the striatum, auditory cortex, and retrospenial cortex. Older 3xTg-AD mice (11 to 12 months-old) displayed the same hypermetabolic clusters, but the size of the hypometabolic clusters was bigger, in particular in the hippocampus (Figures 1D and 1F). The magnitude of the changes in glucose uptake was similar at both ages. Very little neurodegeneration has been detected in 3xTg-AD mice, at least up to the age of 24 months (Oh et al., 2010; Rohn et al., 2008). Our current observation of an unchanged brain volume between the four groups of mice as measured on Nissl stained brain sections for all animals used for in vivo metabolism (Figures S2A-S2C) corroborates the previous experimental evidence. It is therefore unlikely that cell death could contribute to hypometabolism in the 2 cohorts of six to seven months-old and 11 to 12 months-old 3xTg-AD female mice. Since most of energy is used at the level of excitatory synapses (Harris et al., 2012), we also probed whether the density of excitatory synapses were altered in 3xTg-AD mice. We performed serial block-face scanning electron microscopy at the level of the CA1 region of the hippocampus. We found that the density of excitatory synapses was unchanged in 6 month-old $3 \times T$ Tg-AD mice as compared to WT animals $(0.976 \pm 0.036$ vs. 
$0.956 \pm 0.012$; Figures S2D-S2F). This result strongly suggests that the hypometabolism we observed in $3 x \operatorname{Tg}-A D$ mice is not due to anatomical/structural changes and that $3 \times T g-A D$ mice display localized metabolic changes which start at an early stage of the disease. We next investigated whether the metabolic status of astrocytes was altered in 3xTg-AD mice.

\section{Alteration of glucose metabolism in astrocytes of 3xTg-AD mice}

Resting astrocytes produce lactate in a tonic manner via aerobic glycolysis (Sotelo-Hitschfeld et al., 2015). We monitored astrocyte lactate dynamics in real time in hippocampal slices using Laconic, a FRET lactate nanosensor that was expressed in the hippocampus using an AAV2/9 (Figure 1G). We first confirmed the specific astrocytic tropism of the AAV2/9 expressing td-Tomato under the control of the short gfaABC1D promoter (Figures S3A-S3C). Accordingly, expression of Laconic was restricted to astrocytes (Figure 1H). Lactate transport across the astrocytic plasma membrane is mediated by monocarboxylate transporters (MCTs). We therefore used AR-C155858, a MCT blocker (Ovens et al., 2010), to measure the accumulation of lactate in single astrocytes (Figure 11) at physiological extracellular glucose concentrations (Silver and Erecinska, 1994). The accumulation of intracellular lactate under MCT blockade observed in astrocytes of control mice was absent in 3xTg-AD astrocytes (Figure 1I). This result indicates that resting lactate production via the aerobic glycolytic pathway is altered in 3xTg-AD astrocytes. As L-serine is generated from glucose through diversion of the glycolytic intermediate 3-phosphoglycerate into the phosphorylated pathway (Figure 1A), we next investigated whether the defective glycolytic flux in 3xTg-AD astrocytes translated into reduced L-serine production/release.

\section{Lower levels of L-serine in 3xTg-AD mice}

We first measured total L-serine level in the hippocampus and found that it was significantly lower in $3 \times \mathrm{Tg}$ $\mathrm{AD}(880 \pm 48)$ than in control mice $(1089 \pm 42 \mathrm{nmol} / \mathrm{g}$ wet tissue; Figure $1 \mathrm{~J})$. We then measured extracellular L-serine in the hippocampus by in vivo microdialysis and found that its concentration was also significantly lower in $3 x \operatorname{Tg}-\mathrm{AD}(7.64 \pm 1.10)$ than in control mice $(16.61 \pm 1.73 \mu \mathrm{M}$; Figure $1 \mathrm{~K})$. These results strongly suggest that the production and release of L-serine is reduced in young 3xTg-AD mice. We observed these reductions in six-month-old 3xTg-AD mice that do not exhibit $A \beta$ plaques, overt astrocyte reactivity (GFAP staining), or activated microglia (IBA1 staining) in the CA1 region (Figure S1A and Figures S4A-S4D). Lserine is the obligatory precursor of D-serine, the main co-agonist of synaptic NMDARs in the adult hippocampus. We next monitored the levels of D-serine in the hippocampus of 3xTg-AD mice. 


\section{Lower levels of D-serine in 3xTg-AD mice}

We measured total D-serine level in the hippocampus and found that it was significantly lower in 6 monthold control 3xTg-AD (244 \pm 8$)$ than in control mice $(283 \pm 8 \mathrm{nmol} / \mathrm{g}$ wet tissue; Figure $1 \mathrm{~J})$. We then measured extracellular D-serine in the hippocampus by in vivo microdialysis and found that the concentration of extracellular D-serine was also significantly lower in 6 month-old control 3xTg-AD $(2.90 \pm 0.38)$ than in control mice $(4.53 \pm 0.72 \mu \mathrm{M}$; Figure $1 \mathrm{~K})$. These results strongly suggest that the production and release of $D$-serine is reduced in young $3 \times \mathrm{Tg}-\mathrm{AD}$ mice. We did not find any difference in the level of both total and extracellular glutamate between control and 3xTg-AD mice (Figure S6D and S6E) suggesting no major impairment in glutamate synthesis and release/uptake in young 3xTg-AD mice. We next performed electrophysiological recordings to assess the functional impact of a lower extracellular D-serine on the activity of NMDARs in 3xTg-AD mice.

\section{Lower level of occupancy of the co-agonist-binding site of NMDARs in 3XTg-AD mice}

We thus recorded the NMDAR component of field excitatory post-synaptic potentials (NMDAR-fEPSPs) in acute hippocampal slices. In control mice, bath application of D-serine $(50 \mu \mathrm{M})$ induced an increase of NMDAR-fEPSPs $(126.8 \% \pm 7.3$, Figure $2 \mathrm{~A})$. This is in accordance with previous work (Henneberger et al., 2010; Papouin et al., 2012), indicating that the co-agonist binding sites of synaptic NMDARs in this region are not fully saturated. Importantly, the D-serine-mediated increase in synaptic NMDAR-fEPSPs was significantly larger in 6 month-old control 3xTg-AD mice (156.6\% \pm 8.3 , Figure $2 A)$. This is consistent with a reduced level of occupancy of the NMDAR co-agonist-binding site in 3xTg-AD mice because of a reduced level of D-serine within the cleft. Another possibility would be that the NMDAR subunit composition was switched from GluN2B to GluN2A in 3xTg-AD mice, since GluN2A-containing NMDARs have a lower affinity for D-serine than GluN2B receptors (Ferreira et al., 2017). In that case, the amount of NMDARs recruited during synaptic stimulation could be reduced even if endogenous $D$-serine levels were unchanged. We tested this possibility by investigating the inhibitory action of a GluN2B antagonist (Ro-25-6981, $2 \mu \mathrm{M})$ on NMDAR-EPSPs in both control and 3xTg-AD mice. Experiments were performed in the presence of Dserine $(50 \mu \mathrm{M})$ to make sure that all synaptic NMDARs were available for activation and to have a better quantification of the NMDAR population present at the synapse. In WT animals, NMDAR-fEPSPs were slightly decreased by Ro-25-6981 (90.8 $\pm 4.7 \%$ of baseline, Figure $2 \mathrm{~B})$. Interestingly, a similar effect was observed in $3 \times \operatorname{Tg}$ mice ( $89.8 \pm 4.4 \%$ of baseline, Figure $2 \mathrm{~B})$. Taken together, these data indicate, that the fraction of GluN2B receptors present at CA3-CA1 synapses is very limited and, most importantly, that this 
fraction is unchanged in 3xTg-AD mice. This result argues against the possibility of a switch of NMDARs subunits in these mice. We next monitored hippocampal excitatory synaptic transmission and plasticity in 3xTg-AD female mice, given the role played by D-serine in NMDAR activity.

\section{Impaired synaptic plasticity in 3xTg-AD mice}

As originally reported (Oddo et al., 2003), high-frequency stimulation (HFS)-induced LTP was impaired in 6 month-old control 3xTg-AD (156.7\% \pm 6.7 in control vs. $123.5 \% \pm 5.4$ in $3 \times T g-A D$, Figure $2 C)$. We found that low-frequency stimulation (LFS)-induced LTD was also reduced in these animals $(79.9 \% \pm 9.5$ in control vs. $114.5 \% \pm 6.6$ in $3 \times T g-A D$, Figure $2 E$ )

\section{Impaired synaptic plasticity in 3xTg-AD mice is rescued by D-serine}

All these results support the hypothesis that the deficits in synaptic plasticity observed in 3xTg-AD mice are due to a lower concentration of D-serine in the synaptic cleft and thus to fewer NMDARs available for activation during HFS and LFS. In agreement with this hypothesis, LTP was rescued by supplying exogenous D-serine $(50 \mu \mathrm{M})$ to slices obtained from $3 \times \mathrm{Tg}-\mathrm{AD}$ mice $(163.6 \% \pm 9.7$ in control vs. $166.1 \% \pm$ 12.4 in 3xTg-AD; Figure 2D). Similarly, exogenous D-serine $(50 \mu M)$ completely rescued LTD in 3xTg-AD mice $(79.1 \pm 11.3 \%$ in control vs. $87.5 \% \pm 4.9$ in $3 \times T g-A D$, Figure $2 F)$. Acute application of D-serine did not affect LTP and LTD in slices obtained from control mice (Figures 2C-2F). We next assessed whether Dserine could rescue the spatial memory deficits of $3 x \operatorname{Tg}-A D$ mice.

\section{Impaired spatial memory in 3xTg-AD mice is rescued by D-serine}

We evaluated learning and memory using the spatial reference version of the Morris water maze that is hippocampal-dependent (Morris, 1984). 3xTg-AD mice displayed a similar spatial learning performance than age-matched control mice but did not show any preference for the target quadrant during the probe trial (Figure 2G). We chronically treated mice with $\mathrm{D}$-serine in the drinking water ( 100mg/kg body weight), a regimen that has been previously shown to increase levels of D-serine in the brain (Otte et al., 2013). Oral supplementation of $D$-serine for two weeks rescued the cognitive deficits of six-month-old female $3 \times \mathrm{Tg}$ $A D$ mice but did not modify the performance of control mice (Figure $2 G$ ). These results all point to defective D-serine availability at the hippocampal synapses of 3xTg-AD mice. We then asked whether the reduced production of L-serine could be responsible for the D-serine-mediated impairment of synaptic plasticity and spatial behavior. If this is the case, inactivation of the L-serine biosynthetic pathway should recapitulate the signs observed in 3xTg-AD mice. While Phgdh, the first enzyme of the L-serine synthetic pathway, was 
recently reported to be expressed mostly in astrocytes and oligodendrocytes and not in neurons (see http://www.brainrnaseq.org/ and http://mousebrain.org/genesearch.html), the cellular localization of PHGDH has not been thoroughly studied in the brain. We therefore performed a histological study focusing at the hippocampus.

\section{The serine synthetic pathway is primarily located in astrocytes}

The first committed step of the L-serine biosynthetic pathway is the oxidation of 3PG to 3phosphohydroxypyruvate (3PHP) by PHGDH (Figure 1A). A specific antibody directed against PHGDH showed prominent staining of astrocytes not only in mouse but also in non-human primate and human brain (Figure 3A). We performed co-localization studies with confocal microscopy in a control mouse brain and confirmed that PHGDH was mainly expressed by GFAP-expressing astrocytes and not microglial cells (IBA1-positive), neurons (NeuN-positive), or oligodendrocytes (Olig2-positive) in the CA1 region of the hippocampus (Figure 3B). We next developed a conditional mouse model to interrogate the role of the astrocytic hippocampal PHGDH in synaptic plasticity and spatial behavior.

\section{Conditional inactivation of Phgdh leads to impaired synaptic plasticity and spatial memory}

Mice conditionally lacking Phgdh in astrocytes have been previously generated by crossing Phgdh floxfllox mice with hGFAP-Cre transgenic mice (Yang et al., 2010). Since hGFAP-cre transgene mediates gene deletions in a much wider spectrum of neural cells than just astrocytes (Zhuo et al., 2001), we locally and conditionally inactivated Phgdh by injecting an AAV expressing Cre recombinase under the control of the astrocytic gfa-ABC1D promoter in the hippocampus of adult Phgdh floxflox mice (Figure 3C). At the transcriptional level, Phgdh mRNA was $\sim 25 \%$ of its initial value found in both non-injected and AAV-GFPinjected mice (Figure 3D). At the protein level, PHGDH expression was significantly reduced in Phgdh floxfllox mice injected with AAV-Cre in comparison to mice injected with AAV-GFP (Figures 3E-3H). Astrocytes lose some of their normal functions when they become reactive (Liddelow et al., 2017). The levels of expression of mRNA for vimentin and gfap and of GFAP were not significantly different between Phgdh $h^{\text {floxflox }}$ mice injected with AAV-Cre or AAV-GFP (Figure S5A-S5D). We next performed a Sholl analysis on GFAP immunostained astrocytes and showed that the complexity of astrocyte processes was not altered following inactivation of Phgdh (Figure S5E and S5F). These results strongly suggest that astrocytes did not adopt a reactive phenotype following inactivation of Phgdh. The levels of expression of selected neuronal and 
microglial mRNAs (Neun, eaat3, cd68, iba1) and of D-amino acid oxidase (daao), the enzyme that degrades D-serine, were not significantly different between Phgd $h^{\text {floxflox }}$ mice injected with AAV-Cre or AAV-GFP (Figures S5G-S5K), indicating no marked neuronal death, no microglial activation as well as no compensatory mechanisms targeting D-serine levels following local inactivation of Phgdh.

We then confirmed that the levels of L- and D-serine in the brain are determined by their de novo biosynthesis through the phosphorylated pathway in astrocytes. Indeed, the total L-serine, D-serine and glycine content in the whole hippocampus, measured by HPLC (Figure 3l), as well as the level of extracellular D-serine, measured in vivo via a biosensor (Figure 3J), were significantly lower in Phgdh $h^{\text {floxfllox }}$ mice injected with AAV-Cre in comparison to mice injected with AAV-GFP. We subsequently investigated whether long-term synaptic plasticity was impaired in those mice. HFS-induced LTP was significantly impaired in these animals $(166.8 \% \pm 5.8$ in AAV-GFP-injected, and 133.9\% \pm 13.5 in AAV-Cre-injected mice, Figures $3 \mathrm{~L}$ and $3 \mathrm{M})$. Bath application of L-serine $(50 \mu \mathrm{M})$ rescued $\mathrm{LTP}(152.2 \% \pm 12.0$, Figures $3 \mathrm{~L}$ and $3 \mathrm{M}$ ), indicating that L-serine produced by the phosphorylated pathway is required for activity-dependent synaptic plasticity. We performed several behavioral tests on these mice to assess their anxiety and monitor their motor and cognitive performance. The mice with inactivated Phgdh in the hippocampus did not show any alterations in anxiety or spontaneous motor behavior, as assessed using the elevated plus-maze and the Phenotyper® (Figures S5L and S5M). Those mice were tested using the Morris water maze and displayed a similar spatial learning performance than control mice. However, they did show significant impairment of spatial memory when they were tested $72 \mathrm{~h}$ after learning the location of the platform (Figure $30)$, as we observed with $3 x T g-A D$ mice. Finally, to determine whether L-serine is necessary and sufficient to promote spatial memory in the hippocampus, we fed Phgdh floxfllox mice injected with AAV-Cre with a diet enriched in L-serine for one month. We found that the diet was sufficient to restore total levels of L-serine, D-serine and glycine in the whole hippocampus as well as the extracellular levels of D-serine (Figure $3 \mathrm{~N}$ ). Accordingly, the spatial memory was restored in those animals (Figure 30). Overall, these results show that the availability of L-serine synthesized via the phosphorylated pathway in astrocytes is a key determinant for normal NMDAR function and support our hypothesis that its dysregulation could contribute to memory deficits in $\mathrm{AD}$. To gain further insight into the potential contribution of the astrocytic L-serine synthesis pathway in $A D$, we investigated whether the expression of PHGDH was altered both in young $3 \times T g-A D$ mice and in post-mortem brain tissue of $A D$ patients. 


\section{Expression of PHGDH is reduced in the AD brain}

We analyzed the expression of PHGDH in 6 month-old female 3xTg-AD mice that do not display A $\beta$ plaques (Figure 4A) and found no difference as compared to control age-matched animals using immunofluorescent confocal analysis (Figure 4B) or immunoblotting (Figure 4C). This result suggests that the lower L-serine levels in 3xTg-AD mice is more likely resulting from reduced glucose uptake and less substrate available for the L-serine synthesis pathway rather than from a direct effect of $A \beta$ on PHGDH expression, at least during the early phase of $A D$ (i.e. astrocytes are not reactive and $A \beta$ plaques are not formed). We then performed immunohistochemistry on human formalin-fixed paraffin-embedded sections (Figure 4D) from control individuals, intermediate AD (Braak III-IV), and advanced AD (Braak VI) patients (Table 1). Contrarily to 6 month-old female 3xTG-AD mice, advanced AD patients presented numerous $A \beta$ plaques, hyperphosphorylated Tau and reactive GFAP-positive astrocytes (Figure 4E). We observed a reduction of PHGDH staining (Figure 4E), which was confirmed by fluorescent immunoblotting (Figure 4F) of frozen sections from the same patients. The reduction was statistically significant in intermediate AD (-62\%) and even more pronounced in advanced $A D$ patients $(-82 \%)$. These results indicate that a progressive alteration of the astrocytic serine synthetic pathway occurs in the brain of AD patients. Altogether, these data support the contribution of defective production/release of L-serine in astrocytes to the pathogenesis of $A D$ and point to L-serine supplementation as a potential therapy. We finally asked whether supplying exogenous Lserine could also rescue both synaptic plasticity and spatial behavior deficits in 3xTg-AD mice.

\section{Oral L-serine as a potential therapy for AD}

We first assessed the effects of acute L-serine $(50 \mu \mathrm{M})$ on LTP. Bath application of L-serine $(50 \mu \mathrm{M})$ fully rescued LTP in slices obtained from 3xTg-AD mice $(156.8 \% \pm 7.4$ in control vs. $160.5 \% \pm 6.4$ in 3xTg-AD; Figure 5A). Since long-term treatment with exogenous L-serine can compensate for its deficient production in the context of inherited metabolic disorders of L-serine biosynthesis (see discussion), we next assessed the effects of chronic oral L-serine supplementation upon both the long-term synaptic plasticity and the spatial memory performance of 3xTg-AD and control mice. Mice aged four to five months were given a $10 \%$ L-serine-enriched diet for two months (Figure 5B). Total L-serine content in the whole hippocampus was significantly higher in the two groups of animals that received the diet (Figure 5B) as compared to untreated animals (Figure $1 \mathrm{~J}$ ). Two months after chronic L-serine diet, total L-serine content was no longer significantly different between control and 3xTg-AD mice (1590 \pm 87 vs. $1844 \pm 73 \mathrm{nmol} / \mathrm{g}$ wet tissue, 
respectively, Figure 5B). The diet also boosted de novo production of D-serine since its content in the whole hippocampus was significantly higher in the two groups of animals that received the diet (see Figure $1 \mathrm{~J}$ for comparison with untreated animals) up to a level that was not different between control and 3xTg-AD mice (496 \pm 11 vs. $512 \pm 28 \mathrm{nmol} / \mathrm{g}$ wet tissue for control and 3xTg-AD mice, respectively, Figure 5B). Using in vivo microdialysis, we found that the levels of extracellular $L-$ and $D-s e r i n e$ were higher in $3 x T g-A D$ mice receiving the diet vs. untreated $(24.91 \pm 6.29$ vs. $8.66 \pm 1.83 \mu \mathrm{M}$ and $8.22 \pm 1.79$ vs. $2.28 \pm 0.31 \mu \mathrm{M}$ for Land D-serine, respectively). The diet did not significantly alter the total levels of other amino acids measured in the hippocampus; only a modest increase in phenylalanine level was observed (Figures S6A-S6I). We then observed that in 3xTg-AD mice fed with L-serine, bath application of D-serine $(50 \mu \mathrm{M})$ induced a similar increase of NMDAR-fEPSPs to the one measured in control animals $(126.3 \% \pm 3.5$ in control vs. $124.4 \% \pm$ 2.3 in $3 \times T g-A D$, Figure $5 C$ ). This result indicates that the chronic supplementation of $L$-serine was able to rescue the deficit of D-serine availability observed at hippocampal synapses in 3xTg-AD mice, thereby restoring the level of occupancy of the NMDAR co-agonist binding site to its control values. Accordingly, LTP was fully rescued in those animals $(152.0 \% \pm 3.2$ in control vs. $154.5 \% \pm 5.0$ in $3 \times T$ Tg-AD, Figure 5D). We finally probed the spatial memory performance in 3xTg-AD mice fed with L-serine and found that it reached a level similar to the one measured in control mice fed with L-serine (Figure 5E). Altogether, these data support the use of oral L-serine as a ready-to-use and safe therapy for of AD.

\section{DISCUSSION}

Glial cells have been recently implicated in $A D$ with astrocytes and microglia now recognized as potential cellular mediators of synapse dysfunction and loss (Hong et al., 2016; Jo et al., 2014). Here, we have identified an astrocytic metabolic pathway that directly contributes to early synaptic deficits underlying cognitive decline in $A D$, well before microglia and astrocytes become reactive (Liddelow et al., 2017). We showed that the production of L-serine, a non-essential amino acid that is generated from glucose, is impaired in $A D$ astrocytes.

The L-serine biosynthetic pathway has been well studied in cancer cells that exhibit increased glucose metabolism to lactate (the so-called Warburg effect) and in which multiple copies of Phgdh divert glycolytic flux and provide L-serine and glycine for rapid cell growth and proliferation (Locasale et al., 2011; Possemato et al., 2011). L-serine is a central node for the biosynthesis of many molecules such as sphingolipids and phospholipids. It also supplies carbon to the one-carbon pool, which is involved in folate 
metabolism, contributing to purine synthesis (Mattaini et al., 2016). This metabolic pathway is particularly essential for the nervous system as homozygous mutations of each of the three enzymes of the serine biosynthesis pathway cause a syndrome called Neu-Laxova, a rare autosomal-recessive disorder characterized by severe peripheral and central nervous system malformations (microcephaly), leading to prenatal or early postnatal death (Acuna-Hidalgo et al., 2014). This clinical phenotype of L-serine biosynthesis is reminiscent of defects in brain serine transport induced by mutations in SLC1A4, the gene coding for the neutral amino acid transporter ASCT1 (Damseh et al., 2015), underlying the critical role of Lserine biosynthesis and shuttling. L-serine treatment during pregnancy and after birth improves fetal brain growth and prevents neurological symptoms (de Koning et al., 2004), suggesting that exogenous L-serine can compensate for its lack of de novo production in the brain.

In the present work, we focused our attention on glycolysis as a possible regulator of L-serine production in the brain as L-serine is generated from glucose. In $A D$, early alterations of cerebral glucose metabolism, as measured using fluoro-2-deoxy-D-glucose (FDG) and positron emission tomography (PET), are well established. Several studies have shown that abnormalities in FDG-PET can even predict progression from mild cognitive impairment (MCI) to AD (for references see (Cohen and Klunk, 2014)). We used 3D analysis of in vivo brain glucose metabolism to show that 3xTg-AD mice display metabolic impairment in specific brain regions, including the hippocampal formation. Vascular dysregulation (Iturria-Medina et al., 2016) as well as endothelial glucose transporter 1 (GLUT1) reductions are mechanisms by which A $\beta$ could likely exert its deleterious metabolic effects (Winkler et al., 2015). Glucose, the almost exclusive energy substrate of the brain, is glycolytically processed to produce pyruvate and lactate in astrocytes, whereas neurons predominantly process glucose through the pentose phosphate pathway to produce NADPH and utilize pyruvate and lactate from astrocytes to feed the TCA cycle and the associated oxidative phosphorylation to produce ATP (Herrero-Mendez et al., 2009). Our observation that PHGDH, whose substrate is a glycolytic intermediate, is exclusively expressed by astrocytes is consistent with the notion that astrocytes are glycolytic cells. Even if we do not provide a causal link between the defective hippocampal glycolysis and the alteration of the phosphorylated pathway, our findings suggest that astrocytic energy metabolism may control L-serine production, thereby influencing glutamatergic neurotransmission. In addition to lactate (Suzuki et al., 2011; Yang et al., 2014), we propose that another byproduct of aerobic glycolysis (L-serine) may play an important role in plasticity and learning. 
In the brain, L-serine is the obligatory precursor of D-serine (Ehmsen et al., 2013), a physiological ligand of the co-agonist site of synaptic NMDARs in the hippocampus, that is required to sustain synaptic transmission (Panatier et al., 2006; Papouin et al., 2012). Our electrophysiological recordings show a reduced level of occupancy of the NMDAR glycine-binding site in seven-month-old 3xTg-AD mice. Accordingly, D-serine completely rescued both forms of synaptic plasticity (LTP and LTD) as well as spatial memory. Chronic D-serine supplementation has long been considered to be a therapeutic option for pathological conditions involving NMDARs malfunction such as schizophrenia (Kantrowitz et al., 2016) but its slow and weak diffusion through the blood-brain barrier and potential nephrotoxicity have limited its clinical use. L-serine represents a more favorable therapeutic option because it is considered to be safe by the Food and Drug Administration; it has been approved as a normal food additive, it is widely sold as a dietary supplement and is well-tolerated, even at high doses. L-serine is currently prescribed for the treatment of Neu-Laxova syndrome that results in L-serine deficiency (van der Crabben et al., 2013) and is currently in a phase I clinical trial as a treatment for hereditary sensory autonomic neuropathy type 1 (Garofalo et al., 2011) and amyotrophic lateral sclerosis (Levine et al., 2017). L-serine supplementation was recently shown to ameliorate motor and cognitive performance in rare NMDA-related severe encephalopathy leading to glutamatergic signaling deficiency (Soto et al., 2019). Glutamate excitotoxicity has long been implicated in AD pathophysiology, as supported by the use of the uncompetitive NMDAR partial antagonist memantine to treat moderate-severe AD patients. Although it is possible that increasing D-serine concentrations in $A D$ patients may exacerbate glutamate excitotoxicity, this would probably not occur at an early stage of the pathology, when memantine is not yet effective (Schneider et al., 2011). It is noteworthy that people living in Okinawa, a Japanese island known for the overall longevity of its population, have a diet characterized by an L-serine content that is four times higher than that of the average American (Cox and Metcalf, 2017).

This study finally points to direct impairment of the phosphorylated pathway in $A D$, as shown by a marked reduction of PHGDH expression in $\mathrm{AD}$ patients. This is the first demonstration of the selective expression of PHGDH in human hippocampal astrocytes, as well as its decrease during the progression of AD. Since we did not observe any change in PHGDH expression in six-month old 3xTg-AD mice that do not display $A \beta$ plaques and whose astrocytes are not reactive, it is therefore highly conceivable that the primary event leading to less serine production would be related to altered glycolysis flux in early AD and that PHGDH expression would be affected in later AD stages. The fact that brain glucose metabolism is altered in the 
early phase of AD patients is compatible with such hypothesis. Unfortunately, there is no consensus on the evolution of L- and D-serine levels in AD (Biemans et al., 2016; Lin et al., 2017; Madeira et al., 2015). Additional studies are necessary to determine whether, where (brain region, extracellular vs. tissue vs. CSF) and when the levels of L- and D-serine change during disease progression. Altogether, these data raise the prospect of L-serine supplementation as a treatment option for $A D$ and possibly other neurodegenerative diseases.

\section{Limitations of Study}

There are some limitations to our study, which should be acknowledged. First, we only performed this study in a single model of $A D$ ( $3 x T g-A D$ mice). It would be important to investigate whether the reduced production of L-serine by astrocytes we uncovered is a general feature that can be found in another transgenic $A D$ mice models that do not present the Tau mutations. Second, we analyzed a rather limited number of human hippocampal samples and it may be worth to complete the analysis with more samples coming from other brain regions as well. Finally, an intriguing question that will be important to investigate in the future is the impact of the supplementation of L-serine in the diet on the amyloid load and the Tau hyperphosphorylation.

\section{Funding}

This work was supported by grants from the Agence Nationale de la Recherche (ANR 2011 MALZ-0003 to G.B. and B.C.), Association France Alzheimer and Fondation de France (Prix Spécial 2012 to G.B., B.C. and S.H.R.O.), Fondation Plan Alzheimer (G.B.), Infrastructure de Recherche translationnelle pour les Biothérapies en Neurosciences-NeurATRIS ANR-11-INBS-0011 (G.B.), Fondation pour la Recherche Médicale and EU Joint Programme - Neurodegenerative Disease Research (JPND ; Horizon 2020 Framework Programme, grant agreement 643417/DACAPO-AD to S.H.R.O.). J.L.D. is a recipient of a PhD fellowship from the CEA (IRTELIS program). M.Mau. is a recipient of a PhD fellowship from the Ecole Normale Supérieure (ENS). P.A.V is a recipient of a PhD fellowship from the Fondation pour la Recherche Médicale (FRM). P.J. fellowship was provided by Enhanced Eurotalents, a Marie Sklodowska-Curie Actions Programme, co-funded by the European Commission and managed by the French Alternative Energies and Atomic Energy Commission (CEA). M.M is a recipient of a post-doctoral fellowship (DACAPO-AD / JPND / EU H2OH2O grant agreement №643417). This work benefited from the support of various facilities granted by INSERM and LabEX BRAIN ANR-10-LABX-43. The team of G.B. is part of the Ecole des Neurosciences de Paris (ENP) training network and that of S.H.R.O is part of the LaBex BRAIN. 


\section{Author contributions}

J.L.D. performed the confocal analysis, carried out the biochemical, RT-qPCR and the metabolic studies and developed the AAVs with the help of M.Mau, A.P.B. and M.C.G.

J.V. and M.M. performed electrophysiology on 3xTg-AD mice with the help of A.P.

M.Mau. performed all experiments on Phgdh $h^{\text {floxfllox }}$ mice, immunoblotting and all behavioral tests with the help of K.C.

P.J carried out electrophysiology on Phgdhiloxflox mice

P.A.V, P.J. and M.G.G. performed microdialysis

T.T., M.T., S.G., A.G. and A.P. measured extracellular amino acid concentrations using CE-LIF or LCLC/MS

E.F. performed the histological analysis of the 3xTg-AD colony and performed the in vivo metabolic study with the help of G.B. and M.G.G.

X.T. carried out the FRET imaging experiments with the help of J.P., E.G and B.C.

M.V., Y. B., A-S. H. and T.D. performed the 3D image processing and the analysis of the in vivo metabolic data

S.M. and M.Mau. measured extracellular D-serine using biosensors

A.K. and S.F. provided the Phgdh $h^{\text {floxflox }}$ mice and measured amino acid concentrations using HPLC

L.S., V.S and C.D performed and analyzed immunohistochemical stainings on human samples with the help of P.A.V.

G.N. performed EM studies

P.H. and E.B. provided materials and discussed the data

B.C., S.H.R.O. and G.B. obtained funding for the research

A.P. and G.B. coordinated the study and wrote the manuscript

\section{Acknowledgments}

The authors thank Martine Guillermier and Sueva Bernier for useful technical help and Felipe Barros, Juan Bolanos and Igor Allaman for helpful discussion. We thank Noëlle Dufour and Charlène Joséphine for viral production, the Neuro-CEB biobank at the Hôpital de la Pitié-Salpétrière for providing human samples, Anaelle Dubois for electron microscopy at the BioEM Facility of the EPFL (Switzerland) and Alain Chédotal 
and Stéphane Fouquet at the Institut de la Vision for high resolution scans. Authors thank also Delphine Gonzales, Sara Laumond and all the people of the Animal Facility and the Genotyping Facility of the NeuroCentre Magendie for mouse care and genotyping.

Conflict of Interest Statement - The authors declare no conflict of interest. 


\section{Figures and Legends}

Figure 1. 3xTg-AD mice display energy metabolism alterations and decreased L- and D-serine levels (A) The phosphorylated pathway of L-serine biosynthesis is a short metabolic sequence consisting of three enzymatic reactions. The glycolytic intermediate 3-phosphoglycerate (3PG) is converted into phosphohydroxypyruvate (3PHP), in a reaction catalyzed by 3-phosphoglycerate dehydrogenase (PHGDH). 3PHP is metabolized to phosphoserine (3PS) by phosphohydroxypyruvate aminotransferase (PSAT1) and, finally, 3PS is converted into L-serine by phosphoserine phosphatase (PSPH). In the brain, L-serine is converted into $\mathrm{D}$-serine by serine racemase (SRR). 1,2 and 3 indicates the functional parameters we have measured in 3xTg-AD mice. (B) In vivo glucose uptake was measured using 3D-reconstructed autoradiography and voxel-wise statistical analysis to map the cerebral metabolic differences between (C) 6 month-old control $(n=10)$ and 3xTg-AD mice $(n=10)$ and (D) between 12 month-old control $(n=9)$ and 3xTg-AD mice $(n=10)$. Brains of 3xTg-AD mice display hypometabolic (blue) and hypermetabolic (red) clusters at both ages. (E) Only hypometabolic clusters were observed in the hippocampus in 6 month-old 3xTG-AD and $(\mathbf{F})$ their size were larger in 12 month-old 3xTg-AD mice (Student's $t$ test $p<0.01$ ). Numbers indicate the anatomical position relative to Bregma. (G) Design of the AAV2/9 expressing the FRET sensor Laconic that was injected in the CA1 region of the hippocampus in 6 month-old control $(n=3)$ and $3 \times T$ AD $(n=3)$ mice. (H) CA1 astrocytes expressing the FRET lactate sensor Laconic in an acute hippocampal slice showing mTFP (blue) and Venus (green). (I) Typical response of intracellular lactate to bath application of $1 \mu \mathrm{M}$ AR-C155858, a monocarboxylate transporter blocker. Astrocytes of 6 month-old 3xTgAD mice ( $n=3,7$ slices, 26 cells) do not accumulate lactate as compared to control astrocytes $(n=3$ mice, 6 slices, 33 cells; Mann-Whitney U Test, $\left.{ }^{* *} \mathrm{p}<0.01\right)$. (J) Total levels of L-serine and D-serine measured by HPLC are significantly lower in 6 month-old $3 \times T$ Tg-AD mice (Mann-Whitney $U$ test, ${ }^{* *} p=0.005$ ). (K) Extracellular levels of L-serine and D-serine measured by microdialysis and LC-MS/MS are significantly lower in 6 month-old 3xTg-AD mice as compared to control animals (Repeated measures ANOVA, F(1, $10)=15.691, p=0.0027$ for $L$-serine and $F(1,11)=5.4482, p=0.0396$ for $D$-serine $)$.

Figure 2. Deficits of synaptic plasticity at CA3-CA1 synapses and of spatial memory in 3xTg-AD mice are rescued by D-serine 
(A) Electrophysiological recordings were performed on acute brain slices of 6-7 month-old 3xTg-AD and control mice with the stimulating and recording electrodes located in CA1. Effect of D-serine application (50 $\mu \mathrm{M}$ ) on NMDAR-fEPSPs in slices obtained from control (green) and 3xTg-AD mice (purple). Traces of representative NMDAR-fEPSPs recorded before (1) and during (2) D-serine application. Bar graph summarizing results presented in (A) indicates that NMDAR co-agonist binding site occupancy was decreased in 3xTg-AD mice (Mann-Whitney $U$ test, $p=0.008$; control: $n=10$; 3xTg-AD: $n=8$ ). (B) The application of Ro-25-6981 (2 $\mu \mathrm{M})$ only slightly reduces NMDAR-fEPSPs in slices obtained from control and 3xTg-AD mice. D-serine $(50 \mu \mathrm{M})$ was bath applied to make sure that all synaptic NMDARs were available for activation. Bar graph summarizing results presented in B indicates that GluN2B receptors contribute to a small fraction of the synaptic NMDARs in both control and 3xTg-AD mice (Mann-Whitney $U$ test, $p=0.75$; control: $n=9 ; 3 x T g-A D: n=6$ ). (C) Traces represent typical fEPSPs evoked before (1) and after (2) high frequency stimulation (HFS). LTP was significantly impaired in 3xTg-AD mice (Mann-Whitney $U$ test, $p=0.012$ ). Bar graph summarizing experiments presented in $\mathbf{C}$ (control: $n=7 ; 3 x \operatorname{Tg}-A D: n=11$ ). (D) $D$-serine application $(50 \mu \mathrm{M})$ rescued LTP in 3xTg-AD mice (Mann-Whitney $U$ test, $\mathrm{p}=0.958)$. Bar graph summarizing experiments presented in $\mathbf{D}$ (control: $n=6 ; 3 x \operatorname{Tg}-A D: n=10$ ). (E) Representative traces of characteristic fEPSPs evoked before (1) and after (2) low frequency stimulation (LFS). LTD was significantly impaired in 3xTg-AD mice (Mann-Whitney $U$ test, $p=0.008$ ). Bar graph summarizing experiments presented in $\mathbf{E}$ (control: $n=8$; 3xTg-AD: $n=9)$. (F) D-serine application $(50 \mu M)$ rescued LTD in 3xTg-AD mice (MannWhitney $U$ test, $p=0.699$ ). Bar graph summarizing experiments presented in $\mathbf{F}$ (control: $n=5 ; 3 x T g-A D: n=9$ ). (G) 3xTg-AD mice present spatial memory deficits (one tailed one sample t-test against chance level (25\%), $\mathrm{p}=0.19)$ when probed in the Morris Water maze $72 \mathrm{~h}$ after training as compared to control mice $(\mathrm{p}=0.0037)$. Chronic oral D-serine supplementation (drinking water for 2 weeks) restored the spatial memory deficits of 3xTg-AD mice $(p=0.035)$ and was without any effect in control mice $(p=0.014)$. $A Q$, adjacent quadrant, $\mathrm{OQ}$, opposite quadrant, $\mathrm{TQ}$, target quadrant. $\mathrm{n}$ = number of mice, 1 slice/animal.

Figure 3. Conditional inactivation of Phgdh in astrocytes impairs synaptic plasticity and spatial memory

(A) Immunostaining of PHGDH in the hippocampus of a mouse, a non-human primate and a human brain. PHGDH is mainly expressed in astrocytes. (B) Double immunofluorescent staining of brain sections from 
6-month old control mice using PHGDH (green) and either an astrocyte marker (GFAP, red), a microglial marker (IBA1, red), a neuronal marker (NeuN, red) or an oligodendrocyte marker (Olig2, red). (C) Design of the AAV2/9 expressing Cre-IRES-GFP that was injected in the CA1 region of the hippocampus in Phgdh floxfllox mice (D) Level of phgdh mRNA was $~ 25 \%$ of its initial value as compared to both non-injected and GFP-injected mice (Kruskal-Wallis followed by Dunn test, $p=0.004$ vs. not-injected and $p=0.005$ vs. GFP)). (E) Three weeks after injection of the AAV-Cre, expression of PHGDH (red) was markedly decreased compared to the AAV-GFP. (F) Quantification of the PHGDH fluorescence (Nested model $\mathrm{p}=0.011, \mathrm{n}=2$ mice, 10-12 confocal images/mouse). (G) Fluorescent immunoblotting of PHGDH performed using 4 different protein concentrations showed a linear relationship and $(\mathbf{H})$ a significant reduction of PHGDH expression (linear regression model, $\mathrm{P}<0.001$ ). (I) Total levels of D-serine, L-serine and glycine measured by HPLC were significantly reduced in the hippocampus (Mann-Whitney $U$ test, $p=0.012$; $p<0.001, p=0.027$, respectively) as well as $(\mathbf{J})$ extracellular levels of $D$-serine measured using biosensors (Mann-Whitney $U$ test, $\mathrm{p}<0.001$ ). (K) Electrophysiological recordings were performed in $\mathrm{CA} 1$ region expressing fluorescent astrocytes. (L) LTP was significantly impaired in Phgdh flox/flox mice injected with the AAV-Cre. Traces represent typical fEPSPs evoked before (1) and after (2) LTP induction. LTP was rescued by bath application of $50 \mu \mathrm{M}$ L-serine. (M) Bar graphs summarizing results presented in $\mathbf{L}$ (Kruskal-Wallis followed by Dunn test, $p=0.031$ ). (N) Chronic supplementation with L-serine restored both the total levels of D-serine, L-serine and glycine (Mann-Whitney $U$ test, $p=0.026 ; p=0.017, p<0.001$, respectively) as well as the extracellular levels of $D$-serine (Mann-Whitney $U$ test, $\mathrm{p}=0.016$ ). (O) Phgdhfloxflox mice injected with the AAV-Cre displayed a significant impairment of spatial memory during the probe test of the Morris water maze $72 \mathrm{~h}$ after learning the location of the platform (one tailed one sample t-test against chance level (25\%), $\mathrm{p}=0.14$ ), while Phgdh floxfllox mice injected with the AAV-GFP significantly spent more time in the TQ $(\mathrm{p}=0.02)$. Chronic supplementation with L-serine restored spatial memory in Phgdh floxflox mice injected with the $A A V-C r e(p=0.02)$. $A Q$, adjacent quadrant, $O Q$, opposite quadrant, $T Q$, target quadrant. 


\section{Figure 4. Expression of PHGDH in 3xTg-AD mice and in AD Human samples}

(A) Six-month old female 3xTg-AD mice that do not present A $\beta$ plaques (4G8 immunostaining) (B) did not display significant reduction of PHGDH expression as observed using immunofluorescent staining or immunoblotting in the hippocampus (C). Four different concentrations of proteins were loaded per sample and the expression of PHGDH was derived from the slopes of the regression lines (linear regression model, $p=0.79$ ). (D) Human post-mortem brain samples included the hippocampus, parahippocampal gyrus and fusiform gyrus and presented numerous $A \beta$ plaques (6F/3D immunostaining). (E) Expression of $\mathrm{PHGDH}$ was reduced in an advanced $A D$ brain (Braak $\mathrm{VI}$ ) that present amyloid plaques ( $A \beta$ staining using $6 \mathrm{~F} / 3 \mathrm{D}$ antibody), hyperphosphorylated Tau (AT8) and GFAP reactive astrocytes as observed on formalin-fixed paraffin-embedded sections. (F) Fluorescent immunoblots of fresh brain tissues from Controls $(n=5), A D$ Braak III-IV $(n=4)$ and AD Braak VI $(n=5)$. Four different concentrations of proteins were loaded per sample and the expression of PHGDH was derived from the slopes of the regression lines. Expression of PHGDH was significantly lower in intermediates AD cases (-62\%) and in advanced AD patients (-82\%) as compared to controls (linear regression model, $p<0.001$ ).

Figure 5. Deficits of synaptic plasticity at CA3-CA1 synapses and of spatial memory in 3xTg-AD mice are rescued by L-serine

(A) Bath L-serine $(50 \mu \mathrm{M})$ application in hippocampal acute slices rescued LTP in 3xTg-AD mice to the same level than in control mice (Mann-Whitney $U$ test, $p=0.97$; control: $n=8 ; 3 x \operatorname{Tg}-A D: n=5$ ). Traces represent typical fEPSPs evoked before (1) and after (2) LTP induction. Bar graph summarizing experiments presented in A. (B) 3xTg-AD and control 4 month-old mice received chronic oral L-serine supplementation (food enriched with $10 \% \mathrm{~L}$-serine for 2 months). The total concentration of L- and D-serine in the hippocampus was similar in both groups of mice after L-serine treatment. (C) Chronic L-serine diet restored NMDAR co-agonist binding site occupancy measured in 3xTg-AD mice to the same value measured in control mice (Mann-Whitney $U$ test, $p=0.63$; control: $n=5 ; 3 x \operatorname{Tg}-A D: n=13$ ). Traces of representative NMDAR-fEPSPs recorded before (1) and during (2) D-serine application (50 $\mu \mathrm{M})$. Bar graph summarizing results presented in C. (D) Chronic oral L-serine supplementation fully restored the LTP 
deficits of 3xTg-AD mice (Mann-Whitney $U$ test, $p=0.8$; control: $n=7 ; 3 x \operatorname{Tg}-A D: n=7$ ). Representative traces of characteristic fEPSPs evoked before (1) and after (2) LTP induction. Bar graph summarizing results presented in d. (E) 3xTg-AD mice fed with a food enriched in 10\% L-serine for 2 months spent more time in the target quadrant (one tailed one sample t-test against chance level $(25 \%), p=0.007$ ), similarly to control mice fed with the same diet $(p=0.0011)$, during the probe test of the Morris water maze. $A Q$, adjacent quadrant, $\mathrm{OQ}$, opposite quadrant, $\mathrm{TQ}$, target quadrant. 


\section{STAR Methods}

\section{Lead Contact and Materials Availability}

Further information and requests for resources and reagents should be directed to and will be made available upon reasonable request by the Lead Contact, Gilles Bonvento (gilles.bonvento@cea.fr). This study did not generate new unique reagents.

\section{Experimental Model and Subject Details}

\section{Mouse models}

All experimental procedures using animals were performed in strict accordance with French regulations (Code Rural R214/87 to R214/130). They conform to the ethical guidelines of both the European Directive $(2010 / 63 / E U)$ and the French National Charter on the ethics of animal experimentation. They were approved by a local ethics committee and submitted to the French Ministry of Education and Research (Approvals 12-084, 14-015, APAFIS\#617 and APAFIS\#617-2015050516068503 v2). The animal facility is accredited by the French authorities (B9-032-02). All mice were group-housed and maintained in individually ventilated cages with standard enrichment and conventional health status. Mice were housed in a temperature $\left(22 \pm 1^{\circ} \mathrm{C}\right)$ and humidity-controlled room (50\%) on a $12 \mathrm{~h}$ light/dark cycle (lights on 7:00) with ad libitum access to water and food (Altromin 1310). We used homozygous female 3xTg-AD mice (age range 6-12 months) generated and maintained on a mixed J29/C57BL6 background (RRID:MMRRC_034830-JAX). 3xTg-AD mice express the mutated gene PS1M146V (knock-in) and the mutated human genes APPSwe and tauP301L in the same locus, both under the control of the mouse Thy1.2 regulatory element (Oddo et al., 2003). We also used age-matched NonTg control mice on the same background strain (B6129SF1/J; RRID:IMSR_JAX:101043). Mice with homozygous conditional Phgdh alleles (Phgdh $h^{\text {floxflox}}$ ) have been previously described (Yang et al., 2010). These mice were produced by introducing two loxP sites flanking exons 4 and 5 and were backcrossed with the C57BL/6J strain for more than 10 generations. We used Phgdh $h^{\text {floxflox }}$ male mice (age range 3-6 months).

\section{Human samples}

Frozen brain tissue (hippocampus, parahippocampal gyrus and fusiform gyrus) from Controls $(n=5), A D$ Braak III-IV $(n=4)$, and AD Braak VI $(n=5)$ were provided by the GIE NeuroCeb biobank in Paris. Paraffin sections of the same brain area from Controls $(n=6$; age average 66.3yr, female and 73.5yr, male), AD 
Braak III-IV ( $\mathrm{n}=7$; age average 79.4yr, female and 75.5yr, male) and AD Braak VI $(n=8$; age average 81.3yr, female and 73.8yr, male) were provided by the Laboratory of Neuropathology at the Hôpital PitiéSalpêtrière. We did not analyze the influence of sex on our results because of the low number of samples. Previous immunostaining of Tau (AT8, Innogenetics, 1/500) and A $(6 F / 3 D$, Dako, 1/200) had been performed on all cases. Detailed information on pathology and demographic data are summarized in Table 1. The NeuroCEB brain bank meets the criteria of the French law on biological resources, including consent and data protection (Article L1243-4 of the Public Health Code, August 2007). It has received approval from the Ministry of Higher Education, Research and Innovation to retain human samples and provide them to research teams (CODECOH approval number: AC-2018-3290).

\section{Method details}

\section{In Vivo [14C]-2-Deoxyglucose Uptake}

We measured [14C]-2-Deoxyglucose (2-DG) uptake in four experimental groups: 6-month-old female 3xTgAD mice $(n=10), 6$-month-old female control mice $(n=9)$, 12-month-old female $3 x \operatorname{Tg}-\operatorname{AD}$ mice $(n=10)$, and 12-month-old female control mice $(n=10)$. Experiments were performed in conscious, lightly restrained animals that were previously habituated to the constraint. Animals fasted for $12 \mathrm{~h}$ before the experiment but had free access to water. On the day of the experiment, the mice were anesthetized with isoflurane (2\% in $\mathrm{O}_{2}$ ) and two catheters were inserted into the femoral artery and vein, respectively. Body temperature was maintained at $37^{\circ} \mathrm{C}$. The mice were allowed to recover from anesthesia for $1 \mathrm{~h}$ and intravenously injected with $\left[{ }^{14} \mathrm{C}\right]-2 \mathrm{DG}(16.5 \mu \mathrm{Ci} / 100 \mathrm{~g}$ body weight; Perkin Elmer, Boston, MA, USA). Glycemia was measured using a DIGL-100 QuantiChrom ${ }^{\mathrm{TM}}$ Glucose Assay Kit. The mice were euthanized by injection of a lethal dose of sodium pentobarbital $45 \mathrm{~min}$ after injection. The brains were rapidly removed and immediately frozen at $-40^{\circ} \mathrm{C}$ in isopentane. They were cut into $20 \mu \mathrm{m}$-thick coronal sections with a CM3050S cryostat (Leica, Rueil-Malmaison, France). Every other section was mounted on a coverslip, rapidly heat-dried, and placed against autoradiographic film (Kodak Biomax MR) for 10 days together with radioactive [14C] standards (146C, American Radiochemical Company, St Louis, MO, USA). The sections not used for the autoradiography study were mounted on Superfrost glass slides that were then processed for Nissl staining, to obtain additional information about brain anatomy.

\section{Postmortem Image Registration, Three-Dimensional Reconstruction and Analysis}


Autoradiographic and Nissl-stained sections were digitized using a high-resolution flatbed scanner (ImageScanner III; GE Healthcare Europe, Orsay, France) at 600 dpi (pixel size $42 \times 42 \mu \mathrm{m}^{2}$ ) and 1,200 dpi (pixel size $21 \times 21 \mu \mathrm{m}^{2}$ ) in-plane resolution, respectively. Image processing was performed using our in-house software platform BrainVISA (http://brainvisa.info/). Each anatomic volume was first reconstructed in $3 \mathrm{D}$, and each autoradiographic volume was reconstructed in 3D using the corresponding anatomic volume as a geometrical reference for co-registration (Dubois et al., 2008). The non-rigid registration approach is based on FFD (Free Form Deformation, polynomial model) and has been previously found to be very robust (Lebenberg et al., 2010; Rueckert et al., 1999). Autoradiographic images were converted from gray scale to activity ( $\mathrm{nCi} / \mathrm{g})$ using the [14C] standards and normalized at $200 \mathrm{nCi} / \mathrm{g}$. A brain template was created using all the anatomic brain volumes at a final resolution of $0.1 \times 0.1 \times 0.1 \mathrm{~mm}^{3}$. Regional differences in cerebral glucose uptake between $3 \times T g-A D$ and control mice were then assessed using a voxel-wise two-tailed unpaired t-test implemented in BrainVISA (Vandenberghe et al., 2016).

\section{Generation of AAVs and stereotaxic injection in mice}

The plasmid encoding the sensor Laconic (San Martin et al., 2013) was obtained from Addgene (www.addgene.org). The plasmid encoding Cre-IRES-GFP was kindly provided by Martine Cohen-Salmon. We generated adeno-associated viral vectors (AAV2/9) expressing Laconic, td-Tomato, GFP or Cre-IRESGFP under the control of the short $\mathrm{gfaABC}_{1} \mathrm{D}$ promoter. The design, production, and titration of $A A V 2 / 9$ vectors have been described previously (Berger et al., 2015). Mice were anesthetized with a mixture of ketamine $(150 \mathrm{mg} / \mathrm{kg})$ and xylazine $(10 \mathrm{mg} / \mathrm{kg})$. Lidocaine $(5 \mathrm{mg} / \mathrm{kg})$ was injected subcutaneously under the scalp 5 min before the beginning of surgery. The mice received bilateral stereotaxic injections of AAVs administered by a $10-\mu \mathrm{l}$ Hamilton syringe via a 34-gauge blunt needle. The stereotaxic coordinates used were as follows: AP - $2 \mathrm{~mm} ; \mathrm{L}+/-2 \mathrm{~mm} ; \mathrm{V}-1.2 \mathrm{~mm}$ with the tooth bar set at 0 . Mice received a dose of $10^{10}$ viral genomes $(\mathrm{VG})$ in a total volume of $2 \mu \mathrm{l}$ per injection site at a rate of $0.2 \mu \mathrm{l} / \mathrm{min}$. At the end of the injection, the needle was left in place for 5 min before being slowly removed. The skin was sutured, and the mice were allowed to recover for three to six weeks.

\section{FRET imaging of brain slices}

Injections of $A A V s$ in mice

Five-month old female 3xTg-AD and control mice were injected in the dorsal hippocampus with an AAV2/9 expressing Laconic under the control of the short gfaABC ${ }_{1} D$ promoter and used four to six weeks later. 


\section{Slice Preparation}

The mice were deeply anesthetized with Ketamine/Xylazine. Heparin (1000 U) was directly injected into the left heart ventricle to prevent blood coagulation, and the mice were perfused transcardially with oxygenated ice-cold sucrose artificial cerebrospinal fluid (ACSF) containing: $126 \mathrm{mM} \mathrm{NaCl}, 2.5 \mathrm{mM} \mathrm{KCl}, 1.25 \mathrm{mM}$ $\mathrm{NaH}_{2} \mathrm{PO}_{4}, 2 \mathrm{mM} \mathrm{CaCl}_{2}, 1 \mathrm{mM} \mathrm{MgCl}$, $26 \mathrm{mM} \mathrm{NaHCO}_{3}, 2.5 \mathrm{mM}$ glucose, $25 \mathrm{mM}$ sucrose, and $3 \mathrm{mM}$ kynurenic acid (Sigma) as previously described (Hay et al., 2015). The brains were quickly removed and sagittal slices (300 $\mu \mathrm{m}$ thick) containing the hippocampus were cut with a vibratome (VT1000S; Leica). Slices were allowed to recover $10 \mathrm{~min}$ at $37^{\circ} \mathrm{C}$ in oxygenated sucrose ACSF and then placed at room temperature for $1 \mathrm{~h}$ in ACSF saturated with $\mathrm{O}_{2} / \mathrm{CO}_{2}(95 \% / 5 \%)$, containing $2.5 \mathrm{mM}$ glucose and $22.5 \mathrm{mM}$ sucrose. The slices were transferred to a submerged recording chamber and perfused with oxygenated ACSF lacking kynurenic acid.

\section{Fluorescence imaging}

Two-photon images were obtained with a custom-built 2-photon laser scanning microscope based on an Olympus BX51WI upright microscope (Olympus) with a 40X (0.8 NA) water-immersion objective and a titanium:sapphire laser (MaiTai HP; SpectraPhysics) tuned at $850 \mathrm{~nm}$ for mTFP excitation. Galvanometric scanners (model 6210; Cambridge Technology) were used for scanning, and a piezo-driven objective scanner (P-721 PIFOC; Physik Instrumente GmbH) was used for z-stack image acquisition. A two-photon emission filter was used to reject residual excitation light (E700 SP; Chroma Technology). A fluorescence cube containing 479/40 and 542/50 emission filters and a 506-nm dichroic beam splitter (FF01-479/40, FF01-542/50 and FF506-Di02-25x36 Brightline Filters; Semrock) was used for the separation of the mTFP and Venus signals. Two imaging channels (H9305 photomultipliers; Hamamatsu) were used for simultaneous detection of the two types of fluorescence emission. An image stack of 10 to 20 images with a 1- $\mu \mathrm{m}$ interval was acquired every $30 \mathrm{~s}$. Occasional $\mathrm{x}, \mathrm{y}$, and $\mathrm{z}$ drifts were corrected using custom macros developed from ImageJ plugins TurboReg,StackReg, MultiStackReg and Image CorrelationJ. mTFP and Venus fluorescence intensities were measured at the soma of astrocytes. Fluorescence ratios $(R)$ were calculated by dividing the mean mTFP intensity of a given ROI by the mean Venus intensity of the same $\mathrm{ROI}$. The ratios were normalized to the baseline ratio (R0) calculated in the same ROI during the 10 -min prior to the application of AR-C155858 $(1 \mu \mathrm{M})$. Cells exhibiting a baseline with a slope smaller than $0.5 \%$ min-1 were considered to be stable and further analyzed. Effect of monocarboxylate transporter 
blockade was quantified by averaging the normalized ratio (R/R0) during the last five minutes of drug application.

\section{Electron microscopy}

Six-month-old female mice ( 3 control and $3 \times T g-A D$ ) were euthanized with an overdose of pentobarbital and immediately perfused, via the heart, with a buffered mix of $2.5 \%$ glutaraldehyde and $2.0 \%$ paraformaldehyde in $0.1 \mathrm{M}$ phosphate buffer $(\mathrm{pH} 7.4)$. Brains were then removed and stored overnight in PBS at $4^{\circ} \mathrm{C}$. Coronal vibratome sections were cut at 80 microns thickness, post-fixed in potassium ferrocyanide (1.5\%) and osmium (2\%), then stained with thiocarbohydrazide (1\%) followed by osmium tetroxide $(2 \%)$. They were then stained overnight in uranyl acetate $(1 \%)$, washed in distilled water at $50^{\circ} \mathrm{C}$, before being stained with lead aspartate at the same temperature. They were finally dehydrated in increasing concentrations of alcohol and then embedded in Spurs resin and hardened at 65 degrees for 24 $\mathrm{h}$ between glass slides. The regions containing the hippocampal region CA1 were trimmed from the rest of the section using a razor blade and glued to an aluminium stub and mounted inside scanning electron microscope (Zeiss Merlin, Zeiss NTS). Serial sections were cut from the face using an ultramicrotome mounted in the microscope (Gatan, 3View) and the block face imaged after every cut using a beam voltage of $1.7 \mathrm{kV}$ and pixel size of $6 \mathrm{~nm}$ with a dwell time of 1 microsecond. Series of $200-300$ sections were collected, aligned in the FIJI imaging software (www.fiji.sc) and synapses counted in the TrakEM2 plugin. Synapses were counted through discrete volumes through the series of images and classified according to their morphology. Asymmetric synapses were presumed excitatory (glutamatergic) and symmetric, inhibitory (GABAergic). A total of 1067 synapses were counted in the 3xTg-AD mice and 1094 in the controls.

\section{Immunohistochemistry of human brain samples}

Immunohistochemistry was performed on a VENTANA Discovery XT automated staining instrument according to the manufacturer's instructions. All solutions were from Roche Diagnostics (Meylan, France). Briefly, slides were de-paraffinized using EZprep solution for $30 \mathrm{~min}$ at $75^{\circ} \mathrm{C}$, followed by epitope retrieval with RiboCC solution for 20 min at $95^{\circ} \mathrm{C}$. Primary rabbit polyclonal PHGDH antibody (Frontier Institute, Hokkaido, Japan) was diluted with the provided Discovery Ab Diluent at 1:300 and applied manually. Slides were developed using the DABMap detection kit, counterstained with hematoxylin II for 8 min, washed, 
dehydrated, and coverslipped. Labelled slides were scanned using a NanoZoomer Digital slide scanner (Hamamatsu Photonics, Massy, France) at the Imaging platform of the Institut de la Vision in Paris.

\section{Immunofluorescence staining of mouse brain}

Mice were euthanized by an overdose of pentobarbital and perfused transcardially with $100 \mathrm{ml}$ of cold $4 \%$ paraformaldehyde (PFA) solution in phosphate buffer $(\mathrm{PB}, 0.1 \mathrm{M}, \mathrm{pH}$ 7.4). The brains were cryoprotected in a 30\% sucrose solution in PB for $24 \mathrm{~h}$. Sagittal and coronal brain sections $(35 \mu \mathrm{m})$ were cut on a freezing microtome, serially collected, and stored at $-20^{\circ} \mathrm{C}$ until analysis. The slices were permeabilized with $0.2 \%$ Triton X-100 (Sigma) and blocked with 4.5\% normal goat serum (Sigma) for 30 min and were incubated overnight at room temperature (RT) with the following primary antibodies: Glial fibrillary acidic protein (GFAP) (1:1000, rabbit; Dako), PHGDH (1:500, guinea pig or rabbit; Frontier Institute), NeuN (1:500, mouse; Chemicon), IBA1 (1:1000, rabbit; Dako) or Olig2-Alexa 488 (1:500, rabbit; Millipore). After rinsing, the brain slices were incubated for $3 \mathrm{~h}$ at RT with fluorescent secondary 488 and 594 Alexa Fluorconjugated antibodies (Invitrogen) and mounted with FluorSave reagent (Calbiochem). Images were acquired by confocal microscopy (Leica SP8) and analyzed using Fiji (http://fiiji.sc/Fiii).

\section{Immunohistochemistry of mouse brain}

Brain slices were pretreated in $0.3 \% \mathrm{H}_{2} \mathrm{O}_{2}$, blocked in 4.5\% NGS (Sigma), and incubated with the following primary antibodies: 4G8 (1:1000, mouse; Signet Covance), AT8 (1:400, mouse; ThermoScientific), OC (1:500, rabbit, Millipore), AT180 (1:1000, mouse, ThermoScientific), and HT7 (1:500, mouse, Innogenetics) for $48 \mathrm{~h}$ at $4{ }^{\circ} \mathrm{C}$. After rinsing, the brain slices were incubated with biotinylated secondary antibodies (Vector Laboratories) for $1 \mathrm{~h}$ at RT. Finally, they were incubated with the Vectastain Elite ABC Kit (Vector Laboratories) and revealed with the DAB kit (Vector Laboratories). Antigen retrieval with formic acid (70\% for $2 \mathrm{~min}$ ) was performed for the $4 \mathrm{G} 8$ antibody.

\section{Sholl analysis}

Analysis of the astrocyte ramification was performed from stacked confocal images (13 steps; z-step $1 \mu \mathrm{m}$, maximum intensity stack) acquired with the $40 \mathrm{X}$ objective, zoom 2 (pixel size of $0.284 \times 0.284 \mu \mathrm{m}^{2}$ ). The image stacks of GFAP staining were reconstructed as binarized representations and the Sholl method of concentric circles (Sholl, 1953) was used to determine astrocyte ramification. Each cell was manually outlined to exclude adjacent cells by tracing a region of interest $(\mathrm{ROI})$ and analyzed by selecting the center 
of its soma and then running the Sholl analysis procedure, which counts the number of intersections at circles of increasing radii ( $1-\mu \mathrm{m}$ increased radius of each $\mathrm{ring})$ from the center. The maximal ring with an intersecting process (max distance), the sum of the number of intersections (branching complexity) for all circles, and the ramification index were calculated for each cell.

\section{Immunoblotting of Human brain samples}

Samples were homogenized using a sonicator in $50 \mathrm{mM}$ Tris- $\mathrm{HCl}, \mathrm{pH} 7.4,100 \mathrm{mM} \mathrm{NaCl}$, and 1\% SDS with protease (Roche) and phosphatase (Sigma) inhibitor cocktails. The protein concentration was determined by the $\mathrm{BCA}$ method. Four serial dilutions were prepared for each protein sample in $50 \mathrm{mM}$ Tris $-\mathrm{HCl}, \mathrm{pH}$ 7.4, $100 \mathrm{mM} \mathrm{NaCl}$. Samples were further diluted in NuPAGE LDS sample buffer with NuPAGE Sample Reducing agent (Invitrogen), boiled for $10 \mathrm{~min}$ at $90^{\circ} \mathrm{C}$, loaded on a $4-20 \%$ Criterion TGX Stain-free gel (Bio-Rad Laboratories), separated, and transferred to a nitrocellulose membrane using a Trans-Blot $\AA$ Turbo $^{\mathrm{TM}}$ transfer device (Bio-Rad Laboratories). The membranes were blocked in Tris-buffered saline with $0.1 \%$ Tween 20 and $5 \%$ milk for $1 \mathrm{~h}$ at RT and then incubated overnight at $4{ }^{\circ} \mathrm{C}$ with PHGDH antibody (1:10000, Frontier Institute) diluted in Tris-buffered saline with $0.1 \%$ Tween 20 and 5\% milk. After rinsing, the membrane was incubated with a fluorescent secondary antibody (1:5000, IRDye® 680RD Goat antiRabbit IgG, LI-COR Biosciences) diluted in Tris-buffered saline with $0.1 \%$ Tween 20 and $5 \%$ milk for $1 \mathrm{~h}$. Antibody binding was detected using an Odyssey ${ }^{\circledR}$ CLX imaging system (LI-COR Biosciences). Band intensity was measured using Image Studio 5.2 software. To avoid using housekeeping proteins, a significant source of confusion in quantitative immunoblotting, and to confirm that our experimental conditions lead to a linear response according to the amount of proteins that was loaded, we designed a protocol using four serial dilutions as previously described (Janes, 2015; McDonough et al., 2015). The slope was determined for each sample from four dilutions by linear regression.

\section{Immunoblotting of mouse brain samples}

Phgdh $h^{\text {floxflox }}$ mice injected with AAVs expressing either GFP or Cre-IRES-GFP were euthanized with an overdose of sodium pentobarbital. The brains were rapidly collected and sliced into $1-\mathrm{mm}$ thick coronal sections with a brain matrix and the hippocampus was dissected out. The samples were then homogenized using a sonicator in $50 \mathrm{mM}$ Tris- $\mathrm{HCl}, \mathrm{pH} 7.4,100 \mathrm{mM} \mathrm{NaCl}$, and 1\% SDS, with protease (Roche) and phosphatase (Sigma) inhibitor cocktails. Samples were processed as for the human samples.

\section{RNA extraction and RT-qPCR}


Mice were euthanized under pentobarbital anesthesia. The brains were rapidly collected and the hippocampi dissected out on ice. Total RNA was isolated with TRIzol (Invitrogen). Reverse transcription (RT) was performed with $350 \mathrm{ng}$ total RNA using Superscript II VILO reverse transcriptase (Invitrogen). Complementary DNA (7 ng) was processed for RT-qPCR on a Mastercycler® ep realplex machine (Eppendorf). PCR products were quantified by measuring the incorporation of SYBR green fluorescent dye (Master Mix, Invitrogen). The primers used were as follows: phgdh 5'AAGTTCATGGGGACAGAGCTGAAC-3' (forward) and 5'-CCTTCACCATGTCCACAAACTGGA-3' (reverse); gfap 5'-ACGACTATCGCCGCCAACT-3' (forward) and 5'-GCCGCTCTAGGGACTCGTTC-3' (reverse); vimentin 5'-TCGAGGTGGAGCGGGACAAC-3' (forward) and 5'TGCAGGGTGCTTTCGGCTTC-3' (reverse); rbfox3 (Neun) 5'-CAACTCCACCCTTCCGACCC-3' (forward) and 5'-TCCCGAATTGCCCGAACAT-3' (reverse); s/c1a1 (eaat3) 5'-ATGTGCTACATGCCGATTGG-3' (forward) and 5'-CTCAGGACAGTGGCCATGTAAA-3' (reverse), cd68 5'-GCCAGCCCTACGACCAG-3' (forward) and 5'-TGGTGGTGGCAGGGTTATGA-3' (reverse); iba1 5'-CCAGCCTAAGACAACCAGCGTC3' (forward) and 5'-GCTGTATTTGGGATCATCGAGGAA-3' (reverse); ppia (cyclophiline A) 5'ATGGCAAATGCTGGACCAAA-3' (forward) and 5'-GCCTTCTTTCACCTTCCCAAA-3' (reverse); daao 5'GGTGGCAAGAGGAGTGGAT-3' (forward) and 5'- GATGATGTACGGAGAGTTGTAGATA-3' (reverse). Relative expression was assessed using the $\Delta \Delta \mathrm{Ct}$ calculation.

\section{Microdialysis}

Age matched control and 3xTg-AD mice received a unilateral cannula implantation surgery. Briefly, mice were anesthetized using ketamine $(100 \mathrm{mg} / \mathrm{kg})$ and xylazine $(10 \mathrm{mg} / \mathrm{kg})$. Buprenorphine $(0.05 \mathrm{mg} / \mathrm{kg}$, subcutaneous) was given pre-operative as well as lidocaine $(0.5 \%$ in water, $50 \mu \mathrm{l}$ subcutaneous at the level of the scalp). Mice were fixed in a stereotaxic frame, the skull was exposed, cleaned, and a bonding agent (OptiBond® FL) was applied. A guide cannula (CMA P000138) was inserted above the CA1 region of the hippocampus (coordinates: AP, $-2 \mathrm{~mm}$; L, $2 \mathrm{~mm}$ from bregma; V, $0.5 \mathrm{~mm}$ from dura) and sealed in place with a photopolymerizable dental cement (Tetric EvoFlow®). Mice recovered 4-7 days before sampling. Mice were habituated to the polycarbonate enclosure (STANK/WF, Instech) for 3 days. On the day of sampling (usually at $1 \mathrm{pm}$ ), a microdialysis probe (CMA 7, 1mm cuprophane (6KD), CMA P000082) was inserted through the guide cannula. Probes were perfused with aCSF $(147 \mathrm{mM} \mathrm{NaCl}, 2.7 \mathrm{mM} \mathrm{KCl}, 1.2 \mathrm{mM}$ $\mathrm{CaCl}_{2}$, and $0.85 \mathrm{mM} \mathrm{MgCl}_{2}$ ) at a rate of $1 \mu \mathrm{l} / \mathrm{min}$ for $24 \mathrm{~h}$. Dialysis samples were collected every hour using 
a refrigerated fraction collector (MAB85, MBT) and frozen at $-80 \mathrm{C}$ before analysis. Cannula implantation was verified at the end of the experiments using Nissl staining.

\section{Determination of $L$ - and $D$-serine}

We used two different analytical methods to determine the extracellular concentrations of L- and D-serine following microdialysis. Only data obtained using LC-MS/MS are presented in the manuscript.

\section{Capillary Electrophoresis coupled to Laser-Induced Fluorescence (CE-LIF)}

Ten $\mu \mathrm{L}$ of sample were mixed with $37.5 \mu \mathrm{L}$ of $10 \mathrm{mM}$ sodium borate buffer $\mathrm{pH} 10$ containing $5 \mu \mathrm{M}$ cysteic acid, as internal standard, and $6 \mu \mathrm{L}$ of the derivatization solution containing 4-Fluoro-7-nitro-2,1,3benzoxadiazole (NBD-F) at $2.5 \mathrm{mg} / \mathrm{mL}$ and $250 \mu \mathrm{M}$ hydrochloric acid in methanol / water (50/50 v/v). The mixture was heated at $65^{\circ} \mathrm{C}$ for $30 \mathrm{~min}$ and the samples kept at $7 \pm 2^{\circ} \mathrm{C}$ in the $\mathrm{CE}$ autosampler until analysis. Quantitative analysis of L-serine was performed using Capillary Electrophoresis coupled to Laser-induced Fluorescence detection as previously described (Lorenzo et al., 2013). Capillary electrophoresis experiments were carried out using a PA800 plus instrument (Sciex, formerly Beckman Coulter, Redwood City, CA, USA). The instrument was coupled with LIF detection equipped with a $3.5 \mathrm{~mW}$ argon-ion laser. Excitation and emission wavelengths were 488 and $520 \mathrm{~nm}$, respectively. Data acquisition and instrument control were carried out using 32 KaratTM system software version 7.0 (Sciex). Electrophoretic conditions were: $175 \mathrm{mM}$ borate buffer $\mathrm{pH} 10.25$ and $12.5 \mathrm{mM} \beta$-cyclodextrin for the electrolyte. Separation was performed in a $50 \mathrm{~cm} \times 75 \mu \mathrm{m}$ Id silica capillary at $21 \mathrm{kV}$ and at $25^{\circ} \mathrm{C}$.

\section{LC-MS/MS}

We used high performance liquid chromatography tandem mass spectrometry (LC/MS/MS) for the simultaneous determination of extracellular D-serine, L-serine and L-glutamate (Sugimoto et al., 2015). The LC-MS/MS system consisted of an UPLC Acquity I-CLASS and a Xevo-TQ-XS triple quadruple mass spectrometer (Waters SAS, Saint-Quentin-en-Yvelines, France) with an ESI interface. The CROWNPAK CR-I(+) column (5 $\mathrm{m}, 3 \mathrm{mmID}, 150 \mathrm{~mm}$ ) Daicel Corporation, Tokyo, Japan) was used for the chiral chromatographic separation in a container cooled between 0 and $+1^{\circ} \mathrm{C}$ during the analysis. The mobile phase consisted of $0.3 \%$ trifluoroacetic acid in $10 \%$ acetonitrile. The flow rate of the mobile phase was 0.15 $\mathrm{mL} / \mathrm{min}$ with an isocratic mode. The samples were diluted (1/2) in the mobile phase and $10 \mu \mathrm{L}$ was injected in the LC-MS/MS system. In these conditions, retention times were 4.60, 4.82 and 11.0 min for D-serine, L- 
serine and L-glutamate, respectively. Precursor-product ion pair transitions were chosen for a multiple reaction monitoring in positive ionization mode.

HPLC

Total amino acid concentrations were measured by preparing hippocampal homogenates from mice anesthetized with a lethal dose of sodium pentobarbital. Tissues were weighed, homogenized, and centrifuged. Proteins in the supernatant were removed by adding $5 \%$ perchloric acid. Samples were derivatized with a fluorescent labeling reagent, 4-fluoro-7-nitro-2,1,3-benzoxadiazole. Amino acids were separated using HPLC and fluorescence of the derivatized amino acids was detected at $530 \mathrm{~nm}$ with excitation at $470 \mathrm{~nm}$ as previously described (Esaki et al., 2011).

\section{Microelectrode biosensor recordings}

We measured extracellular D-serine concentrations in vivo in anesthetized Phgdh ${ }^{\text {floxfllox }}$ mice using microelectrode biosensors. They were prepared at the AniRA-Neurochem Technological platform (Lyon, France) as previously described (Pernot et al., 2008; Vasylieva et al., 2011). Biosensors were calibrated with D-serine in PBS $(0.01 \mathrm{M}, \mathrm{pH} 7.4)$ before and after in vivo recordings, and their selectivity was verified by the absence of detection of serotonin $(20-40 \mu \mathrm{M})$. Mice were anesthetized using ketamine $(100 \mathrm{mg} / \mathrm{kg})$ and xylazine $(10 \mathrm{mg} / \mathrm{kg})$, an $\mathrm{Ag} / \mathrm{AgCl}$ reference electrode was placed under the skin of the neck, and the biosensor implanted in the hippocampus (AP $-2 \mathrm{~mm} ; \mathrm{L}+/-2 \mathrm{~mm}$; V -1.2 mm from Bregma). A control biosensor coated with bovine serum albumin was inserted $\sim 100 \mu \mathrm{m}$ away from the D-serine biosensor to record background current. Amperometric recordings were performed for $1 \mathrm{~h}$ and the current recorded by the control biosensor was subtracted from that recorded by the D-serine biosensor in order to estimate the specific D-serine current, and hence its extracellular concentration.

\section{Electrophysiology}

Slice Preparation

Experiments were carried out on adult mice (six to seven months old) in accordance with the French National Code of Ethics on Animal Experimentation and approved by the Committee of Ethics of Bordeaux (authorization no. A50120109). Briefly, mice were anesthetized with isoflurane and euthanized. The brain was quickly removed from the skull and placed in cold ACSF saturated with $95 \% \mathrm{O}_{2}$ and $5 \% \mathrm{CO}_{2}$. ACSF 
was used for dissection, slicing, and recording. The ACSF composition was: $125 \mathrm{mM} \mathrm{NaCl}, 2.5 \mathrm{mM} \mathrm{KCl}$, $1.25 \mathrm{mM} \mathrm{NaH}_{2} \mathrm{PO}_{4}, 1.3 \mathrm{mM} \mathrm{MgCl}_{2}, 2 \mathrm{mM} \mathrm{CaCl}_{2}, 26 \mathrm{mM} \mathrm{NaHCO}_{3}$, and $10 \mathrm{mM}$ glucose $(\mathrm{pH}$ 7.3, 300-305 $\mathrm{mOsm} / \mathrm{kg}$ ). A block of tissue containing the hippocampus was prepared and hippocampal sagittal slices $(350 \mu \mathrm{m})$ were cut using a vibratome (Leica, VT1200S, Germany). The slices were incubated $30 \mathrm{~min}$ at $32^{\circ} \mathrm{C}$ and then allowed to recover for at least one hour at room temperature.

\section{Field Recordings}

For electrophysiological recordings, the slices were transferred into a recording chamber continuously perfused with ACSF ( $3 \mathrm{ml} / \mathrm{min})$. A cut between CA3 and CA1 was made to avoid epileptiform activity, due to the presence of picrotoxin $(100 \mu \mathrm{M})$ added to the ACSF just before recording. CA3-CA1 areas were identified with differential interference contrast microscopy (Olympus BX50). Field excitatory postsynaptic potentials (fEPSPs) were recorded with a Multiclamp 700B amplifier (Axon Instruments, Inc.) using pipettes (3.5-5 M $)$ filled with ACSF and placed in the stratum radiatum of the CA1 area, close to the subiculum. NMDA fEPSPs were isolated with low $\mathrm{Mg}^{2+}$ ACSF $(0.2 \mathrm{mM})$ in the presence of picrotoxin $(100 \mu \mathrm{M})$ and 2,3dihydroxy-6-nitro-7-sulfamoyl-benzo[f]quinoxaline-2,3-dione (NBQX) $(10 \mu \mathrm{M})$ to block $\mathrm{GABA}_{A}$ and AMPA/kainate receptors, respectively. Synaptic potentials were evoked at $0.05 \mathrm{~Hz}$ by orthodromic stimulation $(100 \mu \mathrm{s})$ of Schaffer collaterals using either a glass pipette filled with ACSF or a bipolar tungsten stimulating electrode placed in the stratum radiatum $>200 \mu \mathrm{m}$ away from the recording electrodes. LTP was induced by applying a high-frequency stimulation (HFS) protocol $(100 \mathrm{~Hz}$ train of stimuli for $1 \mathrm{~s}$, repeated four times at 20-s intervals) performed in current clamp mode. LTD was induced was induced by applying a low frequency stimulation protocol (LFS) consisting in a 1- $\mathrm{Hz}$ train of stimuli applied for 30 min. The change in the slope of the fEPSP was evaluated 50-60 min post-HFS or post-LFS, and normalized to the slope measured during the $10 \mathrm{~min}$ immediately before HFS or LFS. L-serine $(50 \mu \mathrm{M})$ and D-serine (50 $\mu \mathrm{M}$ ) were bath applied 20 min before the recording and then during the whole experiment of long-term synaptic plasticity. Average fEPSP traces presented in figures were obtained from 10 min of recordings. Signals were filtered at $2 \mathrm{kHz}$ and digitized at $10 \mathrm{kHz}$ via a DigiData 1322 interface (Axon Instruments, Inc.). Data were collected and analyzed offline using pClamp 9 software (Axon Instruments Inc.).

\section{Behavioral analyses}

Elevated plus-maze 
The apparatus consisted of four arms elevated $40 \mathrm{~cm}$ above floor level. Two of the arms contained $15 \mathrm{~cm}$ high walls (enclosed arms) and the other two none (open arms). Each mouse was placed in the middle section facing an open arm and left to explore the maze for a single 5-min session. The time spent in open and closed arms and the duration of head-dipping into open arms were analyzed using a video-camera and a video-tracking system (Ethovision, Noldus Information Technology Inc.).

\section{Spontaneous motor behavior}

We used the PhenoTyper ${ }^{\circledR}$ chamber (Noldus Information Technology Inc.) to monitor the spontaneous motor behavior of mice for $47 \mathrm{~h}$. A video-tracking system was used to collect behavioral data during this period.

\section{Morris Water Maze}

Experiments were performed in a circular tank filled with water and equipped with a 10-cm diameter platform submerged $0.5 \mathrm{~cm}$ beneath the surface of the water. Visual clues were positioned around the pool, to provide the mouse with spatial landmarks, and luminosity was maintained at 400 lux. The mice were initially exposed to a learning phase, which consisted of daily sessions (three trials per session) on five consecutive days. The starting position varied between the four cardinal points for each trial. A mean interval of 30 min was left between trials. The trial was stopped when the animal reached the platform. A 60 -s cutoff was used, after which the mice were gently guided to the platform. Once on the platform, the animals were allowed to rest for $30 \mathrm{~s}$ before being returned to their cage. Long-term spatial memory was assessed $72 \mathrm{~h}$ after the last training trial (fifth day) in a probe trial in which the platform was removed. The position of the animals was monitored by a video-tracking system (Ethovision, Noldus Information Technology Inc.) for 60

\section{S.}

\section{Supplementation of L- or D-serine}

Phgdh $h^{\text {floxfllox }}$, 3xTg-AD and control mice were placed on a rodent diet (Altromin 1324) enriched with 10\% Lserine (w/w) for two months (Garofalo et al., 2011) including the period of the Morris water maze test. Two other groups of 3xTg-AD and control mice were given D-serine $(600 \mathrm{mg} / \mathrm{L}$, Sigma-Aldrich, St. Louis, MO, USA) in the drinking water for two weeks, including the period of the Morris water maze test. This protocol resulted in a daily dose of approximately $100 \mathrm{mg} / \mathrm{kg}$ D-serine per body weight (average weight: $30 \mathrm{~g}$, average drinking volume: $5 \mathrm{~mL} /$ day) 


\section{Quantification and Statistical Analyses}

No statistical methods were used to determine sample sizes but our sample sizes (4 to 10$)$ are similar to those generally employed in the field. Randomization was not employed. Investigators that performed electrophysiological recordings were blinded to group allocation. Other experiments were not performed blind to group allocation. For each analysis, normality of residues and homoscedasticity were assessed. Data are presented as the mean \pm SEM. A p-value of less than 0.05 was considered statistically significant. Statistical analyses were performed using Statistica, R or Prism software. We used the nonparametric Mann-Whitney $U$ test for comparison between two groups and the nonparametric Kruskal-Wallis test followed by Dunn post doc test for multiple comparisons between groups. Other specific statistical tests are mentioned in the figure legends.

\section{Data and Code Availability}

All data generated or analyzed during this study are included in this published article and its supplementary information files.

\section{Declaration of Interests}

The authors declare no competing interests. 


\section{References}

Acuna-Hidalgo, R., Schanze, D., Kariminejad, A., Nordgren, A., Kariminejad, M.H., Conner, P., Grigelioniene, G., Nilsson, D., Nordenskjold, M., Wedell, A., et al. (2014). Neu-Laxova Syndrome Is a Heterogeneous Metabolic Disorder Caused by Defects in Enzymes of the L-Serine Biosynthesis Pathway. American Journal of Human Genetics 95, 285-293.

An, Y., Varma, V.R., Varma, S., Casanova, R., Dammer, E., Pletnikova, O., Chia, C.W., Egan, J.M., Ferrucci, L., Troncoso, J., et al. (2018). Evidence for brain glucose dysregulation in Alzheimer's disease. Alzheimers \& Dementia 14, 318-329.

Bak, L.K., and Walls, A.B. (2018). CrossTalk opposing view: lack of evidence supporting an astrocyte-toneuron lactate shuttle coupling neuronal activity to glucose utilisation in the brain. J Physiol 596, 351-353.

Barros, L.F., Bolanos, J.P., Bonvento, G., Bouzier-Sore, A.K., Brown, A., Hirrlinger, J., Kasparov, S., Kirchhoff, F., Murphy, A.N., Pellerin, L., et al. (2018). Current technical approaches to brain energy metabolism. Glia 66, 1138-1159.

Barros, L.F., and Weber, B. (2018). CrossTalk proposal: an important astrocyte-to-neuron lactate shuttle couples neuronal activity to glucose utilisation in the brain. J Physiol 596, 347-350.

Berger, A., Lorain, S., Josephine, C., Desrosiers, M., Peccate, C., Voit, T., Garcia, L., Sahel, J.A., and Bemelmans, A.P. (2015). Repair of rhodopsin mRNA by spliceosome-mediated RNA trans-splicing: a new approach for autosomal dominant retinitis pigmentosa. Molecular therapy : the journal of the American Society of Gene Therapy 23, 918-930.

Biemans, E.A., Verhoeven-Duif, N.M., Gerrits, J., Claassen, J.A., Kuiperij, H.B., and Verbeek, M.M. (2016). CSF d-serine concentrations are similar in Alzheimer's disease, other dementias, and elderly controls. Neurobiol Aging 42, 213-216.

Cohen, A.D., and Klunk, W.E. (2014). Early detection of Alzheimer's disease using PiB and FDG PET. Neurobiol Dis 72 Pt A, 117-122.

Cox, P.A., and Metcalf, J.S. (2017). Traditional Food Items in Ogimi, Okinawa: I-Serine Content and the Potential for Neuroprotection. Curr Nutr Rep 6, 24-31.

Damseh, N., Simonin, A., Jalas, C., Picoraro, J.A., Shaag, A., Cho, M.T., Yaacov, B., Neidich, J., AlAshhab, M., Juusola, J., et al. (2015). Mutations in SLC1A4, encoding the brain serine transporter, are associated with developmental delay, microcephaly and hypomyelination. J Med Genet 52, 541-547.

de Koning, T.J., Klomp, L.W., van Oppen, A.C., Beemer, F.A., Dorland, L., van den Berg, I., and Berger, R. (2004). Prenatal and early postnatal treatment in 3-phosphoglycerate-dehydrogenase deficiency. Lancet $364,2221-2222$.

Dubois, A., Herard, A.S., Delatour, B., Hantraye, P., Bonvento, G., Dhenain, M., and Delzescaux, T. (2010). Detection by voxel-wise statistical analysis of significant changes in regional cerebral glucose uptake in an APP/PS1 transgenic mouse model of Alzheimer's disease. Neuroimage 51, 586-598.

Dubois, A., Herard, A.S., Flandin, G., Duchesnay, E., Besret, L., Frouin, V., Hantraye, P., Bonvento, G., and Delzescaux, T. (2008). Quantitative validation of voxel-wise statistical analyses of autoradiographic rat brain volumes: application to unilateral visual stimulation. Neuroimage 40, 482-494.

Ehmsen, J.T., Ma, T.M., Sason, H., Rosenberg, D., Ogo, T., Furuya, S., Snyder, S.H., and Wolosker, H. (2013). D-serine in glia and neurons derives from 3-phosphoglycerate dehydrogenase. J Neurosci 33, 12464-12469.

Esaki, K., Kokido, T., Ohmori, T., Tsukino, M., Ohshima, T., and Furuya, S. (2011). Soy peptide ingestion increases neuroactive amino acids in the adult brain of wild-type and genetically engineered serine-deficient mice. J Nutr Food Sci 1, 109. 
Ferreira, J.S., Papouin, T., Ladepeche, L., Yao, A., Langlais, V.C., Bouchet, D., Dulong, J., Mothet, J.P., Sacchi, S., Pollegioni, L., et al. (2017). Co-agonists differentially tune GluN2B-NMDA receptor trafficking at hippocampal synapses. Elife 6 .

Forner, S., Baglietto-Vargas, D., Martini, A.C., Trujillo-Estrada, L., and LaFerla, F.M. (2017). Synaptic Impairment in Alzheimer's Disease: A Dysregulated Symphony. Trends in Neurosciences 40, 347-357.

Garibotto, V., Herholz, K., Boccardi, M., Picco, A., Varrone, A., Nordberg, A., Nobili, F., Ratib, O., and Geneva Task Force for the Roadmap of Alzheimer's, B. (2017). Clinical validity of brain fluorodeoxyglucose positron emission tomography as a biomarker for Alzheimer's disease in the context of a structured 5-phase development framework. Neurobiol Aging 52, 183-195.

Garofalo, K., Penno, A., Schmidt, B.P., Lee, H.J., Frosch, M.P., von Eckardstein, A., Brown, R.H., Hornemann, T., and Eichler, F.S. (2011). Oral L-serine supplementation reduces production of neurotoxic deoxysphingolipids in mice and humans with hereditary sensory autonomic neuropathy type 1 . J Clin Invest $121,4735-4745$.

Gordon, B.A., Blazey, T.M., Su, Y., Hari-Raj, A., Dincer, A., Flores, S., Christensen, J., McDade, E., Wang, G., Xiong, C., et al. (2018). Spatial patterns of neuroimaging biomarker change in individuals from families with autosomal dominant Alzheimer's disease: a longitudinal study. Lancet Neurol 17, 241-250.

Harris, J.J., Jolivet, R., and Attwell, D. (2012). Synaptic energy use and supply. Neuron 75, 762-777.

Hay, Y.A., Lambolez, B., and Tricoire, L. (2015). Nicotinic Transmission onto Layer 6 Cortical Neurons Relies on Synaptic Activation of Non-alpha7 Receptors. Cereb Cortex 26, 2549-2562.

Henneberger, C., Papouin, T., Oliet, S.H., and Rusakov, D.A. (2010). Long-term potentiation depends on release of D-serine from astrocytes. Nature 463, 232-236.

Herrero-Mendez, A., Almeida, A., Fernandez, E., Maestre, C., Moncada, S., and Bolanos, J.P. (2009). The bioenergetic and antioxidant status of neurons is controlled by continuous degradation of a key glycolytic enzyme by APC/C-Cdh1. Nature Cell Biology 11, 747-752.

Hong, S., Beja-Glasser, V.F., Nfonoyim, B.M., Frouin, A., Li, S., Ramakrishnan, S., Merry, K.M., Shi, Q., Rosenthal, A., Barres, B.A., et al. (2016). Complement and microglia mediate early synapse loss in Alzheimer mouse models. Science 352, 712-716.

Iturria-Medina, Y., Sotero, R.C., Toussaint, P.J., Mateos-Perez, J.M., Evans, A.C., and Neuroimaging, A.s.D. (2016). Early role of vascular dysregulation on late-onset Alzheimer's disease based on multifactorial data-driven analysis. Nature communications 7.

Janes, K.A. (2015). An analysis of critical factors for quantitative immunoblotting. Science signaling 8, rs2.

Jo, S., Yarishkin, O., Hwang, Y.J., Chun, Y.E., Park, M., Woo, D.H., Bae, J.Y., Kim, T., Lee, J., Chun, H., et al. (2014). GABA from reactive astrocytes impairs memory in mouse models of Alzheimer's disease. Nat Med 20, 886-896.

Kantrowitz, J.T., Epstein, M.L., Beggel, O., Rohrig, S., Lehrfeld, J.M., Revheim, N., Lehrfeld, N.P., Reep, J., Parker, E., Silipo, G., et al. (2016). Neurophysiological mechanisms of cortical plasticity impairments in schizophrenia and modulation by the NMDA receptor agonist D-serine. Brain 139, 3281-3295.

Lebenberg, J., Herard, A.S., Dubois, A., Dauguet, J., Frouin, V., Dhenain, M., Hantraye, P., and Delzescaux, T. (2010). Validation of MRI-based 3D digital atlas registration with histological and autoradiographic volumes: An anatomofunctional transgenic mouse brain imaging study. Neuroimage 51, 1037-1046.

Levine, T.D., Miller, R.G., Bradley, W.G., Moore, D.H., Saperstein, D.S., Flynn, L.E., Katz, J.S., Forshew, D.A., Metcalf, J.S., Banack, S.A., et al. (2017). Phase I clinical trial of safety of L-serine for ALS patients. Amyotroph Lateral Scler Frontotemporal Degener 18, 107-111. 
Liddelow, S.A., Guttenplan, K.A., Clarke, L.E., Bennett, F.C., Bohlen, C.J., Schirmer, L., Bennett, M.L., Munch, A.E., Chung, W.S., Peterson, T.C., et al. (2017). Neurotoxic reactive astrocytes are induced by activated microglia. Nature 541, 481-487.

Lin, C.H., Yang, H.T., Chiu, C.C., and Lane, H.Y. (2017). Blood levels of D-amino acid oxidase vs. D-amino acids in reflecting cognitive aging. Sci Rep-Uk 7.

Locasale, J.W., Grassian, A.R., Melman, T., Lyssiotis, C.A., Mattaini, K.R., Bass, A.J., Heffron, G., Metallo, C.M., Muranen, T., Sharfi, H., et al. (2011). Phosphoglycerate dehydrogenase diverts glycolytic flux and contributes to oncogenesis. Nat Genet $43,869-874$.

Lorenzo, M.P., Villasenor, A., Ramamoorthy, A., and Garcia, A. (2013). Optimization and validation of a capillary electrophoresis laser-induced fluorescence method for amino acids determination in human plasma: Application to bipolar disorder study. Electrophoresis 34, 1701-1709.

Lunt, S.Y., and Vander Heiden, M.G. (2011). Aerobic Glycolysis: Meeting the Metabolic Requirements of Cell Proliferation. Annu Rev Cell Dev Bi 27, 441-464.

Madeira, C., Lourenco, M.V., Vargas-Lopes, C., Suemoto, C.K., Brandao, C.O., Reis, T., Leite, R.E., Laks, J., Jacob-Filho, W., Pasqualucci, C.A., et al. (2015). d-serine levels in Alzheimer's disease: implications for novel biomarker development. Transl Psychiatry 5, e561.

Magistretti, P.J., and Allaman, I. (2015). A cellular perspective on brain energy metabolism and functional imaging. Neuron 86, 883-901.

Magistretti, P.J., and Allaman, I. (2018). Lactate in the brain: from metabolic end-product to signalling molecule. Nature Reviews Neuroscience 19, 235-249.

Mattaini, K.R., Sullivan, M.R., and Vander Heiden, M.G. (2016). The importance of serine metabolism in cancer. J Cell Biol 214, 249-257.

McDonough, A.A., Veiras, L.C., Minas, J.N., and Ralph, D.L. (2015). Considerations when quantitating protein abundance by immunoblot. Am J Physiol-Cell Ph 308, C426-C433.

Morris, R. (1984). Developments of a Water-Maze Procedure for Studying Spatial-Learning in the Rat. Journal of Neuroscience Methods 11, 47-60.

Mosconi, L., Sorbi, S., de Leon, M.J., Li, Y., Nacmias, B., Myoung, P.S., Tsui, W., Ginestroni, A., Bessi, V., Fayyazz, M., et al. (2006). Hypometabolism exceeds atrophy in presymptomatic early-onset familial Alzheimer's disease. J Nucl Med 47, 1778-1786.

Oddo, S., Caccamo, A., Shepherd, J.D., Murphy, M.P., Golde, T.E., Kayed, R., Metherate, R., Mattson, M.P., Akbari, Y., and LaFerla, F.M. (2003). Triple-transgenic model of Alzheimer's disease with plaques and tangles: intracellular Abeta and synaptic dysfunction. Neuron 39, 409-421.

Oh, K.J., Perez, S.E., Lagalwar, S., Vana, L., Binder, L., and Mufson, E.J. (2010). Staging of Alzheimer's pathology in triple transgenic mice: a light and electron microscopic analysis. Int J Alzheimers Dis 2010.

Otte, D.M., de Arellano, M.L.B., Bilkei-Gorzo, A., Albayram, O., Imbeault, S., Jeung, H., Alferink, J., and Zimmer, A. (2013). Effects of Chronic D-Serine Elevation on Animal Models of Depression and AnxietyRelated Behavior. Plos One 8.

Ovens, M.J., Davies, A.J., Wilson, M.C., Murray, C.M., and Halestrap, A.P. (2010). AR-C155858 is a potent inhibitor of monocarboxylate transporters MCT1 and MCT2 that binds to an intracellular site involving transmembrane helices 7-10. Biochemical Journal 425, 523-530.

Panatier, A., Theodosis, D.T., Mothet, J.P., Touquet, B., Pollegioni, L., Poulain, D.A., and Oliet, S.H. (2006). Glia-derived D-serine controls NMDA receptor activity and synaptic memory. Cell 125, 775-784. 
Papouin, T., Ladepeche, L., Ruel, J., Sacchi, S., Labasque, M., Hanini, M., Groc, L., Pollegioni, L., Mothet, J.P., and Oliet, S.H. (2012). Synaptic and extrasynaptic NMDA receptors are gated by different endogenous coagonists. Cell 150, 633-646.

Pernot, P., Mothet, J.P., Schuvailo, O., Soldatkin, A., Pollegioni, L., Pilone, M., Adeline, M.T., Cespuglio, R., and Marinesco, S. (2008). Characterization of a yeast D-amino acid oxidase microbiosensor for D-serine detection in the central nervous system. Analytical Chemistry 80, 1589-1597.

Possemato, R., Marks, K.M., Shaul, Y.D., Pacold, M.E., Kim, D., Birsoy, K., Sethumadhavan, S., Woo, H.K., Jang, H.G., Jha, A.K., et al. (2011). Functional genomics reveal that the serine synthesis pathway is essential in breast cancer. Nature 476, 346-350.

Protas, H.D., Chen, K., Langbaum, J.B., Fleisher, A.S., Alexander, G.E., Lee, W., Bandy, D., de Leon, M.J., Mosconi, L., Buckley, S., et al. (2013). Posterior cingulate glucose metabolism, hippocampal glucose metabolism, and hippocampal volume in cognitively normal, late-middle-aged persons at 3 levels of genetic risk for Alzheimer disease. Jama Neurol 70, 320-325.

Rohn, T.T., Vyas, V., Hernandez-Estrada, T., Nichol, K.E., Christie, L.A., and Head, E. (2008). Lack of pathology in a triple transgenic mouse model of Alzheimer's disease after overexpression of the antiapoptotic protein Bcl-2. Journal of Neuroscience 28, 3051-3059.

Rueckert, D., Sonoda, L.I., Hayes, C., Hill, D.L.G., Leach, M.O., and Hawkes, D.J. (1999). Nonrigid registration using free-form deformations: Application to breast MR images. leee T Med Imaging 18, 712721.

San Martin, A., Ceballo, S., Ruminot, I., Lerchundi, R., Frommer, W.B., and Barros, L.F. (2013). A genetically encoded FRET lactate sensor and its use to detect the Warburg effect in single cancer cells. PLoS One 8, e57712.

Schneider, L.S., Dagerman, K.S., Higgins, J.P.T., and McShane, R. (2011). Lack of Evidence for the Efficacy of Memantine in Mild Alzheimer Disease. Archives of Neurology 68, 991-998.

Sholl, D.A. (1953). Dendritic Organization in the Neurons of the Visual and Motor Cortices of the Cat. Journal of Anatomy 87, 387-406.

Silver, I.A., and Erecinska, M. (1994). Extracellular glucose concentration in mammalian brain: continuous monitoring of changes during increased neuronal activity and upon limitation in oxygen supply in normo-, hypo-, and hyperglycemic animals. J Neurosci 14, 5068-5076.

Sotelo-Hitschfeld, T., Niemeyer, M.I., Machler, P., Ruminot, I., Lerchundi, R., Wyss, M.T., Stobart, J., Fernandez-Moncada, I., Valdebenito, R., Garrido-Gerter, P., et al. (2015). Channel-mediated lactate release by K(+)-stimulated astrocytes. J Neurosci 35, 4168-4178.

Soto, D., Olivella, M., Grau, C., Armstrong, J., Alcon, C., Gasull, X., Santos-Gomez, A., Locubiche, S., de Salazar, M.G., Garcia-Diaz, R., et al. (2019). I-Serine dietary supplementation is associated with clinical improvement of loss-of-function GRIN2B-related pediatric encephalopathy. Science signaling 12.

Spires-Jones, T.L., and Hyman, B.T. (2014). The intersection of amyloid beta and tau at synapses in Alzheimer's disease. Neuron 82, 756-771.

Sugimoto, H., Kakehi, M., and Jinno, F. (2015). Bioanalytical method for the simultaneous determination of $\mathrm{D}$ - and L-serine in human plasma by LC/MS/MS. Analytical Biochemistry 487, 38-44.

Suzuki, A., Stern, S.A., Bozdagi, O., Huntley, G.W., Walker, R.H., Magistretti, P.J., and Alberini, C.M. (2011). Astrocyte-neuron lactate transport is required for long-term memory formation. Cell 144, 810-823.

van der Crabben, S.N., Verhoeven-Duif, N.M., Brilstra, E.H., Van Maldergem, L., Coskun, T., RubioGozalbo, E., Berger, R., and de Koning, T.J. (2013). An update on serine deficiency disorders. J Inherit Metab Dis 36, 613-619. 
Vandenberghe, M.E., Herard, A.S., Souedet, N., Sadouni, E., Santin, M.D., Briet, D., Carre, D., Schulz, J., Hantraye, P., Chabrier, P.E., et al. (2016). High-throughput 3D whole-brain quantitative histopathology in rodents. Sci Rep 6, 20958.

Vasylieva, N., Barnych, B., Meillerd, A., Maucler, C., Pollegioni, L., Lin, J.S., Barbier, D., and Marinesco, S. (2011). Covalent enzyme immobilization by poly(ethylene glycol) diglycidyl ether (PEGDE) for microelectrode biosensor preparation. Biosens Bioelectron 26, 3993-4000.

Vlassenko, A.G., and Raichle, M.E. (2015). Brain aerobic glycolysis functions and Alzheimer's disease. Clin Transl Imaging 3, 27-37.

Winkler, E.A., Nishida, Y., Sagare, A.P., Rege, S.V., Bell, R.D., Perlmutter, D., Sengillo, J.D., Hillman, S., Kong, P., Nelson, A.R., et al. (2015). GLUT1 reductions exacerbate Alzheimer's disease vasculo-neuronal dysfunction and degeneration. Nature Neuroscience 18, 521-530.

Yang, J.H., Wada, A., Yoshida, K., Miyoshi, Y., Sayano, T., Esaki, K., Kinoshita, M.O., Tomonaga, S., Azuma, N., Watanabe, M., et al. (2010). Brain-specific Phgdh deletion reveals a pivotal role for L-serine biosynthesis in controlling the level of $\mathrm{D}$-serine, an $\mathrm{N}$-methyl-D-aspartate receptor co-agonist, in adult brain. J Biol Chem 285, 41380-41390.

Yang, J.Y., Ruchti, E., Petit, J.M., Jourdain, P., Grenningloh, G., Allaman, I., and Magistretti, P.J. (2014). Lactate promotes plasticity gene expression by potentiating NMDA signaling in neurons. Proceedings of the National Academy of Sciences of the United States of America 111, 12228-12233.

Yang, Y.L., Ge, W.P., Chen, Y.R., Zhang, Z.J., Shen, W.H., Wu, C.P., Poo, M.M., and Duan, S.M. (2003). Contribution of astrocytes to hippocampal long-term potentiation through released D-serine. Proceedings of the National Academy of Sciences of the United States of America 100,15194-15199.

Zhuo, L., Theis, M., Alvarez-Maya, I., Brenner, M., Willecke, K., and Messing, A. (2001). hGFAP-cre transgenic mice for manipulation of glial and neuronal function in vivo. Genesis 31, 85-94. 
A

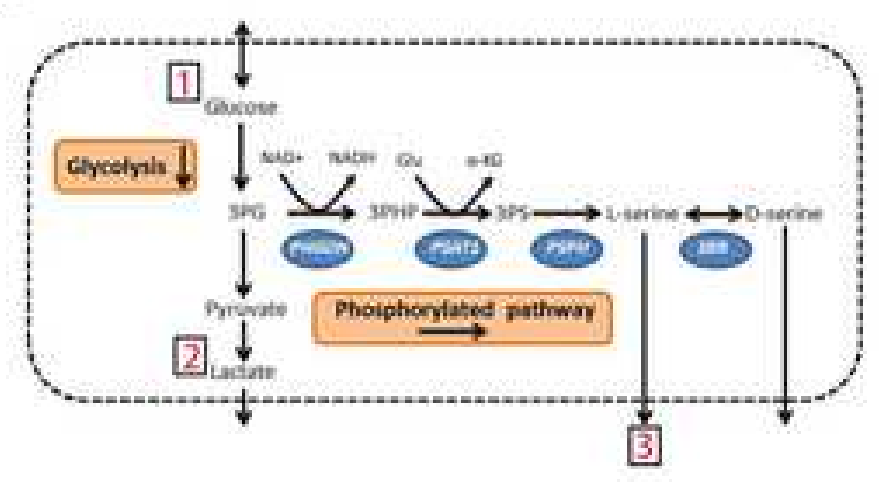

C

6 month-old

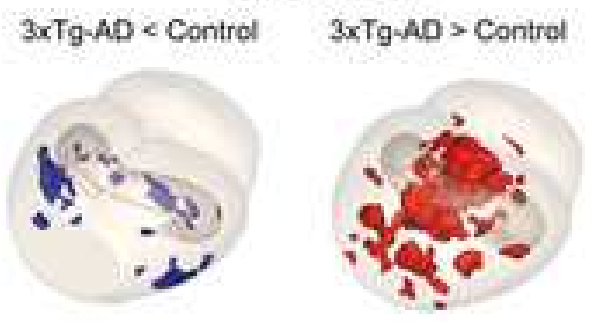

E

6 month-old

$3 \times T g-A D<$ Control : hippocampus

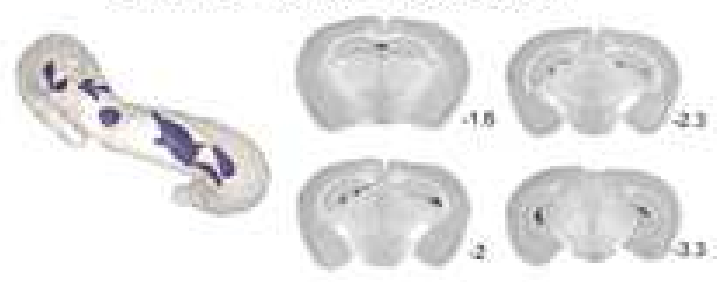

G
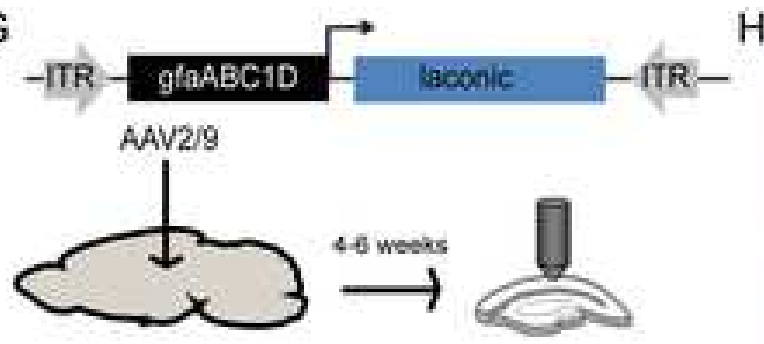

J

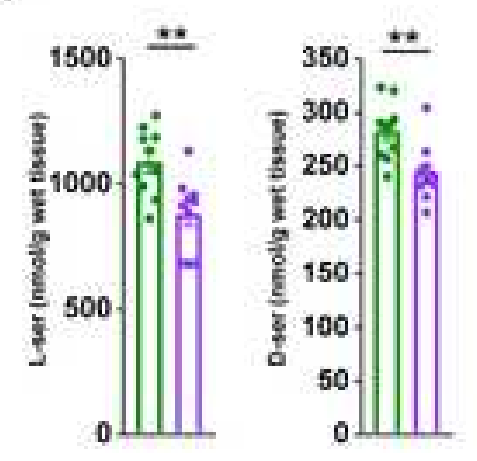

K

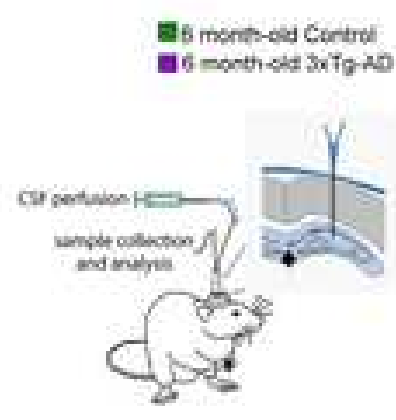

B

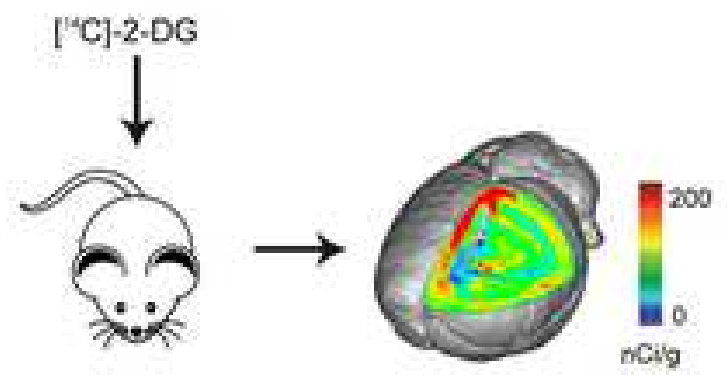

D 12 month-old

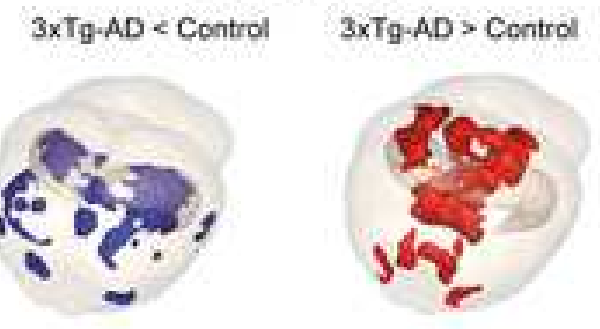

$\mathrm{F}$

12 month-old

$3 \times T_{9}-A D<$ Control : hippocampus
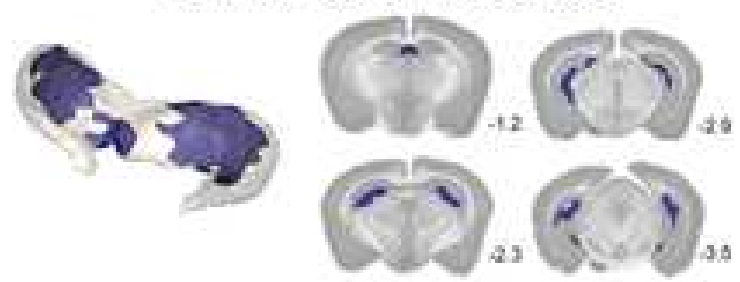

MTFP
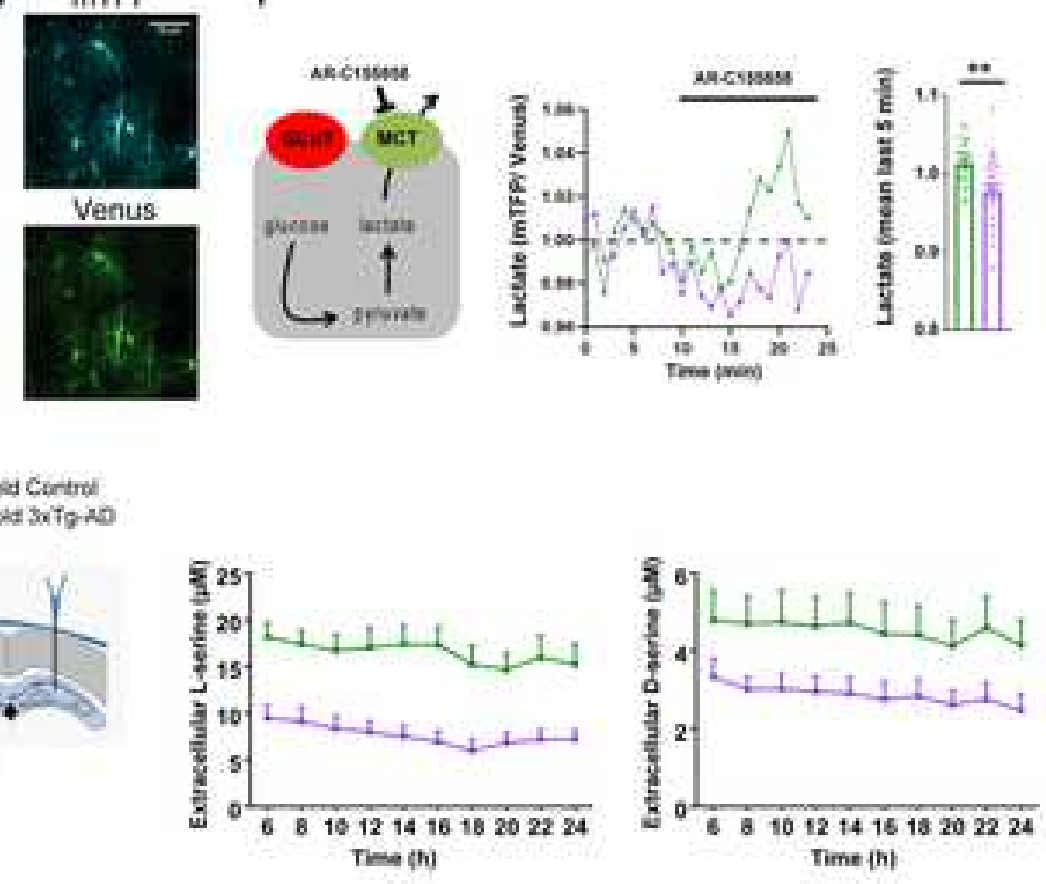
A
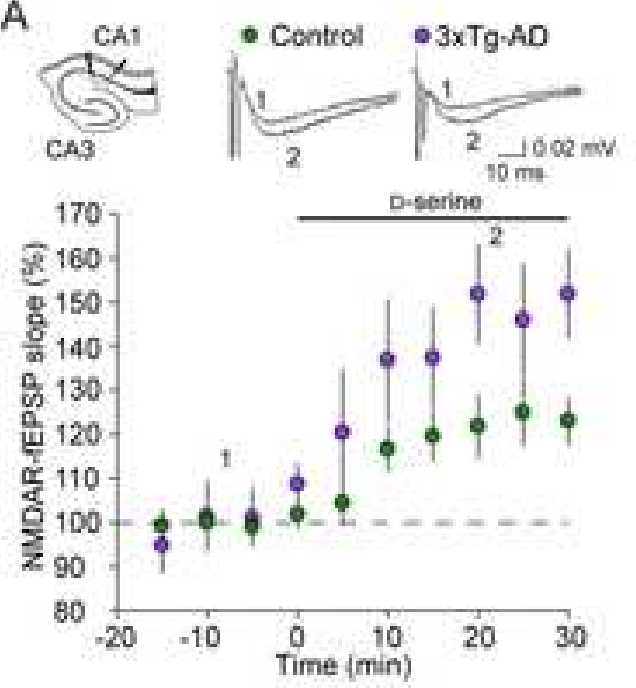

C
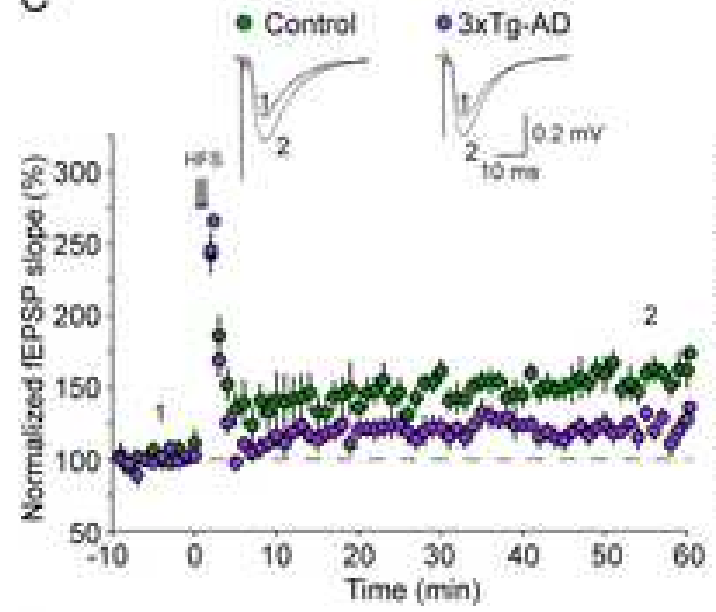

E
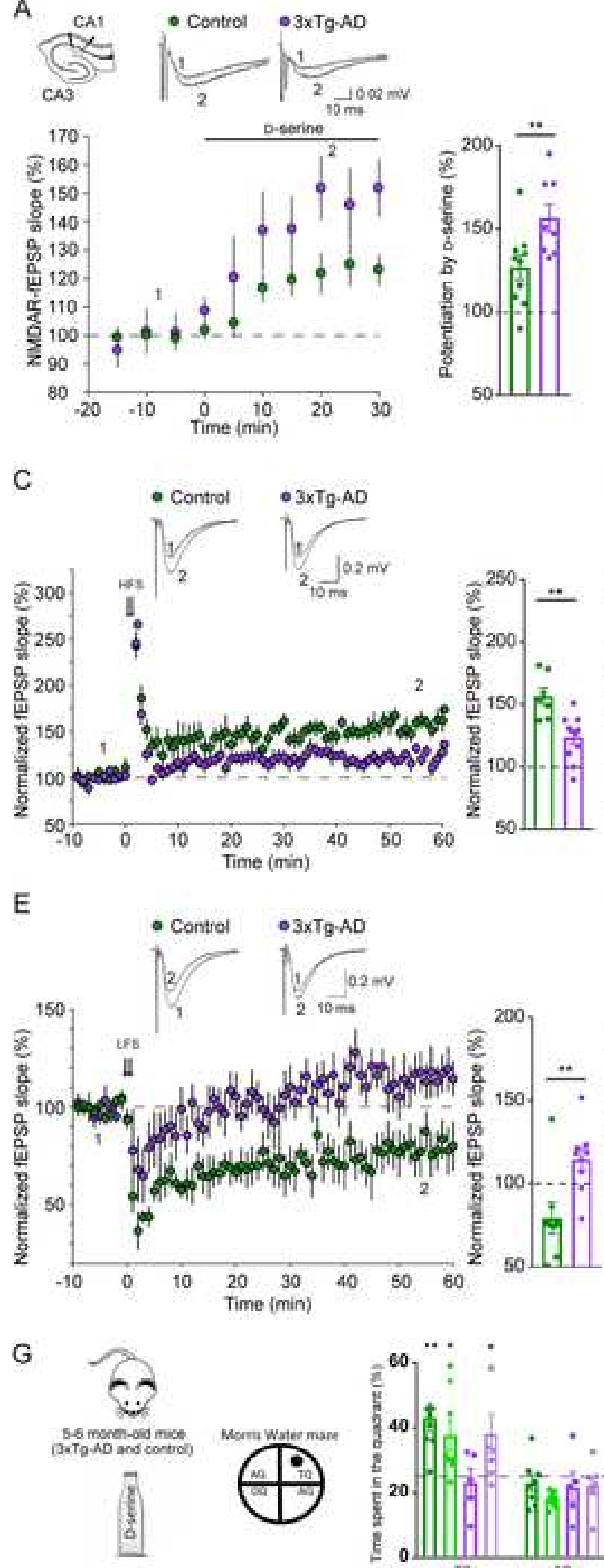

G
B
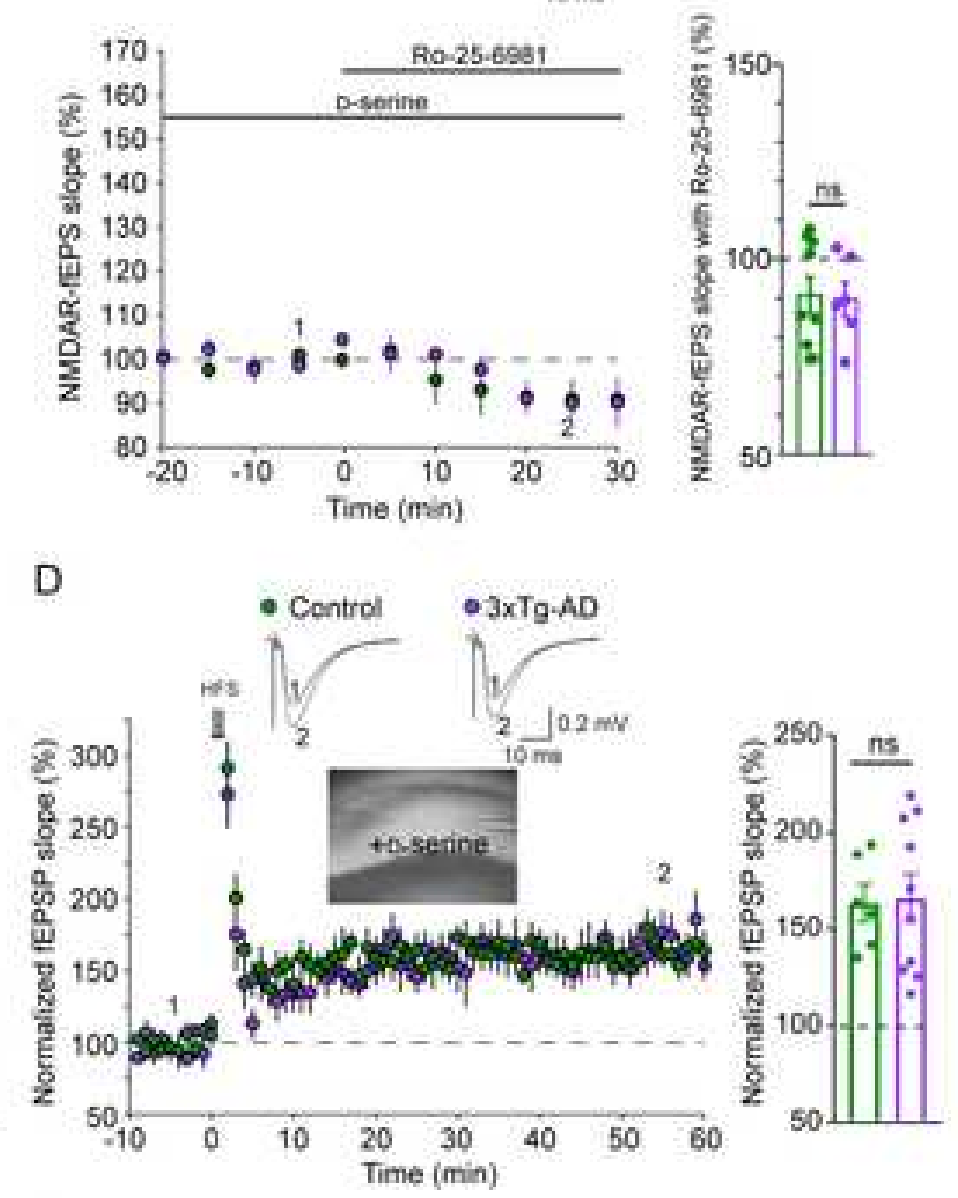

F

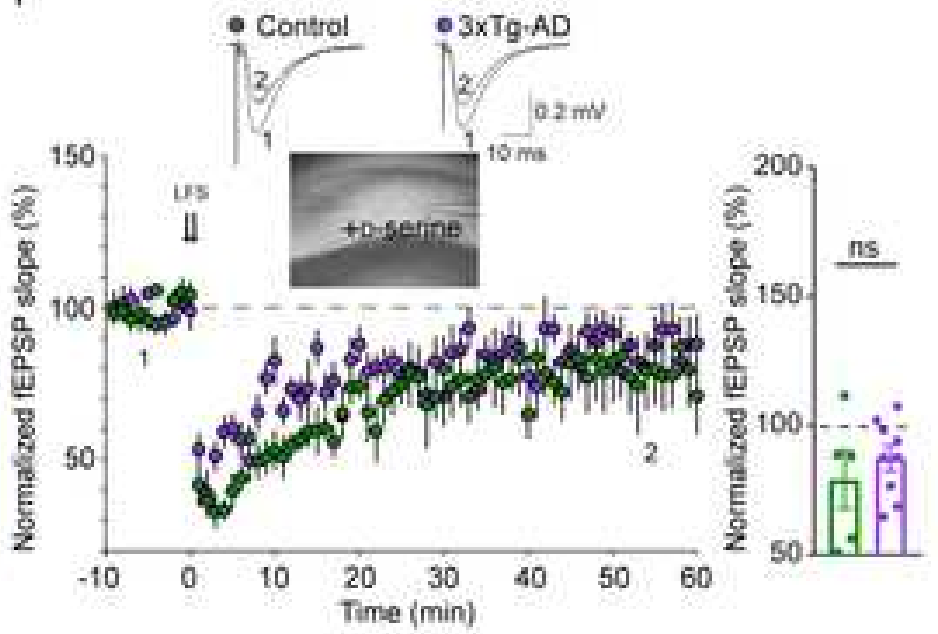

\section{Figure 2}

B
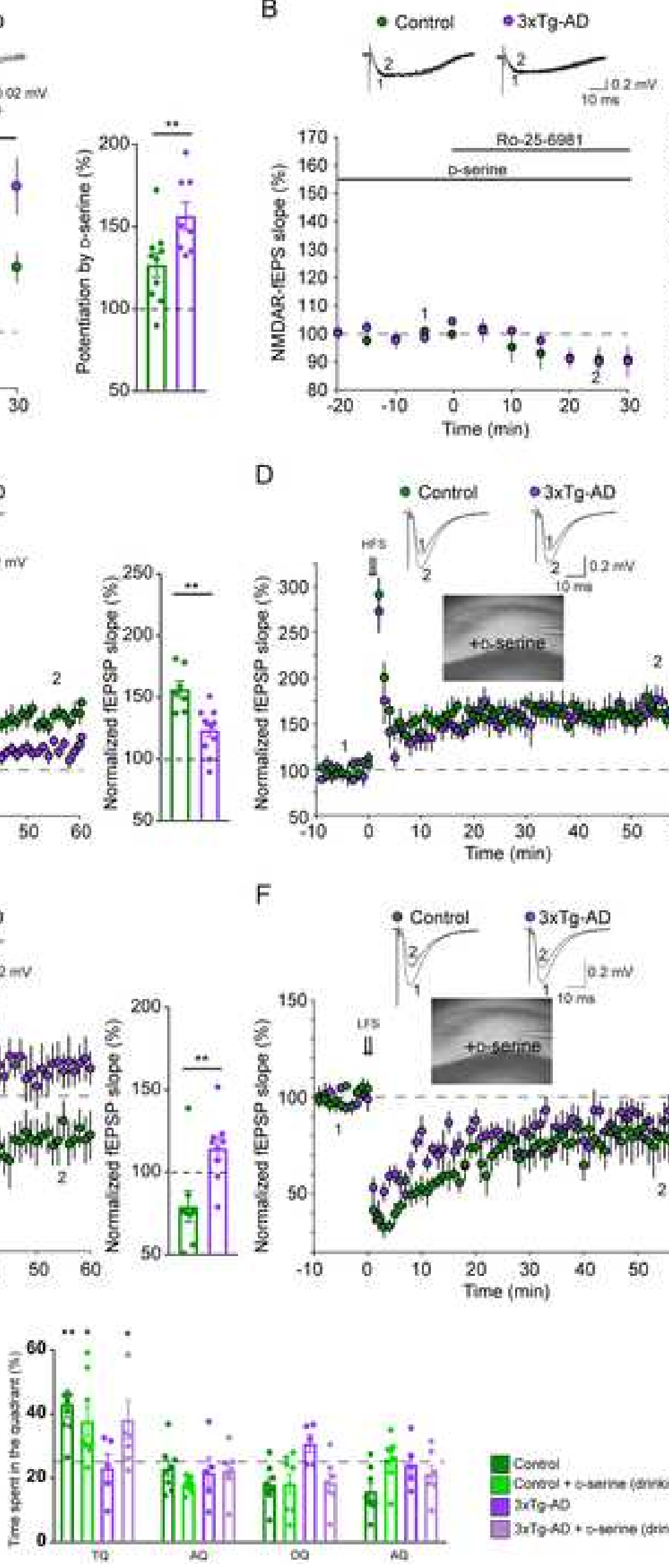

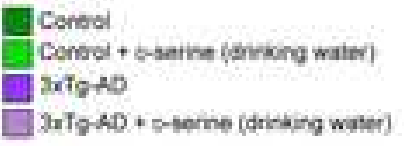



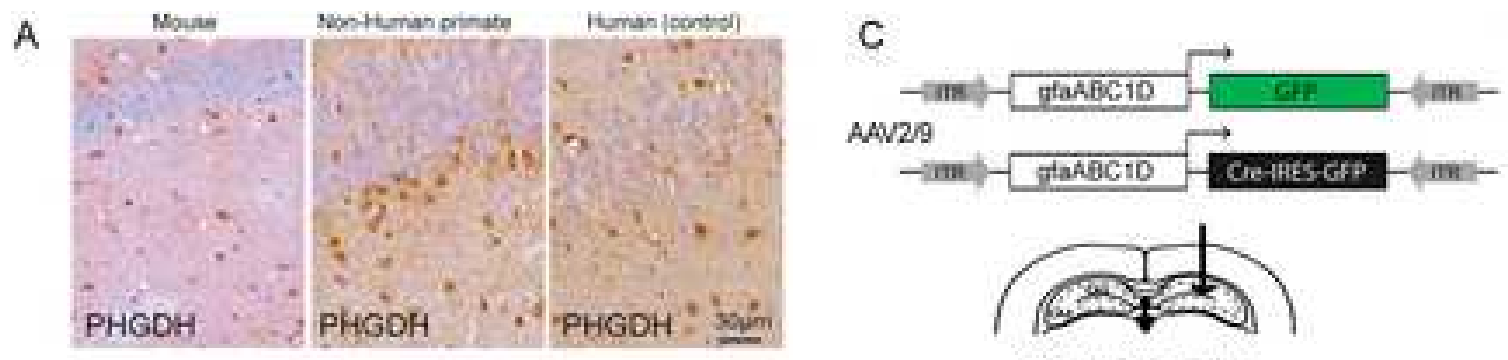

B
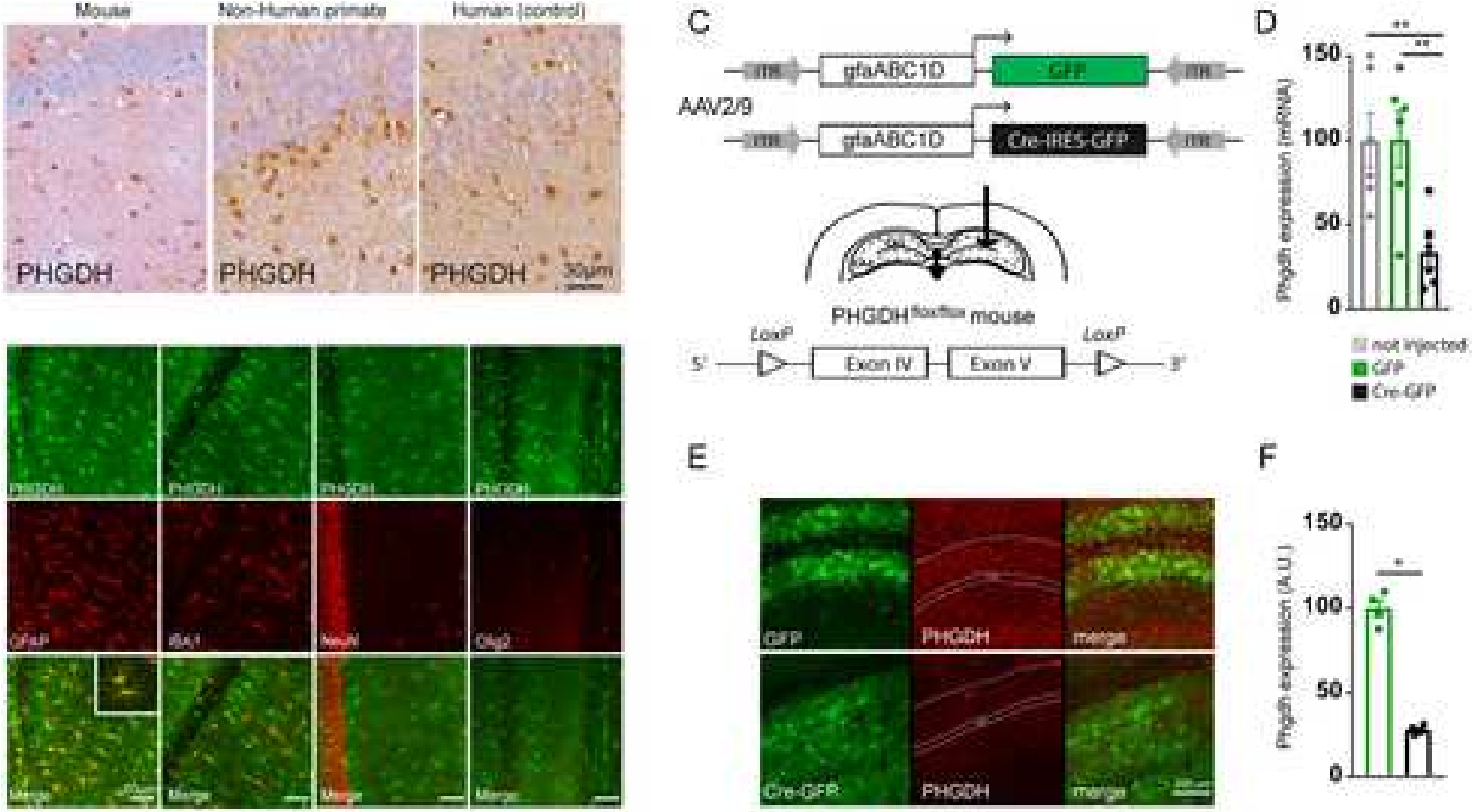

E

F

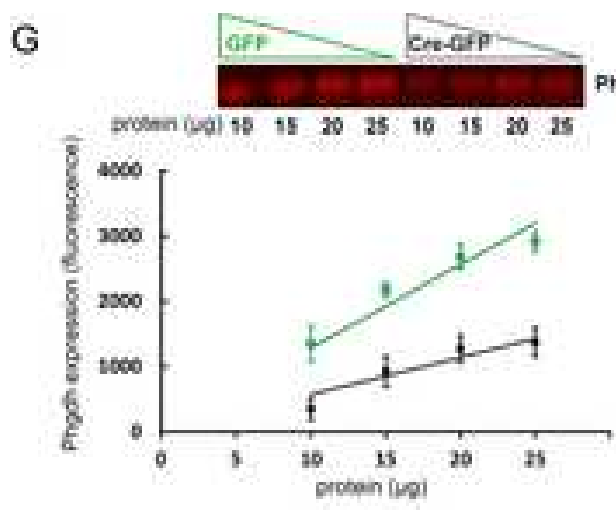

H
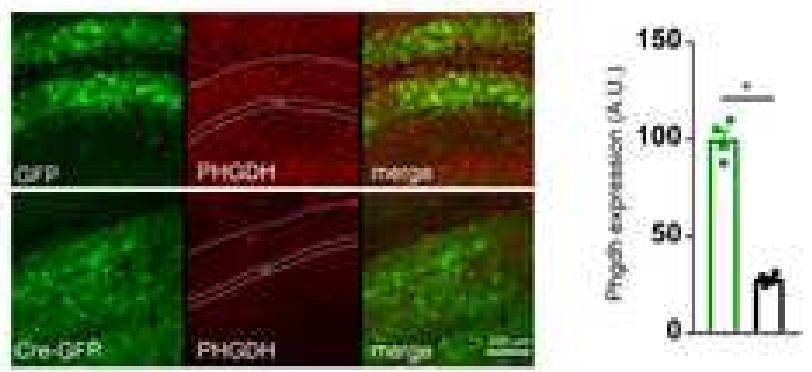

K
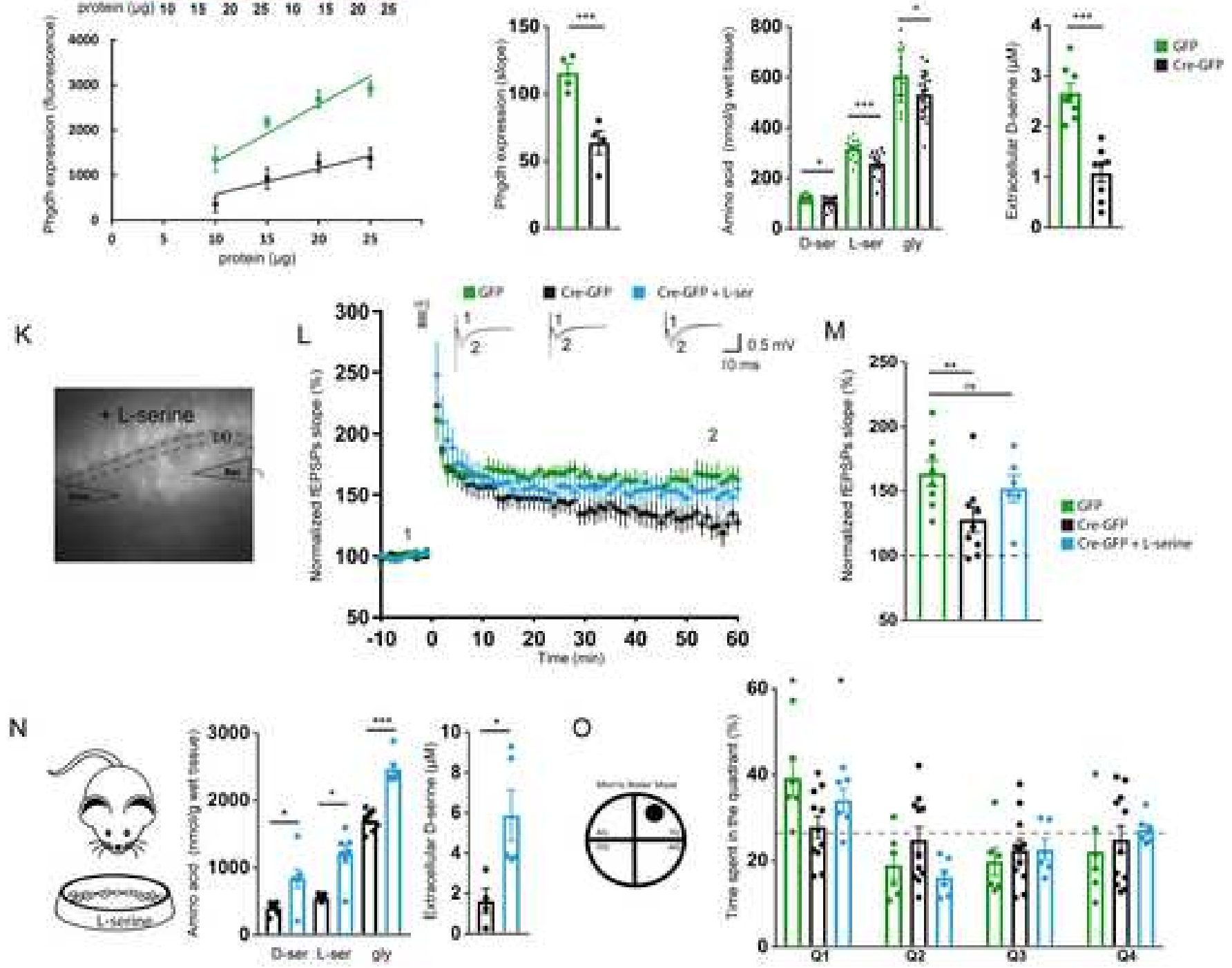
A

D
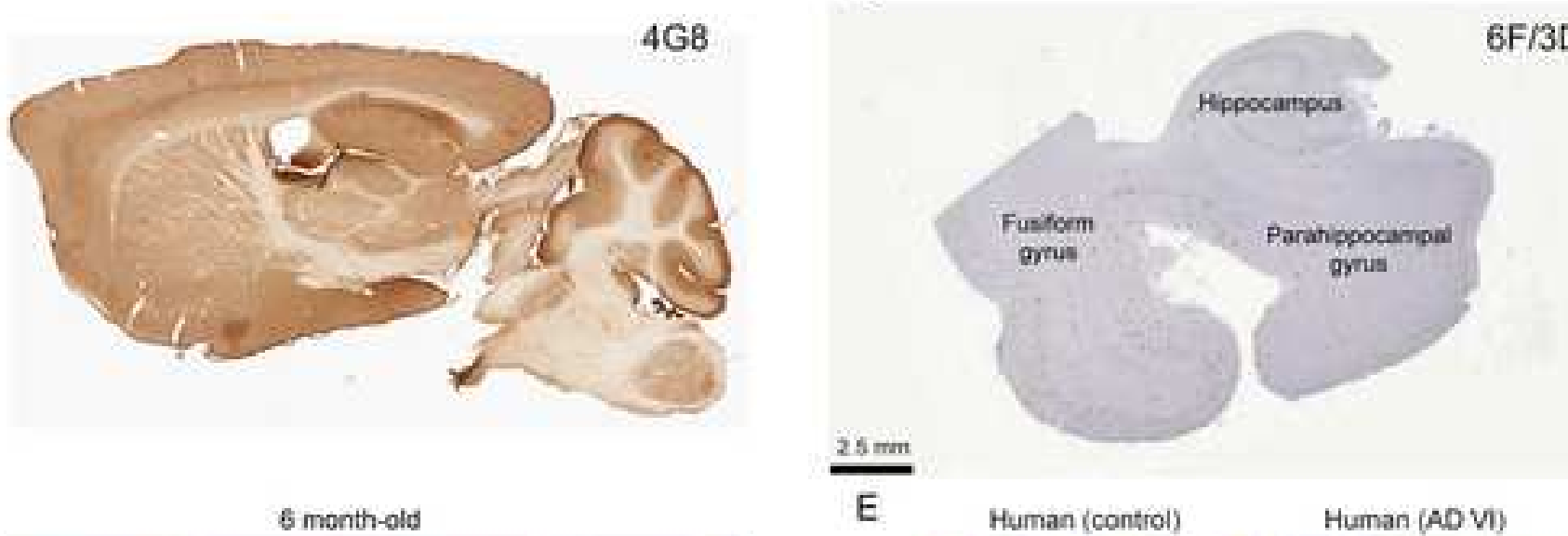

B
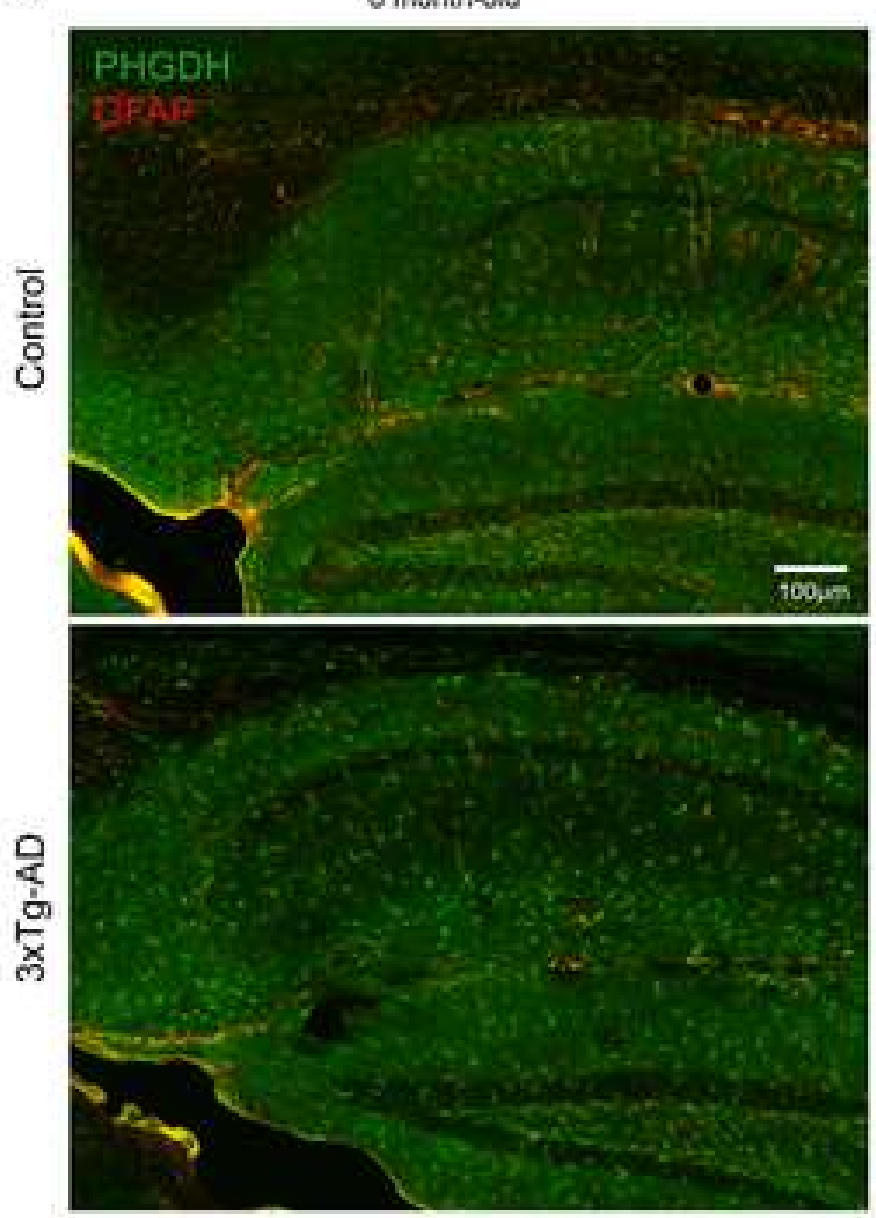

C

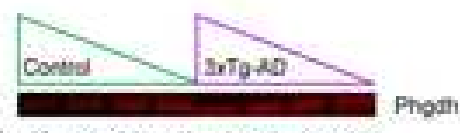

proten (ivg) $10 \quad$ is $20 \quad 25 \quad 10 \quad 15 \quad 20 \quad 25$
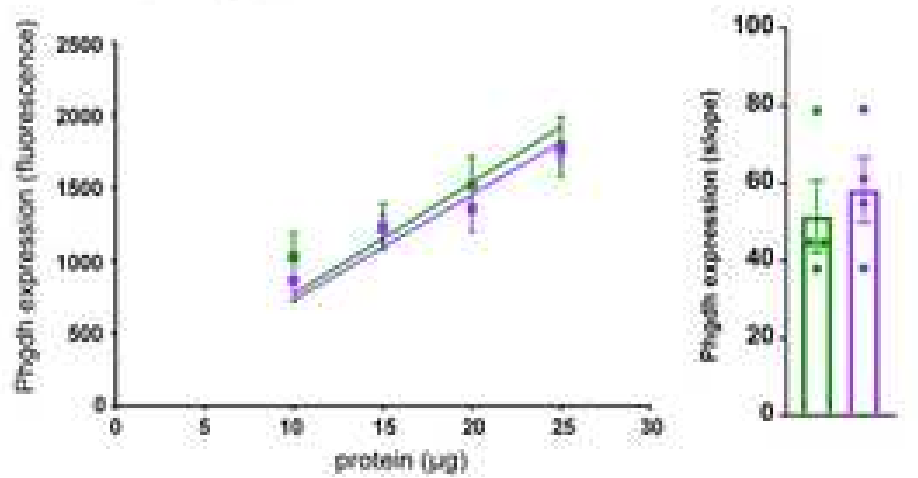
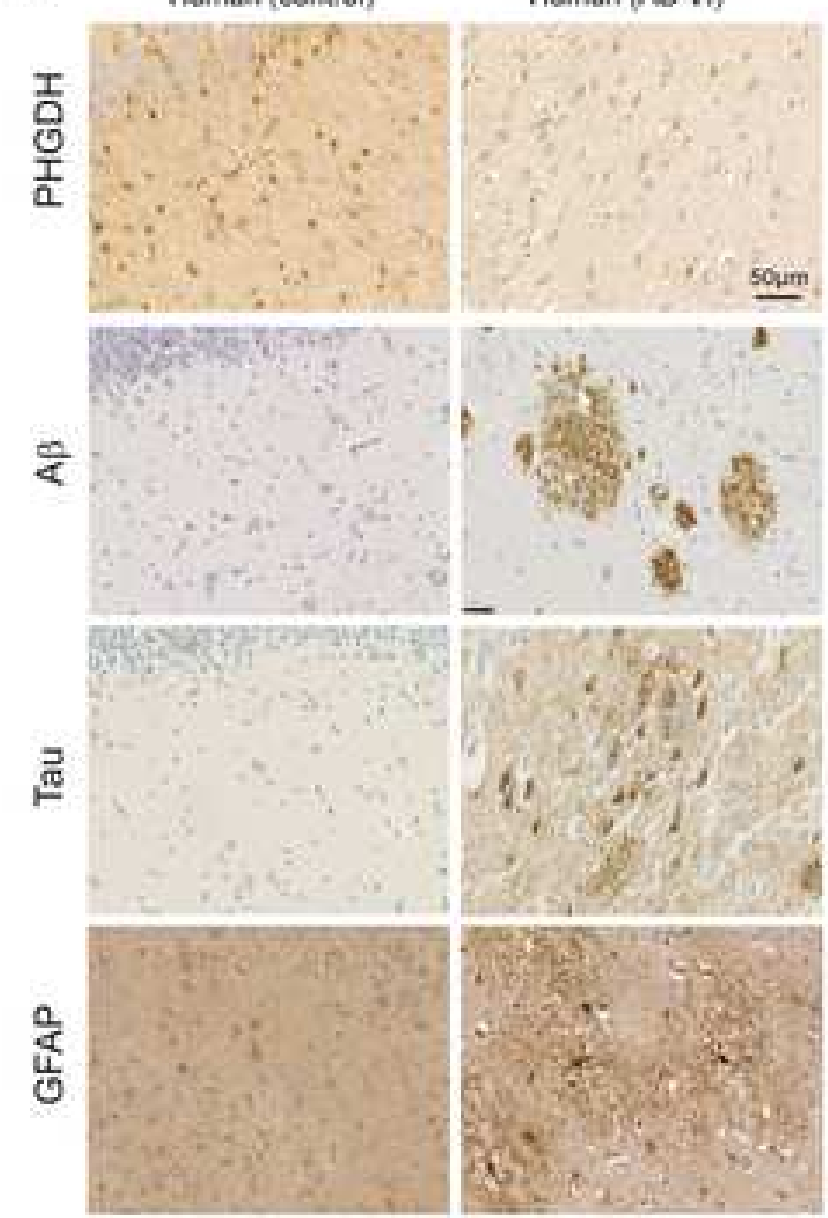

F

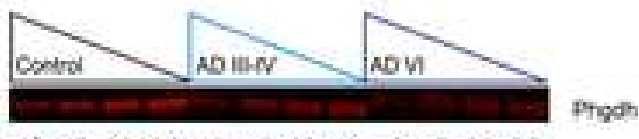

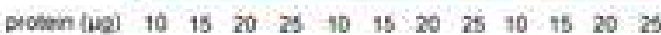

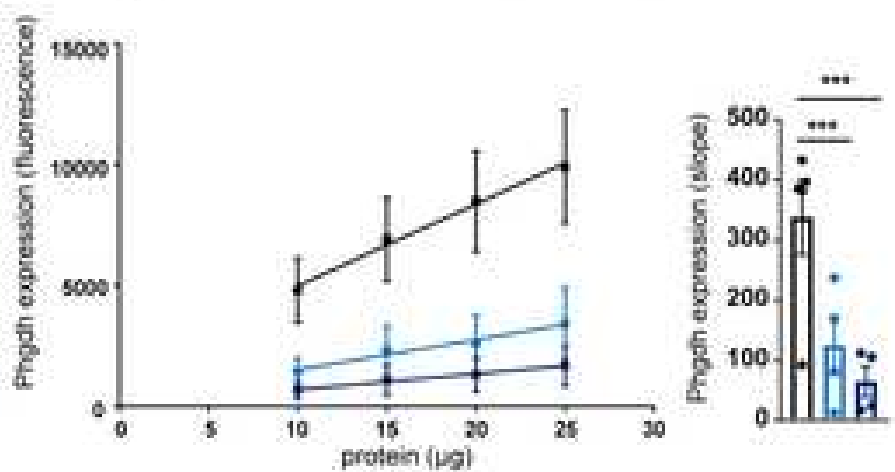


A

B
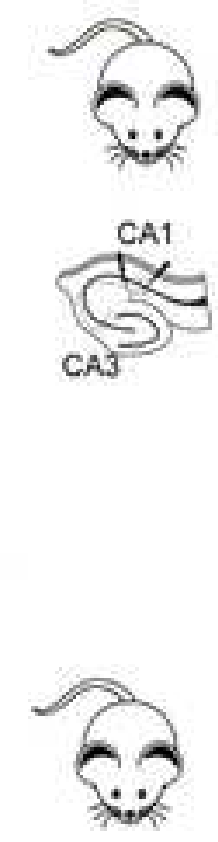

4 menth-old aleet (3xTg-AD and cented)

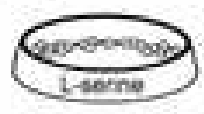

2 moth dint
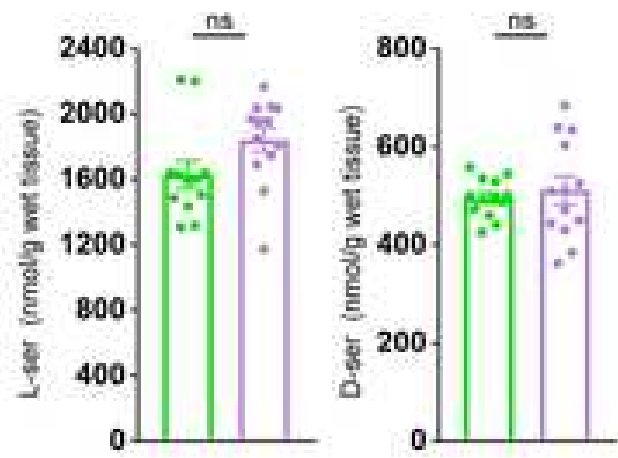

D
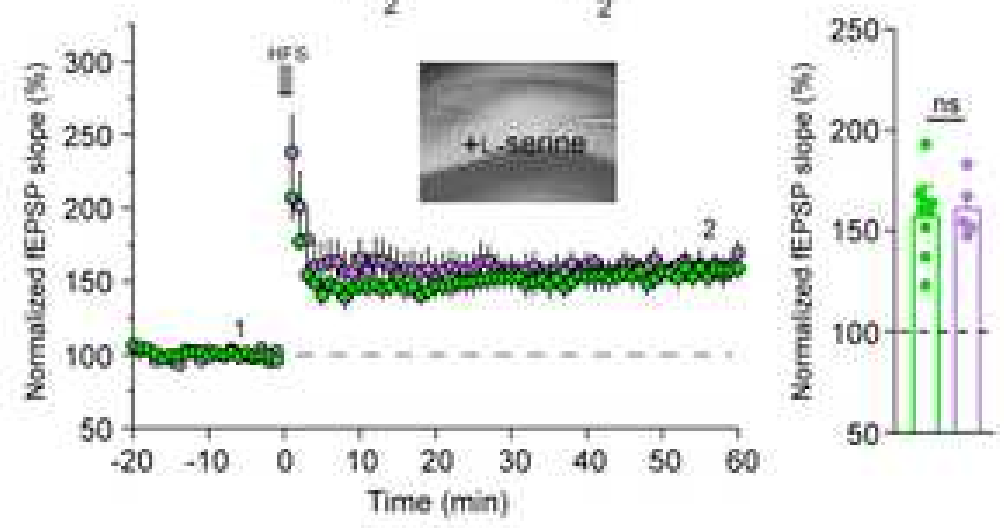

C
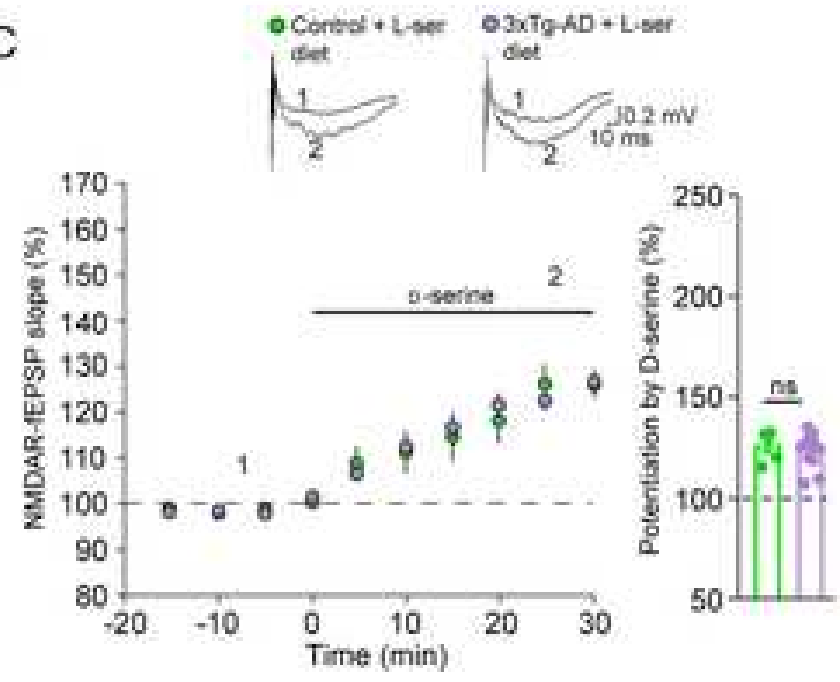

E
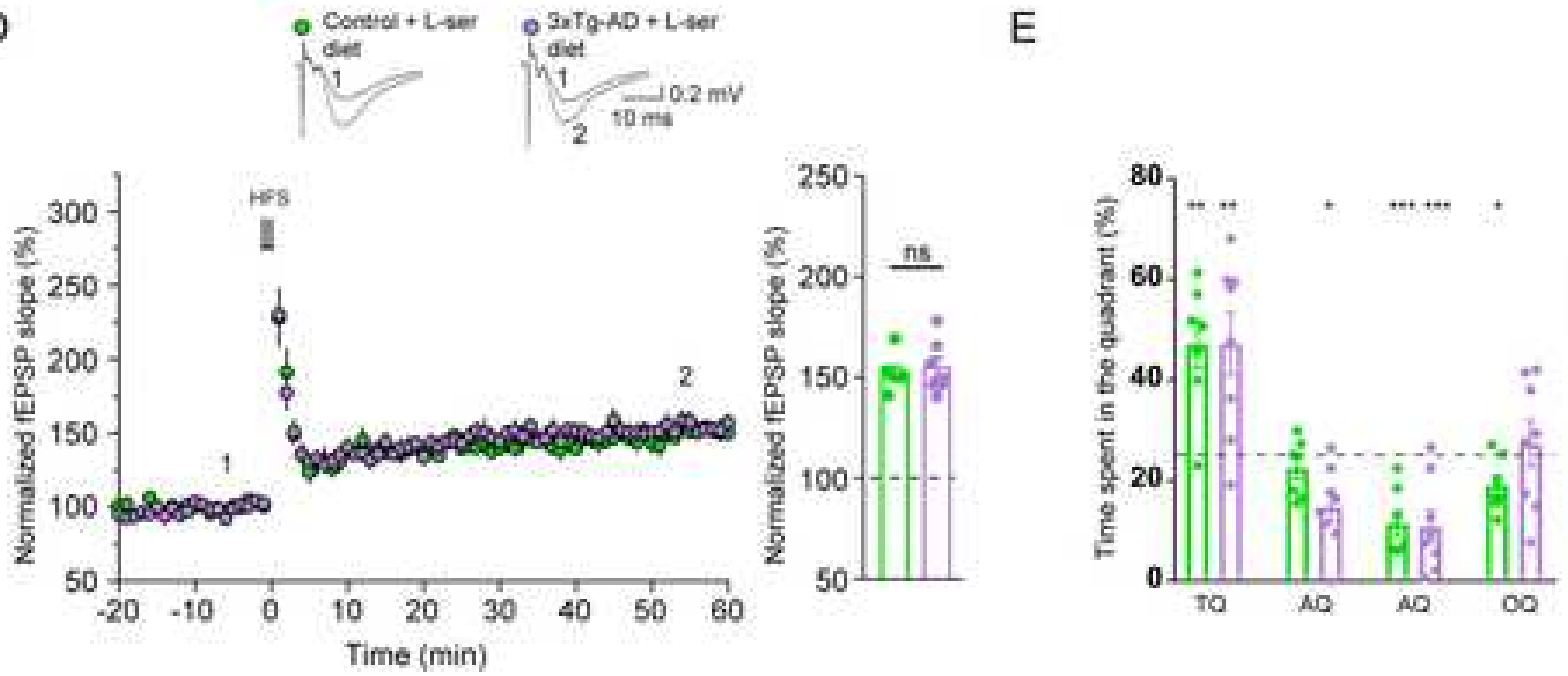

Conbid + t-ser bet BuTpaD + Lser det

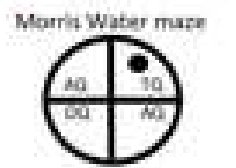


Table 1: Demographic data on studied cases

\begin{tabular}{ccccc}
\hline & & & & \\
Diagnosis & Cases & Sex & Age $($ Yr $)$ & PMD (h) \\
\hline Control & $1 \#$ & M & 78 & 23 \\
& $2 \#$ & F & 92 & 21 \\
& $3 \#$ & F & 60 & 28 \\
& $4 \#$ & M & 69 & 6 \\
& $5 \#$ & M & 81 & 62 \\
AD (III-IV) & 6 & F & 53 & 29 \\
& $7 \#$ & M & 70 & 31 \\
& $8 \#$ & F & 76 & 28 \\
& $9 \#$ & M & 81 & 34.5 \\
& $10 \#$ & F & 73 & 21.5 \\
& 11 & F & 90 & 35 \\
& 12 & F & 92 & 33 \\
& 13 & F & 66 & ND \\
& $14 \#$ & M & 72 & 44 \\
& $15 \#$ & F & 89 & 59 \\
& $16 \#$ & M & 73 & 54 \\
& $17 \#$ & M & 69 & 30 \\
& $18 \#$ & F & 94 & 25 \\
& 19 & M & 68 & 34.5 \\
& 20 & F & 61 & 27 \\
& 21 & M & 87 & 27 \\
\hline
\end{tabular}

AD (III-IV) Alzheimer's disease, Braak III-IV AD (VI) Alzheimer's disease, Braak VI

PMD postmortem delay, N/A Not Available, \# used for immunoblotting 


\section{KEY RESOURCES TABLE}

\begin{tabular}{|c|c|c|}
\hline REAGENT or RESOURCE & SOURCE & IDENTIFIER \\
\hline \multicolumn{3}{|l|}{ Antibodies } \\
\hline $\begin{array}{l}\text { Phgdh (3-phosphoglycerate dehydrogenase), polyclonal } \\
\text { rabbit antibody }\end{array}$ & Frontier Institute & $\begin{array}{l}\text { Cat\# 3PGDH-Rb, } \\
\text { RRID:AB } 2571653\end{array}$ \\
\hline $\begin{array}{l}\text { Phgdh (3-phosphoglycerate dehydrogenase), polyclonal } \\
\text { guinea pig antibody }\end{array}$ & Frontier Institute & $\begin{array}{l}\text { Cat\# 3PGDH-GP, } \\
\text { RRID:AB } 2571654\end{array}$ \\
\hline $\begin{array}{l}\text { Tau, mouse Phospho-Tau (Ser202, Thr205) monoclonal } \\
\text { antibody (AT8) }\end{array}$ & Thermo Fisher & Cat\# MN1020 \\
\hline $\begin{array}{l}\text { Tau, mouse Phospho-Tau (Thr231) monoclonal } \\
\text { antibody (AT180) }\end{array}$ & Thermo Fisher & Cat\# MN1040 \\
\hline Tau, polyclonal rabbit antibody OC & Millipore & Cat\# AB2286 \\
\hline Tau, mouse monoclonal antibody $\mathrm{HT}$ & Innogenetics & Cat\# BR01 \\
\hline $\begin{array}{l}\text { Abeta, clone 6F3D, monoclonal mouse anti-human beta- } \\
\text { amyloid }\end{array}$ & Dako & Cat\# M0872 \\
\hline Abeta, clone 4G8, monoclonal mouse antibody & Covance & Cat\# SIG-39220 \\
\hline Gfap, polyclonal rabbit antibody, Dako, , lot 096 & Dako & Cat\# Z0334 \\
\hline $\begin{array}{l}\text { Gfap-Cy3, monoclonal mouse Anti-Glial Fibrillary Acidic } \\
\text { Protein (GFAP) (mouse IgG1 isotype) conjugated to } \\
\text { Cy3, clone GA5 }\end{array}$ & Sigma & Cat\# C9205 \\
\hline NeuN, monoclonal mouse antibody, clone A60 & Millipore & Cat\#MAB377 \\
\hline Iba1, ployclonal rabbit antibody & Wako & Cat\# 019-19741 \\
\hline $\begin{array}{l}\text { Olig2-Alexa488, rabbit ployclonal antibody to } \\
\text { Oligodendrocyte transcription gactor } 2 \text { (olig2) coupled to } \\
\text { Alexafluor } 488\end{array}$ & Millipore & Cat\# AB9610-af488 \\
\hline \multicolumn{3}{|l|}{ Bacterial and Virus Strains } \\
\hline AAV9-gfaABC1D-Laconic & Our facility & $\mathrm{N} / \mathrm{A}$ \\
\hline AAV9-gfaABC1D-td-Tomato & Our facility & $\mathrm{N} / \mathrm{A}$ \\
\hline AAV9-gfaABC1D-GFP & Our facility & $\mathrm{N} / \mathrm{A}$ \\
\hline AAV9-gfaABC1D-Cre-IRES-GFP & Our facility & $\mathrm{N} / \mathrm{A}$ \\
\hline \multicolumn{3}{|l|}{ Biological Samples } \\
\hline Human hippocampal brain blocks & $\begin{array}{l}\text { GIE NeuroCeb } \\
\text { biobank }\end{array}$ & $\begin{array}{l}\text { https://www.neuroc } \\
\text { eb.org/fr/ }\end{array}$ \\
\hline \multicolumn{3}{|l|}{ Chemicals, Peptides, and Recombinant Proteins } \\
\hline Deoxy-D-glucose, 2-[14C(U)] & Perkin Elmer & $\begin{array}{l}\text { CAT\# } \\
\text { NET328001MC }\end{array}$ \\
\hline AR-C155858 & Tocris & Cat. No. 4960 \\
\hline EZ Prep for paraffin removal & Roche Diagnostics & Cat\# 950-102 \\
\hline $\begin{array}{l}\text { Ribo CC, Citrate based buffer optimized for heat } \\
\text { pretreatments }\end{array}$ & Roche Diagnostics & Cat\# 760-107 \\
\hline Discovery Ab PBS-based diluent & Roche Diagnostics & Cat\# 760-108 \\
\hline DISCOVERY DAB Map Detection Kit & Roche Diagnostics & Cat\# 760-124 \\
\hline \multicolumn{3}{|l|}{ Critical Commercial Assays } \\
\hline QuantiChrom $^{\text {TM }}$ Glucose Assay Kit & Universal Biologicals & CAT\# DIGL-100 \\
\hline
\end{tabular}




\begin{tabular}{|c|c|c|}
\hline \multicolumn{3}{|l|}{ Deposited Data } \\
\hline & & \\
\hline & & \\
\hline & & \\
\hline \multicolumn{3}{|l|}{ Experimental Models: Cell Lines } \\
\hline & & \\
\hline & & \\
\hline & & \\
\hline \multicolumn{3}{|l|}{ Experimental Models: Organisms/Strains } \\
\hline $\begin{array}{l}\text { Mouse: B6;129-Tg(APPSwe,tauP301L)1Lfa } \\
\text { Psen1tm1Mpm/Mmjax }\end{array}$ & $\begin{array}{l}\text { The Jackson } \\
\text { Laboratory }\end{array}$ & $\begin{array}{l}\text { MMRRC Stock } \\
\text { No:34830-JAX }\end{array}$ \\
\hline Mouse: B6129SF1/J & $\begin{array}{l}\text { The Jackson } \\
\text { Laboratory }\end{array}$ & Stock No:101043 \\
\hline Mouse: floxed phgdh & Yang et al. 2010 & $\mathrm{~N} / \mathrm{A}$ \\
\hline \multicolumn{3}{|l|}{ Oligonucleotides } \\
\hline \multicolumn{3}{|l|}{$\begin{array}{l}\text { Primers for mouse phgdh, gfap, vimentin, rbfox3, slc1a1, } \\
\text { cd68, iba1, ppia and daao }\end{array}$} \\
\hline $\begin{array}{l}\text { 5'-AAGTTCATGGGGACAGAGCTGAAC-3' (forward) } \\
\text { and 5'-CCTTCACCATGTCCACAAACTGGA-3' (reverse) }\end{array}$ & phgdh & \\
\hline $\begin{array}{l}\text { 5'-ACGACTATCGCCGCCAACT-3' (forward) and 5'- } \\
\text { GCCGCTCTAGGGACTCGTTC-3' (reverse) }\end{array}$ & gfap & \\
\hline $\begin{array}{l}\text { 5'-TCGAGGTGGAGCGGGACAAC-3' (forward) and 5'- } \\
\text { TGCAGGGTGCTTTCGGCTTC-3' (reverse) }\end{array}$ & vimentin & \\
\hline $\begin{array}{l}\text { 5'-CAACTCCACCCTTCCGACCC-3' (forward) and 5'- } \\
\text { TCCCGAATTGCCCGAACAT-3' (reverse) }\end{array}$ & rbfox3 (NeuN) & \\
\hline $\begin{array}{l}\text { 5'-ATGTGCTACATGCCGATTGG-3' (forward) and 5'- } \\
\text { CTCAGGACAGTGGCCATGTAAA-3' (reverse) }\end{array}$ & Slc1a1 & \\
\hline $\begin{array}{l}\text { 5'-GCCAGCCCTACGACCAG-3' (forward) and 5'- } \\
\text { TGGTGGTGGCAGGGTTATGA-3' (reverse) }\end{array}$ & cd68 & \\
\hline $\begin{array}{l}\text { 5'-CCAGCCTAAGACAACCAGCGTC-3' (forward) and } \\
\text { 5'-GCTGTATTTGGGATCATCGAGGAA-3' (reverse) }\end{array}$ & iba1 & \\
\hline $\begin{array}{l}\text { 5'-ATGGCAAATGCTGGACCAAA-3' (forward) and 5'- } \\
\text { GCCTTCTTTCACCTTCCCAAA-3' (reverse) }\end{array}$ & ppia (cyclophilin) & \\
\hline $\begin{array}{l}\text { 5'- GGTGGCAAGAGGAGTGGAT-3' (forward) and 5'- } \\
\text { GATGATGTACGGAGAGTTGTAGATA-3' (reverse) }\end{array}$ & daao & \\
\hline \multicolumn{3}{|l|}{ Recombinant DNA } \\
\hline & & \\
\hline & & \\
\hline & & \\
\hline
\end{tabular}




\begin{tabular}{|c|c|c|}
\hline \multicolumn{3}{|l|}{ Software and Algorithms } \\
\hline pClamp 9 for electrophysiology & Molecular Devices & $\begin{array}{l}\text { https://www.molecul } \\
\text { ardevices.com/produ } \\
\text { cts/axon-patch- } \\
\text { clamp- } \\
\text { system/acquisition- } \\
\text { and-analysis- } \\
\text { software/pclamp- } \\
\text { software-suite }\end{array}$ \\
\hline Image Studio 5.2 for fluorescent immunoblots & Li-Cor & $\begin{array}{l}\text { https://www.licor.co } \\
\mathrm{m} / \mathrm{bio} / \text { image-studio- } \\
\text { lite/ }\end{array}$ \\
\hline Labchart for voltametry & AD Instruments & $\begin{array}{l}\text { https://www.adinstru } \\
\text { ments.com/products/ } \\
\text { labchart }\end{array}$ \\
\hline Ethovision for behavioral studies & Noldus & $\begin{array}{l}\text { https://www.noldus.c } \\
\text { om/ }\end{array}$ \\
\hline 32 KaratTM system 7.0 for capillary electrophoresis & Sciex & $\begin{array}{l}\text { https://sciex.com.cn/ } \\
\text { Documents/manuals } \\
\text { /pa-800-plus-sw- } \\
\text { validation- } \\
\text { summary.pdf }\end{array}$ \\
\hline Fiji for confocal images & Fiji & https://fiji.sc/ \\
\hline $\mathrm{R}$ for statistical analyses & $\mathrm{R}$ & $\begin{array}{l}\text { https://www.r- } \\
\text { project.org/ }\end{array}$ \\
\hline Prism for statistical analyses & GraphPad & $\begin{array}{l}\text { https://www.graphpa } \\
\text { d.com/scientific- } \\
\text { software/prism/ }\end{array}$ \\
\hline BrainVisa for 3D autoradiography & Brainvisa & http://brainvisa.info \\
\hline ImageJ for FRET data & ImageJ & $\begin{array}{l}\text { https://imagej.nih.go } \\
\text { v/ij/ }\end{array}$ \\
\hline Statistica for statistical analyses & StatSoft & www.statsoft.com \\
\hline \multicolumn{3}{|l|}{ Other } \\
\hline & & \\
\hline & & \\
\hline & & \\
\hline & & \\
\hline
\end{tabular}




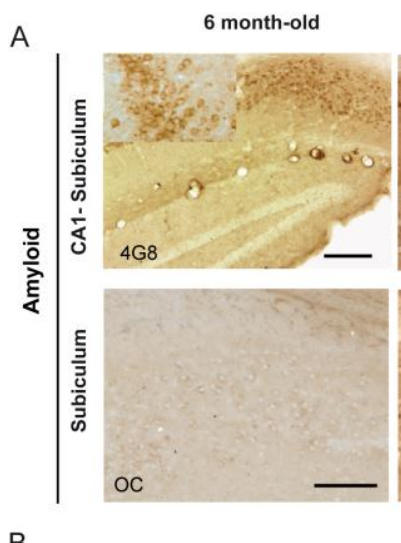

12 month-old

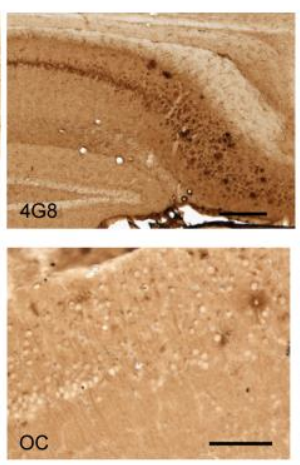

B
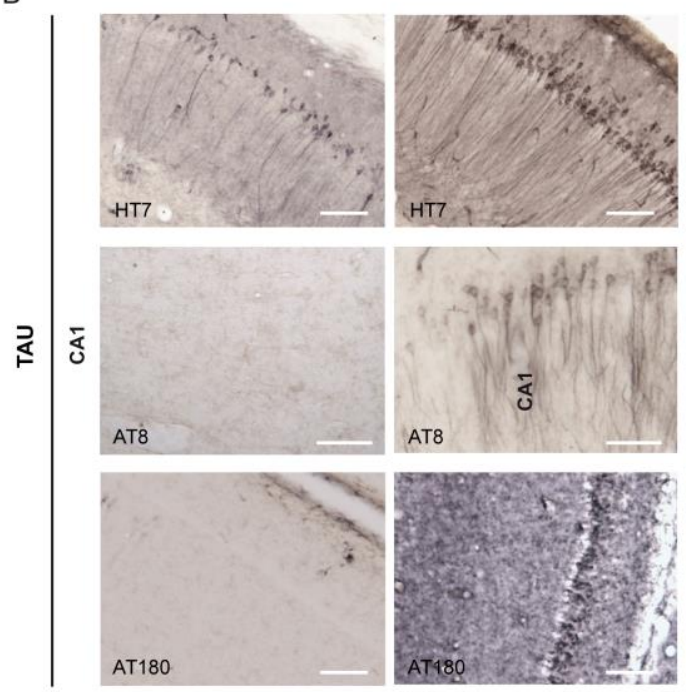

$\circ$

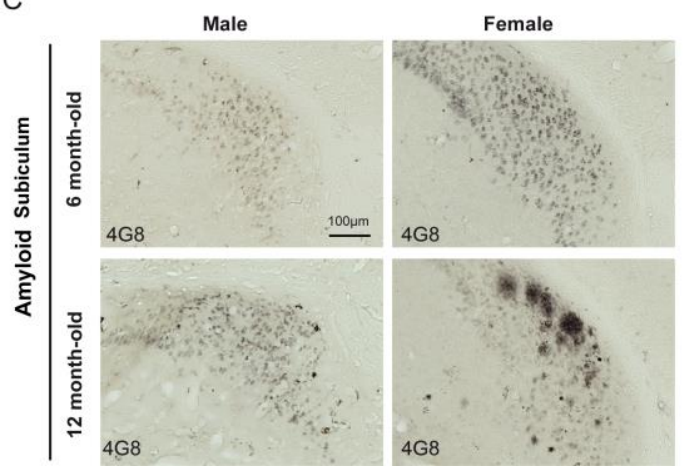

18 month-old
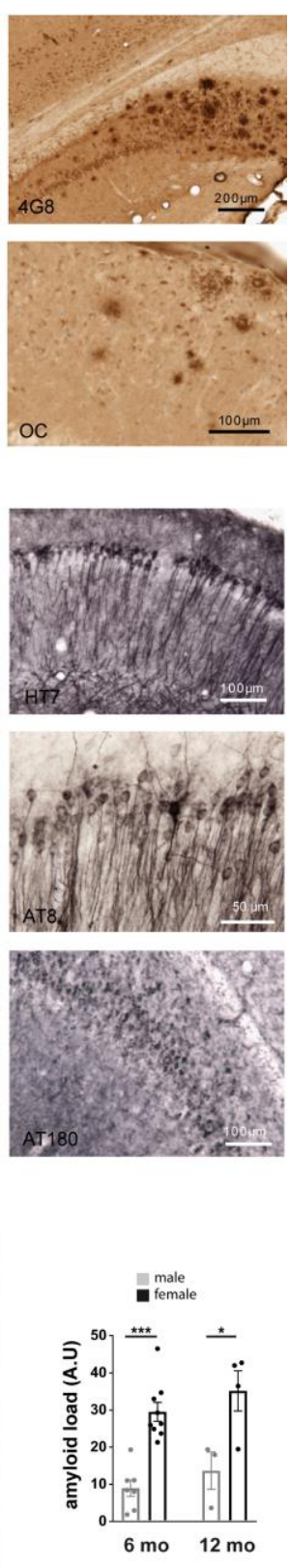

Figure S1. Related to Figure 1. Anatomopathological evaluation of 3xTg-AD mice

(A) Brain sections of 6,12, and 18 month-old 3xTg-AD female mice immunostained with 4G8 or OC antibodies. Progression of the amyloid pathology is slow, and whereas intraneuronal $A \beta$ was already present in 6 month-old 3xTg-AD mice (see insert), oligomers and extracellular plaques were detected mostly in the subiculum and not in the CA1 region of the hippocampus in 12 and 18 month-old $3 x T g-A D$ mice. (B) Tangential brain sections of a 6, 12, and 18 month-old 3xTg-AD mouse immunostained with HT7, AT8, or AT180 tau antibodies. (C) Tangential brain sections of a 6 and 12 month-old 3xTg-AD male and female mouse immunostained with $4 G 8$ showing a more aggressive $A D$ phenotype in the female relative to that of the male in the 3xTg-AD mouse model (one-way ANOVA, $p<0.001$ at 6 month and $p=0.01$ at 12 month). 
A

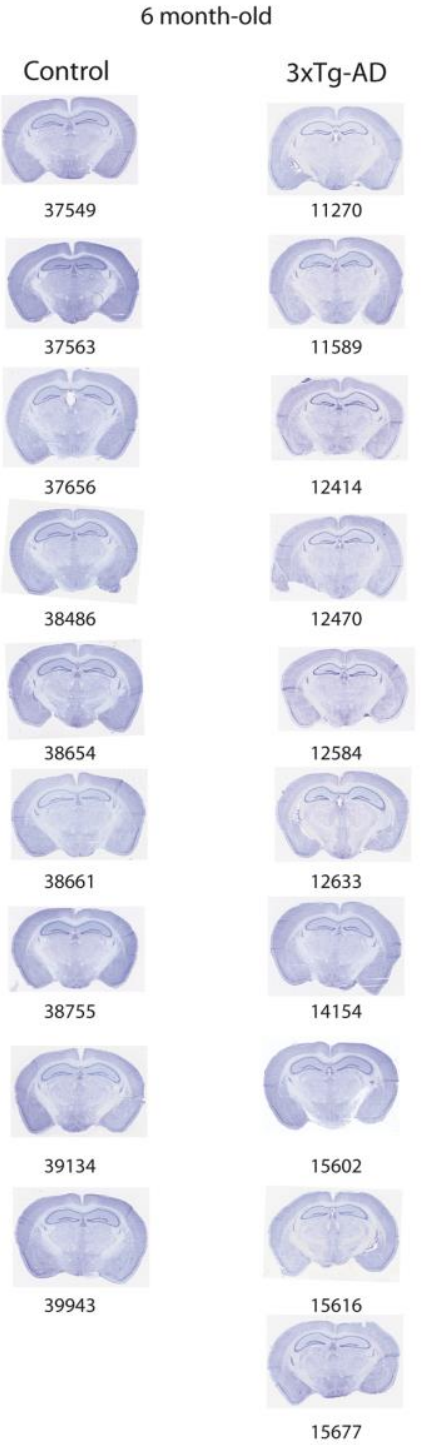

12 month-old

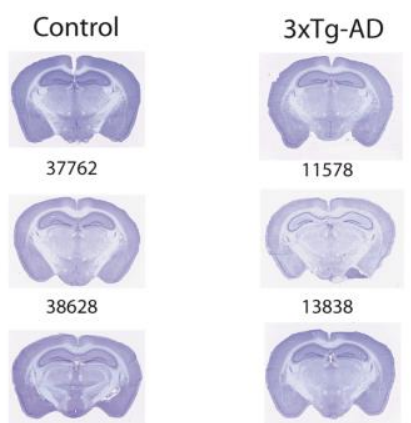

38635

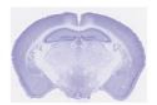

38684

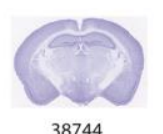

38744

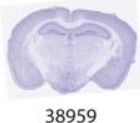

38959

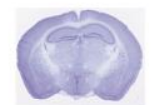

39225

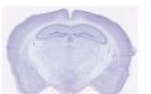

39802

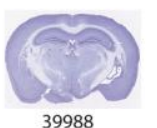

39988

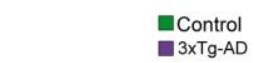

C

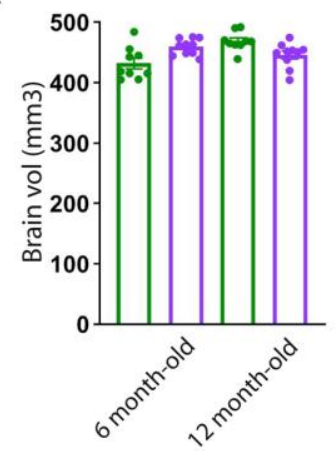

D

E

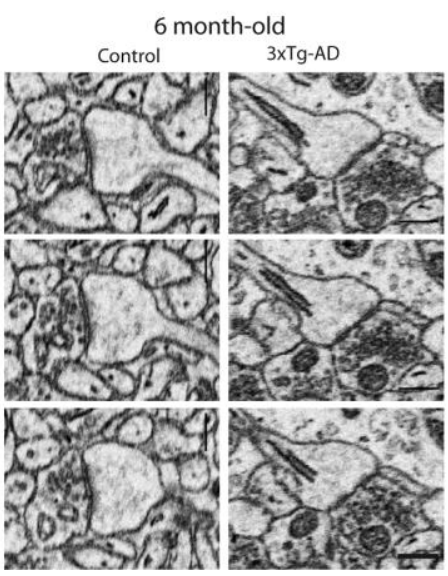

F

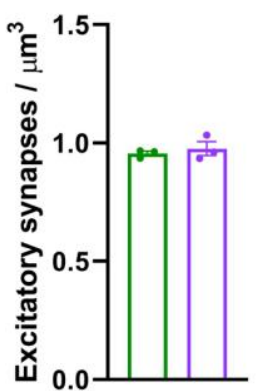

Figure S2. Related to Figure 1. No significant neurodegeneration and no change in CA1 synapse density in 3xTg-AD mice

(A) Typical examples of Nissl stained brain sections in all 6 month-old 3xTg-AD and control mice used for in vivo glucose metabolism (numbers correspond to the identification of mice). (B) Typical examples of Nissl stained brain sections in all 12 month-old 3xTg-AD and control mice used for in vivo glucose 
metabolism. No significant cell loss were observed in 3xTg-AD mice. (C) Brain volume was not significantly different between the 4 groups of mice (Kruskal-Wallis). (D) The red square illustrates the brain region that was analyzed by electron microscopy. To count synapses in stacks of serial EM images (3 Control and 3 $3 \times T g-A D)$, circles were placed at the center of each synapse using the TrakEM2 software in FIJI (www.fiji.sc); Synapses were classified according to their morphology as either asymmetric (presumed glutamatergic) or symmetric (presumed GABAergic). (E) Micrographs showing asymmetric synapses on 3 consecutive planes separated by $50 \mathrm{~nm}$ each. $(\mathbf{F})$ The density of excitatory synapses was not significantly different between 6 month-old control ( $0.956 \pm 0.012$ per $\mu \mathrm{m}^{3}$, total of 1067 synapses) and 3xTg-AD mice $\left(0.976 \pm 0.036\right.$ per $\mu \mathrm{m}^{3}$, total of 1094 synapses). Scale bar in $E$ is 500 nanometers. 


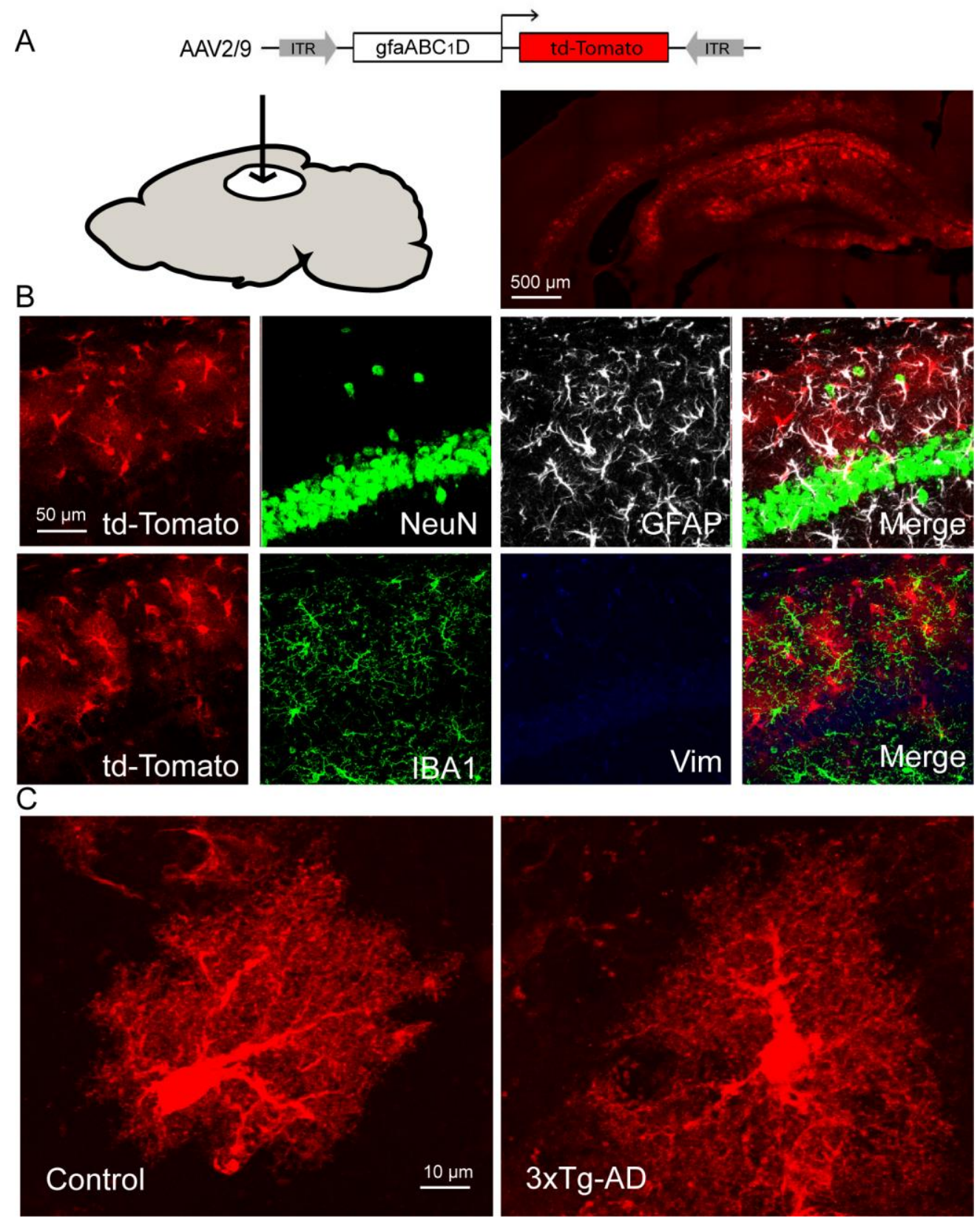

Figure S3. Related to Figure 1. Cellular tropism of AAV2/9 expressing td-Tomato driven by the short gfaABC1D promoter

(A) Three weeks after injection of the AAV2/9 expressing td-Tomato driven by the short gfaABC1D promoter, td-Tomato was widely expressed into the hippocampus. (B) td-Tomato was expressed in GFAPpositive astrocytes but not in NeuN-positive (neurons) or IBA1-positive (microglia) cells. No vimentin staining was observed, indicating that astrocytes did not adopt a reactive phenotype. (C) AD astrocytes did not display major hypertrophy in the CA1 region of 6 month-old female mice. 
A
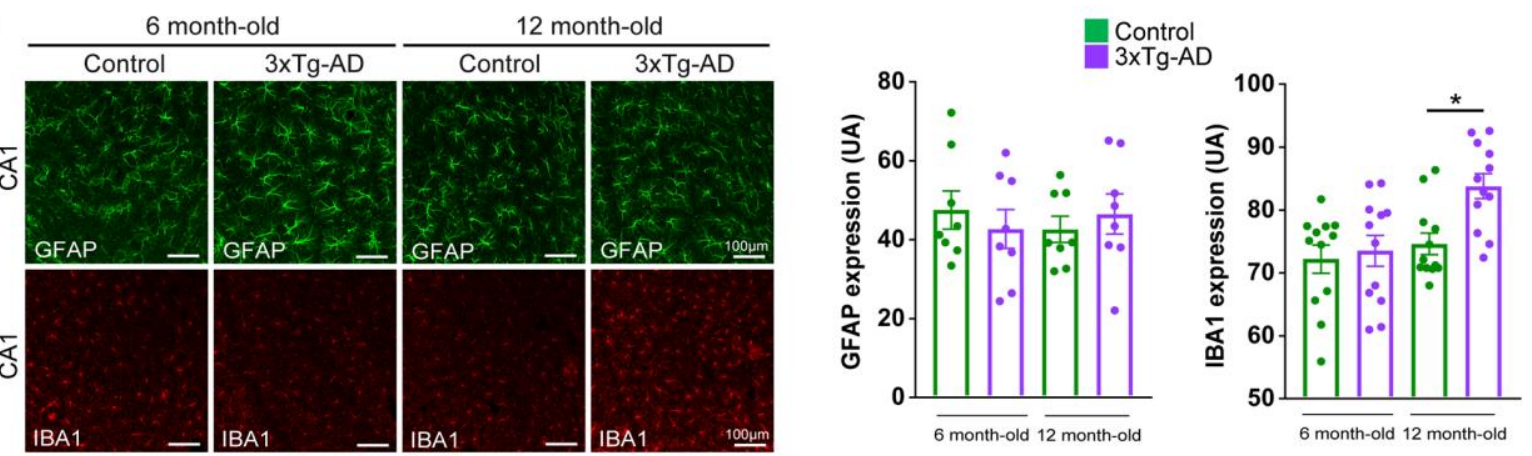

B

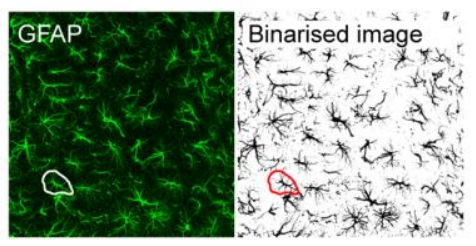

Isolated astrocyte

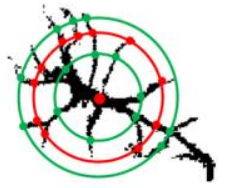
Sholl analysis
surface $\left(\mu \mathrm{m}^{2}\right)$
$-\mathrm{Nm}=$ process maximum (max number of intersections per radius
(red circle)
$-\mathrm{N}_{\mathrm{pp}}=$ number of primary
processes
- ramification index $(R I)=N \mathrm{~N} / \mathrm{N}_{\mathrm{pp}}$

C

6-month-old CA1

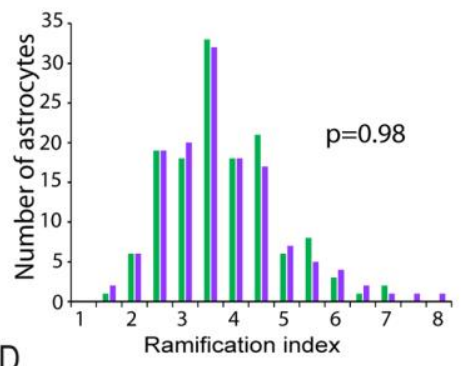

D

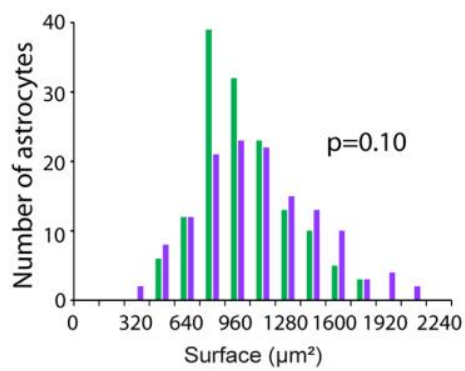

12-month-old CA1
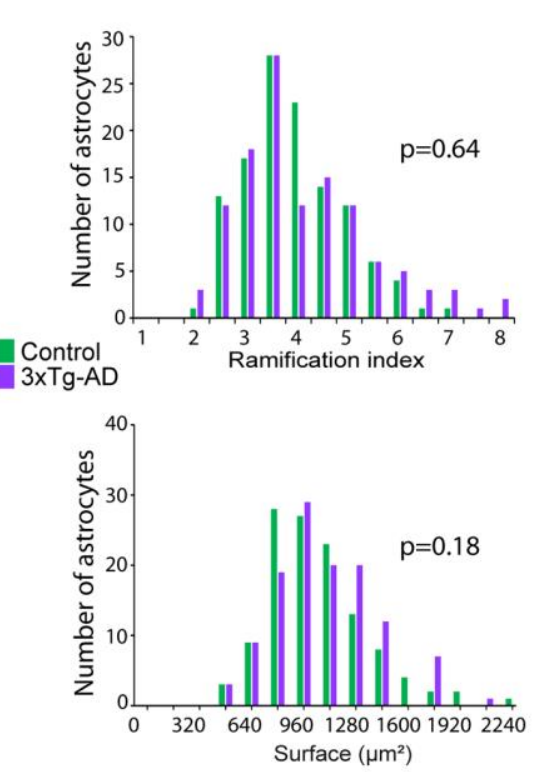
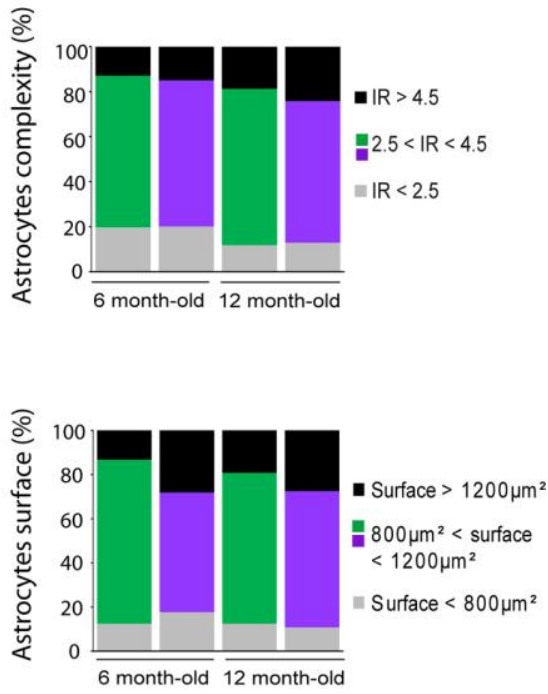

Figure S4. Related to Figure 1. No astrocyte reactivity in the CA1 region of 3xTg-AD mice

(A) Immunofluorescent staining of 6 and 12 month-old control and 3xTg-AD mouse brain using GFAP and IBA1 antibodies. The global expression of GFAP, quantified using Fiji, was unaltered in the CA1 region at both ages. The expression of IBA1 was significantly higher only in 12 month-old 3xTg-AD mice (KruskalWallis followed by Dunn test, $p=0.029$ ). (B) Illustration of Sholl analysis performed on a binarized image taken from a GFAP immunostaining. Astrocytes were manually outlined and the Sholl analysis was performed using Fiji. Sholl analysis generates several parameters such as the surface, the $\mathrm{Nm}$ (process maximum) and the ramification index (RI) for each analyzed cell. Astrocytes of 6 month-old (control $n=$ 136, 3xTg-AD $n=135$ ) and 12 month-old (control $n=120,3 \times T g-A D n=120$ ) mice were analyzed using Sholl analysis. (C, D) The distribution of the ramification index and the surface was similar for all groups (Chi ${ }^{2}$ test), indicating that astrocytes in the CA1 region of 6 and 12 month-old 3xTg-AD mice were not reactive. 

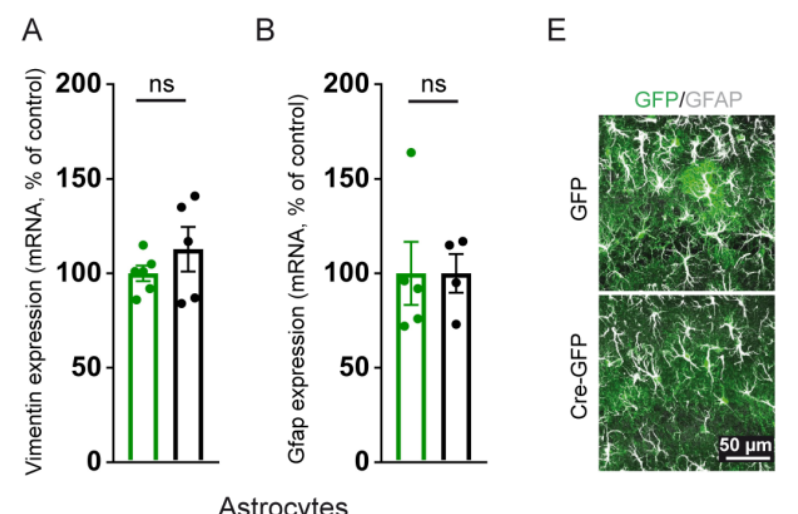

F
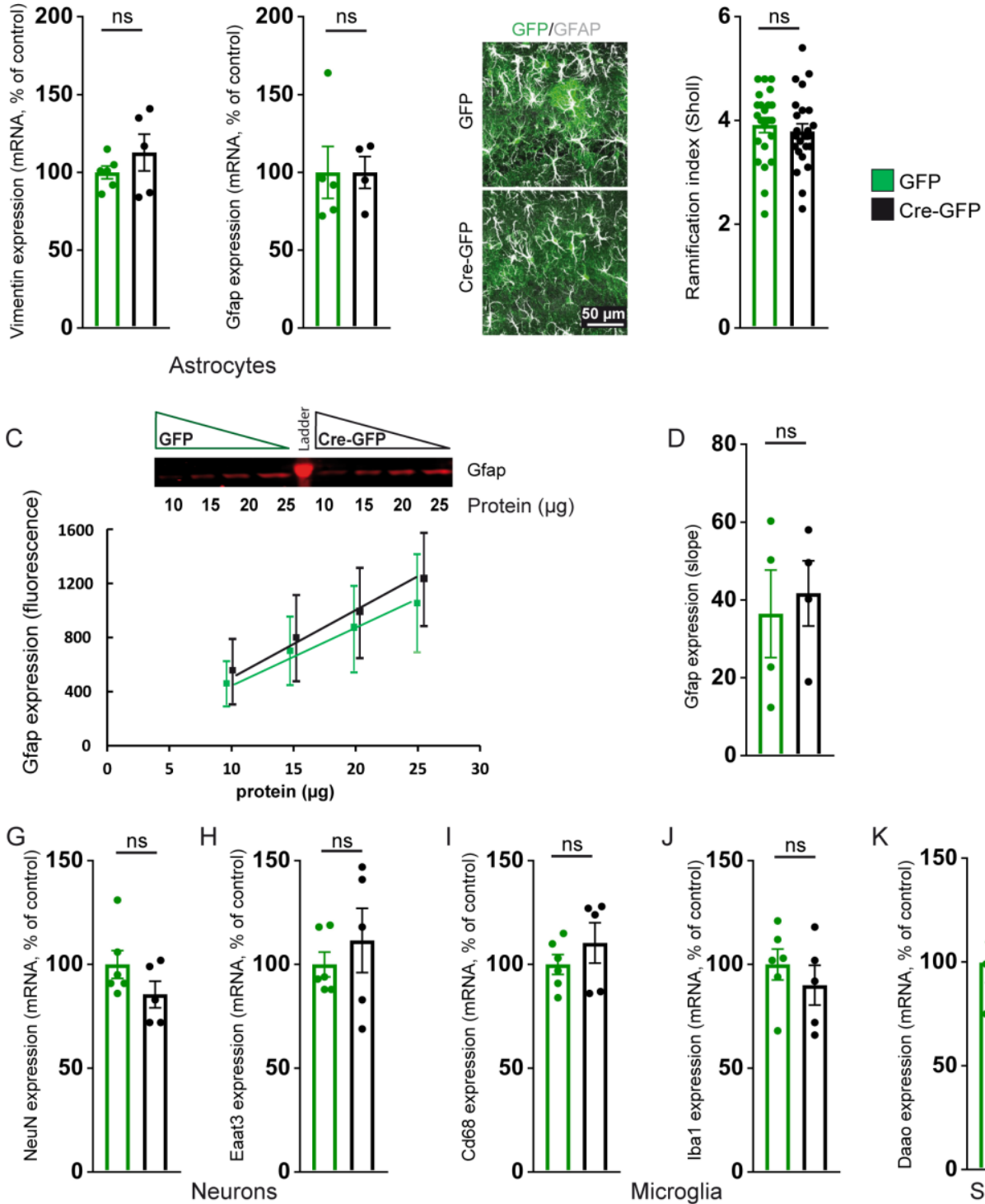

L

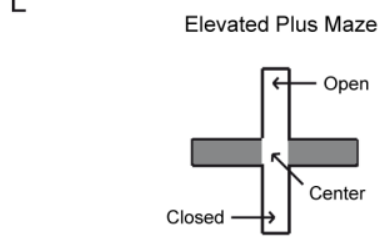

M
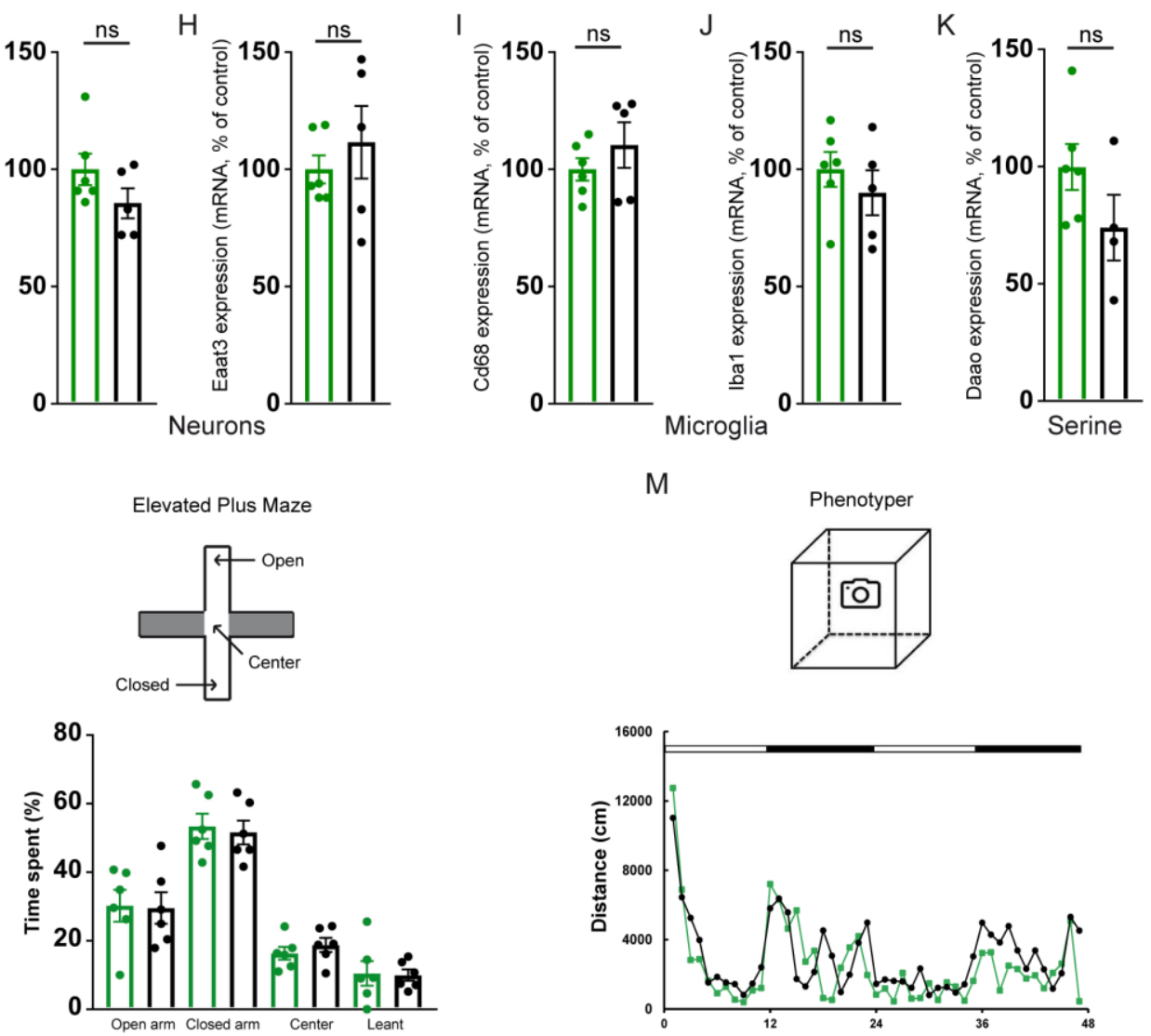
Figure S5. Related to Figure 3. Phgdh deletion does not induce major side-effects on astrocytes, neurons and microglia and does not alter anxiety or spontaneous motor behavior

$(A, B)$ mRNA expression for astrocytic genes quantified by RT-qPCR (Mann-Whithney U-test $p=0.43$ for vimentin and $p=0.19$ for GFAP; $n=6$ hippocampus per group). (C) GFAP fluorescent immunoblots for serial dilutions of protein extracts and fluorescence quantification for each dilution. (D) GFAP protein quantification using the slopes determined on $c$ (Linear model $p=0.82 ; n=4$ animals per group). (E) GFP labelling (green) identified infected astrocytes on hippocampal sections. GFAP labeling (white) was used to quantify processes ramification. $(\mathbf{F})$ Ramification index determined by Scholl analysis (Nested model $\mathrm{p}=0.69 ; \mathrm{n}=2$ animals per group and 30 astrocytes per animal). (G-K) mRNA expression for neuronal and microglial genes quantified by RT-qPCR (Mann-Whithney U-test $p=0.23$ for Neun, $p=0.82$ for eaat3, $p=0.43$ for cd68, $p=0.35$ for lba1 and $p=0.17$ for Daao; $n=4-6$ hippocampus per group). (L) The time spent in open and closed arms and the duration of head-dipping into open arms in the elevated plus maze were not significantly different between Cre (black) and GFP-injected mice (green) (Mann-Whithney $U$ test, $p>0.05$, $\mathrm{n}=6$ animals per group). (M) The spontaneous motor behavior recorded during 47h (white bar, day; black bar, night) was not significantly different between Cre (black) and GFP-injected mice (green), MANOVA, $\mathrm{p}=0.79, \mathrm{n}=3$ animals per group). 
A

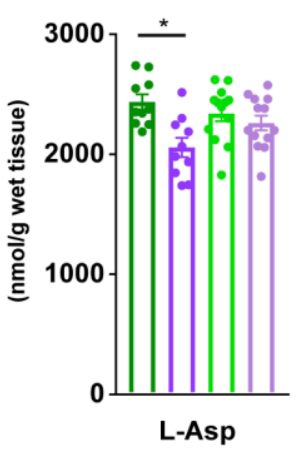

F

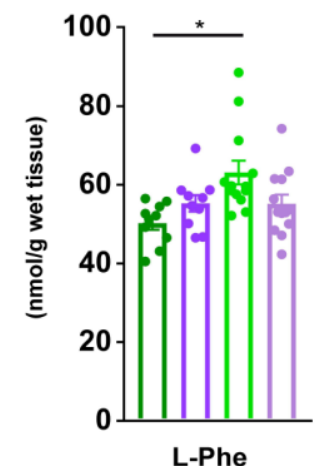

B

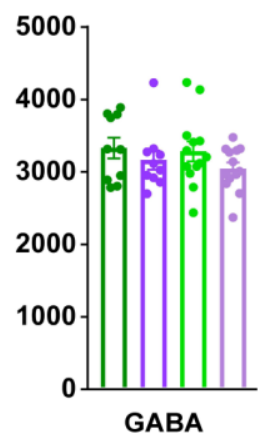

G

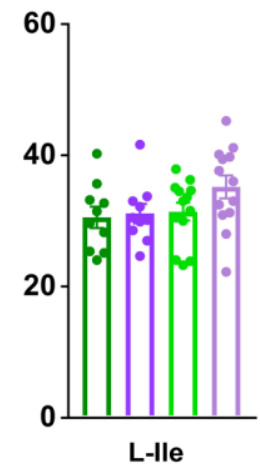

C

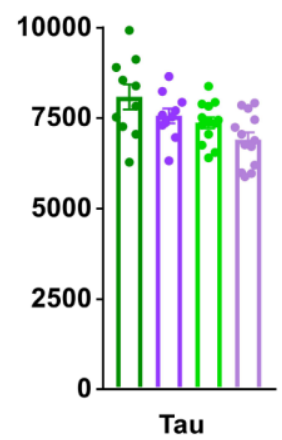

$\mathrm{H}$

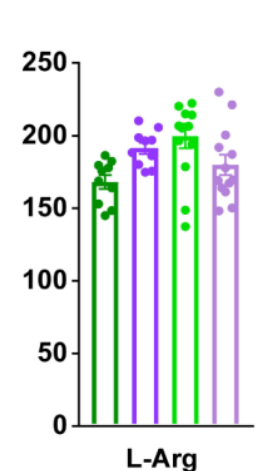

D

E
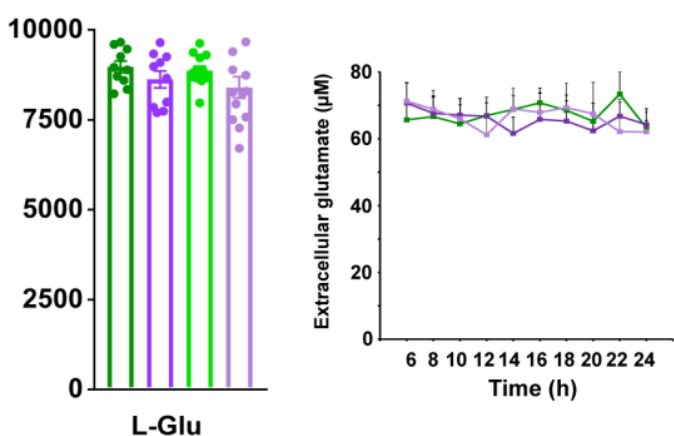

I

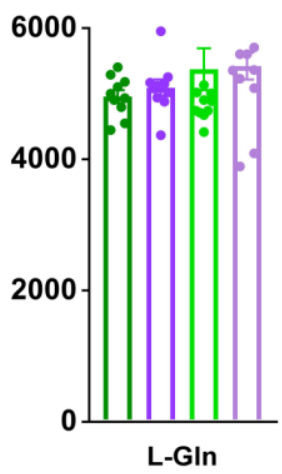

Control

Control + L-ser (food)

3xTg-AD

$3 \times \operatorname{Tg}-A D+L-\operatorname{ser}($ food)

Figure S6. Related to Figures 1 and 5. Effect of a 2-month L-serine diet (10\%) on the concentration of several amino acids in the hippocampus of control and 3xTg-AD mice

(A-I) Total levels of L-aspartate (L-Asp), GABA, Taurine (Tau), L-glutamate (L-glu), L-phenylalanine (LPhe), L-isoleucine (I-lle), L-arginine (L-Arg) and L-glutamine (L-Gln) were measured by HPLC in the hippocampus of 6-month-old female control and 3xTg-AD mice that received or not a diet enriched in Lserine $(10 \%)$ for 2 months ( $n=10-13$ mice per group). Kruskal-Wallis followed by Dunn test if necessary: (L-Asp) $p=0.017$; (L-Phe) $p=0.002$.

(E) Extracellular levels of L-glutamate were similar between 6-month-old female control, 3xTg-AD mice with and without L-serine diet as measured by LC-MS/MS following microdialysis in the hippocampus. 